INSTITUTO DE PESQUISAS ENERGÉTICAS E NUCLEARES

Autarquia associada à Universidade de São Paulo

\author{
AVALIAÇÃO DOS TEORES DE Br, Cl, K, Mg, Mn e V EM \\ MEXILHÕES Perna perna (LINNAEUS, 1758: MOLLUSCA, \\ BIVALVIA) COLETADOS NO LITORAL DO ESTADO DE SÃO \\ PAULO, BRASIL
}

DANIELE SEO

Dissertação apresentada como parte dos requisitos para obtenção do Grau de Mestre em Ciências na Área de Tecnologia Nuclear - Aplicações

Orientadora:

Dra. Marina Beatriz Agostini Vasconcellos 
Dedico a Deus, meus pais Emília e Bernardo e ao meu namorado Anderson. 
"O amor é eterno - a sua manifestação pode modificar-se, mas nunca a sua essência. Através do amor vemos as coisas com mais tranquilidade, e somente com essa tranquilidade um trabalho pode ser bem sucedido".

Vincent Van Gogh 


\section{AGRADECIMENTOS}

A Deus, pelo dom da vida e por tornar possível mais uma etapa em minha vida.

À Dra. Marina Beatriz Agostini Vasconcellos, pela orientação, carinho, dedicação, auxílio financeiro nos eventos científicos, amizade ao longo dos seis anos de convivência e interesse com que acompanhou a execução da presente dissertação em todas as suas etapas.

À Dra. Mitiko Saiki, pela co-orientação dada a este trabalho, amizade, disponibilidade, pelos ensinamentos desde o período de Iniciação Científica no IPEN-CNEN/SP, conhecimento e apoio que contribuíram para a realização e concretização deste trabalho.

À Dra. Eduinetty Ceci Pereira Moreira de Sousa do Instituto Oceanográfico da USP (IO-USP) por permitir a utilização dos laboratórios para a realização das coletas das amostras de mexilhões, colaboração nos ensaios experimentais e disponibilidade na discussão dos resultados obtidos.

À Dra. Marília Gabriela Miranda Catharino Semmler, pela concessão das amostras de mexilhões coletadas, colaboração nos ensaios experimentais e contribuição no desenvolvimento dos artigos científicos.

Ao Dr. Edson Gonçalves Moreira, pelo carinho e amizade, conhecimento, profissionalismo, apoio sempre que se fez necessário durante 0 desenvolvimento desta pesquisa, e pela prazerosa companhia durante as viagens e aventuras que convivemos juntos.

À Universidade de São Paulo (USP) e ao Instituto de Pesquisas Energéticas e Nucleares (IPEN-CNEN/SP), na pessoa do Sr. Superintendente Dr. Nilson Dias Vieira Júnior, pela oportunidade concedida para executar esse trabalho. 
Ao Instituto de Pesquisas Energéticas e Nucleares (IPEN-CNEN/SP) pela concessão da bolsa de mestrado.

Ao meu pai, Bernardo Makoto Seo, cujo exemplo de trabalhador sempre me guiou em minha vida e por todos os momentos felizes que desfrutamos juntos.

À minha mãe, Emília Satoshi Miyamaru Seo, que me apoia e orienta de forma incondicional, levando-me à realização de meus sonhos.

À minha irmã, Juliana Seo, por todos os momentos felizes que passamos juntas.

Ao meu namorado, Anderson Massaiti Hieda, pela pessoa única, compreensiva, amiga, engraçada, por estar sempre presente, torcer por um fim comum e por dividir todos os nossos sonhos e momentos que fazem de mim o que sou.

Aos membros da banca examinadora, Dra. Déborah Inês Teixeira Fávaro, Dra. Maria José Aguirre Armelin, Dra. Eduinetty Ceci Pereira Moreira de Sousa, Dra. Flavia Pinheiro Zanotto e Dra. Ana Maria Graciano Figueiredo.

Aos amigos do Laboratório de Análise por Ativação com Nêutrons (LAN) do IPEN-CNEN/SP, Thalita, Mychelle, Maria Cristina, Rita, Tassiane, Priscila, Diego, Rogério, Roberto, Regina, Edson A., Andreza, Kelly, Raphael, André, Laís, Eliane, Karen, Cássio, Mauro, pela amizade, convivência, apoio sempre que preciso e por todos os bons momentos que passamos juntos.

$\mathrm{E}$, finalmente, a todos aqueles que direta ou indiretamente contribuíram para concretização deste trabalho. 


\title{
AVALIAÇÃO DOS TEORES DE Br, Cl, K, Mg, Mn e V EM MEXILHÕES Perna perna (LINNAEUS, 1758: MOLLUSCA, BIVALVIA) COLETADOS NO LITORAL DO ESTADO DE SÃO PAULO, BRASIL
}

\author{
DANIELE SEO
}

\section{RESUMO}

\begin{abstract}
O ambiente costeiro tem sido fortemente alterado em função de múltiplos impactos ambientais decorrentes das atividades antrópicas, como por exemplo, o escoamento de esgoto proveniente de áreas urbanas, a liberação de inúmeros produtos químicos das indústrias, a agricultura e o fluxo de embarcações, que podem acarretar vazamentos acidentais de petróleo e derivados, combustíveis e outros produtos transportados por via marítima. Neste contexto, um dos meios para avaliação da contaminação ambiental causada por essas substâncias potencialmente tóxicas em água do mar é a monitoração por meio de diferentes espécies de bivalves, que tem sido utilizada por diversos pesquisadores, do Brasil e do exterior. No que se refere aos moluscos bivalves, particularmente os mexilhões, o seu uso no biomonitoramento da contaminação marinha deve-se principalmente à sua ampla distribuição geográfica, hábito séssil e habilidade de concentrar metais tóxicos em até $10^{2}-10^{5}$ vezes em relação às concentrações detectadas na água. No presente trabalho, foi empregado o biomonitoramento passivo com o uso do molusco bivalve Perna perna com relação aos elementos $\mathrm{Br}, \mathrm{Cl}, \mathrm{K}, \mathrm{Mg}, \mathrm{Mn}$ e $\mathrm{V}$. Foram escolhidos estes elementos uma vez que eles podem ser determinados pelo método de INAA (Análise por Ativação com Nêutrons Instrumental), por meio da irradiação curta o que proporciona análises mais rápidas e também por serem importantes do ponto de vista nutricional ou ambiental. O objetivo do presente trabalho foi avaliar os teores de $\mathrm{Br}, \mathrm{Cl}, \mathrm{K}, \mathrm{Mg}, \mathrm{Mn}$ e $\mathrm{V}$ em amostras de mexilhões Perna perna (Linnaeus, 1758: Mollusca, Bivalvia) coletados em regiões costeiras de São Paulo sujeitas à contaminação antrópica (Ponta de Itaipu e llha das Palmas, em Santos), comparando os valores obtidos nos sítios possivelmente impactados com os valores do sítio controle situado na Praia da Cocanha, em Caraguatatuba. Os pontos de coleta no litoral de São Paulo estão localizados nas regiões geográficas $23^{\circ} 37^{\prime} \mathrm{S}-45^{\circ} 24^{\prime} \mathrm{W}$ (Caraguatatuba) e $23^{\circ} 57^{\prime} \mathrm{S}-46^{\circ} 20^{\prime} \mathrm{W}$ (Santos). A coleta dos organismos foi realizada em todas as estações do ano, com início na primavera de 2008 e término no inverno de 2009. As amostras coletadas foram limpas, trituradas, homogeneizadas e secas por meio da liofilização para posterior INAA. O procedimento de INAA consistiu em irradiar alíquotas das amostras obtidas na forma de pó em invólucros de polietileno no reator nuclear IEA - R1 do IPEN/CNEN - SP juntamente
\end{abstract}


com padrões sintéticos de elementos. O tempo de irradiação no reator foi de 8 a 10 s e sob o fluxo de nêutrons térmicos de $6,6 \times 10^{12} \mathrm{n} \mathrm{cm}^{-2} \mathrm{~s}^{-1}$. As concentrações dos elementos foram calculadas pelo método comparativo. $O$ procedimento de INAA foi validado com relação à exatidão e precisão, por meio das análises dos materiais de referência certificados NIST SRM 1566b Oyster Tissue e NIST SRM 2876 Mussel Tissue. Os resultados destes materiais de referência certificados indicaram uma boa qualidade dos resultados com relação à precisão e exatidão. As faixas das concentrações (em base seca) dos elementos obtidos nos mexilhões coletados em Santos e na Praia da Cocanha para as quatro estações do ano foram de: 173,80 a $358,99 \mathrm{mg} \mathrm{kg}^{-1}$ para $\mathrm{Br} ; 45658 \pm 1811$ a $109166 \pm 824 \mathrm{mg} \mathrm{kg}^{-1}$ para Cl; $7043 \pm 856 \mathrm{a}$ $12506 \pm 675 \mathrm{mg} \mathrm{kg}^{-1}$ para K; $2774 \pm 211$ a $5691 \pm 717 \mathrm{mg} \mathrm{kg}^{-1}$ para Mg; 7,01 $\pm 0,30$ a 29,74 \pm $3,32 \mathrm{mg} \mathrm{kg}^{-1}$ para Mn e 0,77 $\pm 0,02$ a $3,43 \pm 0,28 \mathrm{mg} \mathrm{kg}^{-1}$ para $\mathrm{V}$. Foi estudada a variação sazonal e espacial das concentrações desses elementos e também foram comparados esses resultados com valores da literatura. A partir dos resultados obtidos pode - se concluir que os mexilhões da espécie Perna perna, podem ser utilizados como biomonitores da contaminação marinha. 


\title{
EVALUATION OF THE LEVELS OF Br, Cl, $\mathrm{K}, \mathrm{Mg}$, Mn and V IN Perna perna MUSSELS (Linnaeus, 1758: MOLLUSCA, BIVALVIA) COLLECTED IN COAST OF SÃO PAULO, BRAZIL
}

\author{
DANIELE SEO
}

\begin{abstract}
The coastal environment has been heavily altered by multiple environmental impacts of human activities, such as disposal of sewage from urban areas, the release of numerous chemical industries, agriculture and the flow of vessels, which can lead to accidental spills of oil and oil products, fuels and other products transported by sea. In this context, a means of determining concentrations of these potentially toxic substances in the sea water is the biomonitoring by means of different types of bivalves, which have been used by various researchers, in Brazil and other countries. With regard to bivalve mollusks, particularly mussels, their use in monitoring the marine contamination is mainly due to their wide geographic distribution, sessile habit and ability to concentrate toxic metals to $10^{2}-10^{5}$ times in relation to the concentrations detected in water. In the present study, we employed the passive biomonitoring using the Perna perna bivalve mollusk with respect to the elements $\mathrm{Br}, \mathrm{Cl}, \mathrm{K}, \mathrm{Mg}, \mathrm{Mn}$ and $\mathrm{V}$. These elements were chosen since they can be determined by INAA method (Instrumental Neutron Activation Analysis), by means of short irradiation which provides faster analyzes and also due to their importance from the standpoint of environmental or nutritional studies. The aim of this study was to evaluate the content of $\mathrm{Br}$, $\mathrm{Cl}, \mathrm{K}, \mathrm{Mg}, \mathrm{Mn}$ and $\mathrm{V}$ in samples of Perna perna mussels (Linnaeus, 1758: Mollusca, Bivalvia) collected in coastal regions of São Paulo subject to anthropogenic contamination (Ponta de Itaipu and Palmas Island, in Santos), comparing the values obtained in sites potentially impacted with the values of the control site in Praia da Cocanha, in Caraguatatuba. The collection points located in São Paulo coast are located in the geographical areas $23^{\circ} 37^{\prime} \mathrm{S}$ $45^{\circ} 24^{\prime} \mathrm{W}$ (Caraguatatuba) and $23^{\circ} 57^{\prime} \mathrm{S}-46^{\circ} 20^{\prime} \mathrm{W}$ (Santos). The collection of organisms was performed in all seasons of the year, beginning in spring 2008 and ending in winter 2009. The samples were cleaned, crushed, homogenized and dried by lyophilization for further analysis by INAA. The INAA procedure consisted of irradiating aliquots of the samples obtained in powder form in polyethylene envelopes in the nuclear research reactor IEA - R1 of IPEN / CNEN - SP together with synthetic standards of elements. The irradiation time in the reactor was 8 to $10 \mathrm{~s}$ under the thermal neutron flux of $6.6 \times 10^{12} \mathrm{n} \mathrm{cm}^{-2} \mathrm{~s}^{-1}$. The concentrations of the elements were calculated using the comparative method. The INAA
\end{abstract}


procedure was validated with respect to accuracy and precision, through the analysis of certified reference materials NIST SRM 1566b Oyster Tissue and NIST SRM 2876 Mussel Tissue. The results of these certified reference materials indicated good quality of results with respect to precision and accuracy. The ranges of concentrations (dry basis weight) of the elements obtained in mussels collected in Santos and Praia da Cocanha for the four seasons of the year were: 173.80 to $358.99 \mathrm{mg} \mathrm{kg}^{-1}$ for $\mathrm{Br}$; $45658 \pm 1811$ to $109166 \pm 824 \mathrm{mg} \mathrm{kg}^{-1}$ for $\mathrm{Cl} ; 7043 \pm 856$ to $12506 \pm 675 \mathrm{mg} \mathrm{kg}^{-1}$ for K; $2774 \pm 211$ to $5691 \pm 717 \mathrm{mg} \mathrm{kg}^{-1}$ for Mg; $7.01 \pm$ 0.30 to $29.74 \pm 3.32 \mathrm{mg} \mathrm{kg}^{-1}$ for $\mathrm{Mn}$ and $0.77 \pm 0.02$ to $3.43 \pm 0.28 \mathrm{mg} \mathrm{kg}^{-1}$ for $\mathrm{V}$. The seasonal and spatial variations of the concentrations of these elements were studied and the values compared to the literature. From the results obtained it can be concluded that the species of Perna perna mussels, can be used as biomonitors of marine contamination. 


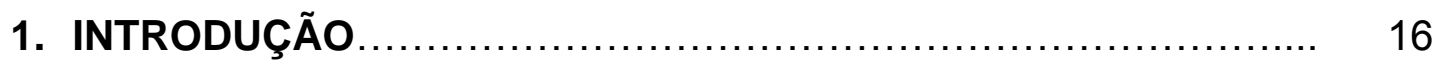

2. OBJETIVO DO TRABALHO ....................................... 21

2.1. Objetivo geral............................................... 21

2.2. Objetivos específicos........................................... 21

3. IMPORTÂNCIA DOS ELEMENTOS PARA O PRESENTE

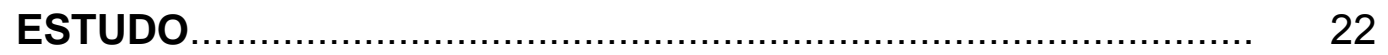

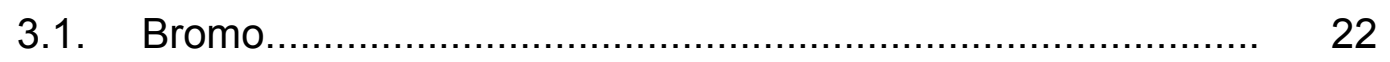

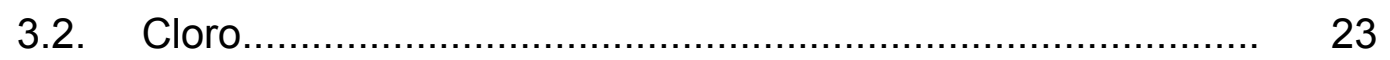

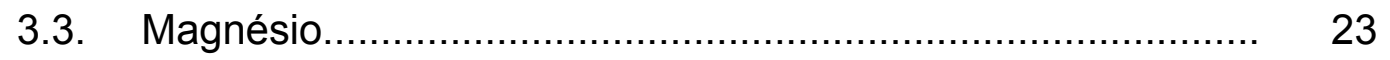

3.4. Manganês................................................................. 24

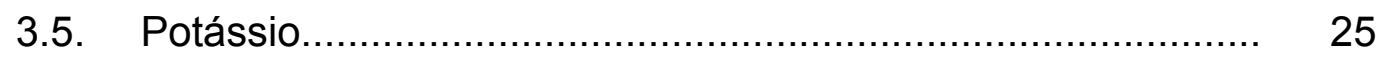

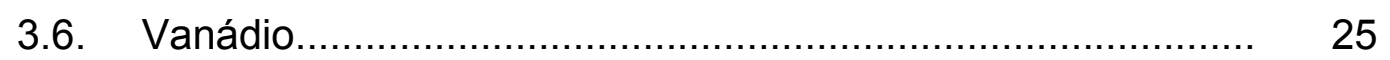

4. CONSIDERAÇÕES GERAIS SOBRE OS MEXILHÕES................. 29

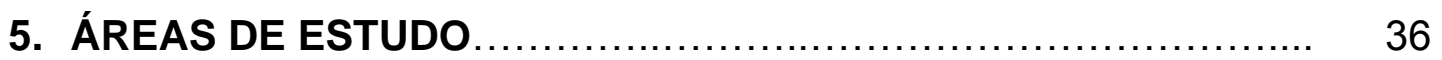

5.1. Caraguatatuba - Praia da Cocanha................................. 38

5.2. Santos - Ilha das Palmas e Ponta de Itaipu......................... 41

6. MÉTODO DE ANÁLISE POR ATIVAÇÃO COM NÊUTRONS

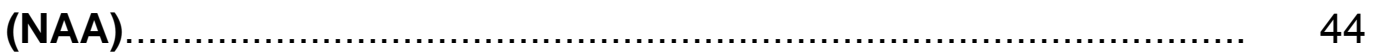

6.1. Considerações gerais sobre análise por ativação com

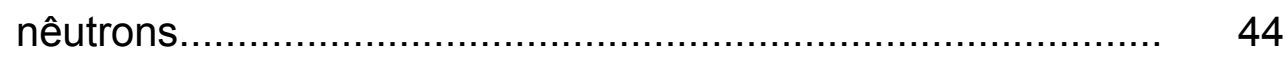

6.2. Princípio do método de análise por ativação com nêutrons

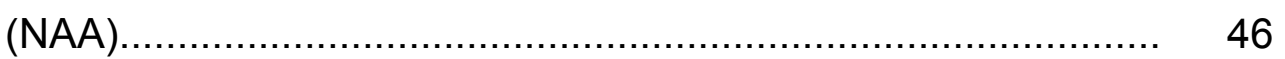

6.3. Equação fundamental da análise por ativação com nêutrons

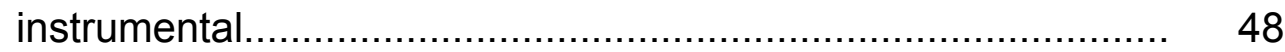

6.4. Método comparativo de análise por ativação.............................. 49

6.5. Vantagens e desvantagens do método de análise por

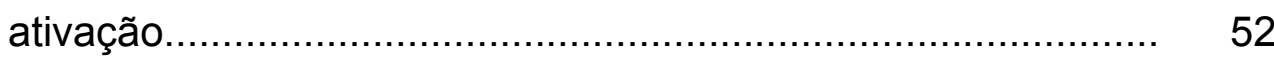

7. PARTE EXPERIMENTAL ........................................................ 54

7.1. Coleta dos organismos............................................................ 54

7.2. Tratamento das amostras..................................................... 57 
7.3. Ensaios preliminares...................................................... 61

7.3.1. Verificação da calibração do balão volumétrico..................... 61

7.3.2. Verificação da calibração do pipetador automático................. 63

7.4. Procedimento para as análises............................................. 64

7.4.1. Preparação de padrões sintéticos dos elementos a serem

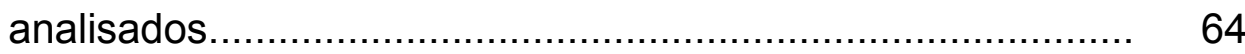

7.4.2. Análise dos materiais de referência certificados................... 66

7.4.3. Determinação da percentagem da perda de umidade nas amostras e em materiais de referência certificados.

7.4.4. Procedimento de análise por ativação com nêutrons instrumental............................................................... 69

7.5. Análise estatística................................................................ 73

8. RESULTADOS E DISCUSSÃO......................................... 74

8.1. Ensaios preliminares....................................................... 74

8.1.1. Verificação da calibração do balão volumétrico e do pipetador automático................................................. 74

8.2. Análise dos materiais de referência certificados...................... 75

8.3. Análise das amostras de mexilhões Perna perna....................... 77

9. CONCLUSÕES ........................................................................ 94

10. REFERÊNCIAS BIBLIOGRÁFICAS ........................................ 97

11. APÊNDICE - ARTIGOS PUBLICADOS .................................. 109 


\section{LISTA DE FIGURAS}

Página

Figura 4.1 Foto da espécie Perna perna - aspecto externo da concha do mexilhão.

Figura 4.2 Estruturas morfológicas de um mexilhão.

Figura 4.3 Visão geral de um mexilhão.

Figura 4.4 Visão interna de um mexilhão.

Figura 4.5 Mexilhão Perna perna. (a) Exemplar macho, mostrando a gônada de cor branca e (b) exemplar fêmea, mostrando a gônada de cor laranja.

Figura 5.1 Mapa dos pontos de coleta e cultivo de mexilhões Perna perna.

Figura 5.2 Região de cultivo de mexilhões localizada na Praia da Cocanha, em Caraguatatuba.

Figura 5.3 Foto do Porto de Santos.

Figura 6.1 Diagrama ilustrativo da seqüência de eventos de uma reação típica $(\mathrm{n}, \mathrm{y})$.

Figura 6.2 Esquema da captura radioativa.

Figura 7.1 (a) Mexilhão Perna perna em água salina. (b) Mexilhão Perna perna aberto.

Figura 7.2 Área de estudo no litoral paulista.

Figura 7.3 Ilustração do procedimento adotado: (a) remoção dos tecidos de mexilhão, (b) trituração e homogeneização, (c) pesagem das amostras de mexilhão.

Figura 7.4 Liofilizador da marca Thermo Electron Corporation, modelo Modulyo D-115.

Figura 7.5 llustração do procedimento adotado: (a) amostras trituradas em almofariz de ágata e peneiradas em peneira de nylon de 100 mesh, (b) amostras na forma de pó foram armazenadas em frascos plásticos e etiquetadas.

Figura 7.6 Foto apresentando a etapa da adição de água no balão volumétrico para a verificação da calibração 
Figura 7.7 Foto da pipetagem de solução padrão em tiras de papel filtro Whatman $n^{\circ} 40$

Figura 7.8 Ilustração do "coelho", da amostra de mexilhão, do material de referência e do padrão sintético em invólucros de polietileno para irradiação curta.

Figura 7.9 Esquema de preparo das amostras para irradiação.

Figura 7.10 (a) Foto do painel de controle para envio das amostras a serem irradiadas no reator IEA-R1 do IPEN-CNEN/SP. (b) Foto da cabine para envio e recebimento de amostra na Estação Pneumática $\mathrm{n}^{\circ} 4$.

Figura 7.11 Foto da blindagem de detector de Ge hiperpuro e da amostra sobre o detector.

Figura 7.12 (a) Foto do envio do "coelho" para irradiação, (b) montagem das amostras irradiadas nos suportes.

Figura 8.1 Médias das concentrações dos elementos em $\mathrm{mg} \mathrm{kg}^{-1}$ nas amostras de mexilhões (em base seca) coletados em diferentes pontos nas quatro estações do ano. Médias com letra minúscula igual indicam que os resultados não diferem pelo teste de Tukey $(p<$ $0,05)$ na análise espacial.

Figura 8.2 Médias das concentrações dos elementos em $\mathrm{mg} \mathrm{kg}^{-1}$ nas amostras de mexilhões (em base seca) coletados em diferentes pontos nas quatro estações do ano. Médias com letra maiúscula igual indicam que os resultados não diferem pelo teste de Tukey $(p<$ $0,05)$ na análise sazonal. 


\section{LISTA DE TABELAS}

Página

Tabela 5.1 Classificação das praias de acordo com a porcentagem de ocorrência em cada categoria e qualificação anual......

Tabela 7.1 Código, período de coleta e procedência das amostras de mexilhão.

Tabela 7.2 Biometria (médias dos comprimentos e das larguras) das conchas dos mexilhões.

Tabela 7.3 Porcentagens da perda de umidade $(P)$ nas secagens das amostras de mexilhões por liofilização.

Tabela 7.4 Massas dos elementos presentes nos padrões sintéticos de elementos.

Tabela 7.5 Porcentagens da perda de umidade $(P)$ nas secagens dos materiais de referência certificados e das amostras de mexilhões

Tabela 7.6 Dados relativos à identificação de cada radioisótopo formado.

Tabela 8.1 Resultados obtidos das verificações da calibração dos balões volumétricos.

Tabela 8.2 Resultados das médias de volumes obtidos na verificação da calibração do pipetador automático.

Tabela 8.3 Concentrações de elementos, em $\mathrm{mg} \mathrm{kg}^{-1}$, no material de referência certificado NIST SRM 1566b Oyster Tissue.

Tabela 8.4 Concentrações de elementos, em $\mathrm{mg} \mathrm{kg}^{-1}$, no material de referência certificado NIST SRM 2976 Mussel Tissue...

Tabela 8.5 Concentrações de $\mathrm{Br}$, em mg kg-1 (base seca), em amostras de mexilhões Perna perna coletados na Praia da Cocanha, Ilha das Palmas e Ponta de Itaipu para as quatro estações do ano.....

Tabela 8.6 Concentrações de $\mathrm{Cl}$, em mg kg-1 (base seca), em amostras de mexilhões Perna perna coletados na Praia da Cocanha, Ilha das Palmas e Ponta de Itaipu para as quatro estações do ano..... 
Tabela 8.7 Concentrações de $\mathrm{K}$, em $\mathrm{mg} \mathrm{kg}^{-1}$ (base seca), em amostras de mexilhões Perna perna coletados na Praia da Cocanha, Ilha das Palmas e Ponta de Itaipu para as quatro estações do ano.....

Tabela 8.8 Concentrações de $\mathrm{Mg}$, em $\mathrm{mg} \mathrm{kg}^{-1}$ (base seca), em amostras de mexilhões Perna perna coletados na Praia da Cocanha, Ilha das Palmas e Ponta de Itaipu para as quatro estações do ano.....

Tabela 8.9 Concentrações de $\mathrm{Mn}$, em $\mathrm{mg} \mathrm{kg}^{-1}$ (base seca), em amostras de mexilhões Perna perna coletados na Praia da Cocanha, Ilha das Palmas e Ponta de Itaipu para as quatro estações do ano.....

Tabela 8.10 Concentrações de $\mathrm{V}$, em $\mathrm{mg} \mathrm{kg}^{-1}$ (base seca), em amostras de mexilhões Perna perna coletados na Praia da Cocanha, Ilha das Palmas e Ponta de Itaipu para as quatro estações do ano.....

Tabela 8.11 Comparação das determinações dos elementos em mexilhões com os valores da literatura (na base seca). 


\section{INTRODUÇÃO}

O ambiente costeiro tem sido fortemente alterado em função de múltiplos impactos ambientais decorrentes das atividades antrópicas, como por exemplo, o escoamento de esgoto proveniente de áreas urbanas, a liberação de diversos produtos químicos (orgânicos e inorgânicos) pelas atividades industriais, a agricultura e o fluxo de embarcações, que podem acarretar vazamentos acidentais de petróleo e derivados, combustíveis e outros produtos transportados por via marítima (KENNISH, 1991). Consequentemente, os ecossistemas aquáticos podem acabar perdendo suas características naturais e sua diversidade biológica.

Inúmeros episódios de contaminação de regiões costeiras, ocorridos no mundo todo, levaram muitos países a estabelecer extensos programas de monitoração, que incluem análises de águas, sedimentos e organismos marinhos, para diversos contaminantes orgânicos e inorgânicos com a finalidade de reduzir os impactos causados a estes ecossistemas aquáticos, que sustentam a biodiversidade marinha, a pesca e os recursos energéticos. Neste contexto, um dos meios para determinação das concentrações dessas substâncias tóxicas em água do mar é a monitoração por meio de diferentes espécies de bivalves, que têm sido utilizadas por diversos pesquisadores, em várias regiões do Brasil e do exterior (VIARENGO e CANESI, 1991; FRANCIONI et al., 2004; MAANAN, 2007; CATHARINO et al., 2008; SEO et al., 2011).

No final da década de 70 , surgiu o interesse pelo uso de monitores biológicos quantitativos, isto é, organismos que pudessem ser utilizados na determinação de variações espaciais e temporais dos contaminantes biodisponíveis no ambiente marinho, oferecendo medidas que fossem relevantes do ponto de vista ecotoxicológico. A partir desse princípio, Belloto 
e Francioni (2008) mencionaram que em 1978, o grupo de pesquisadores sob orientação do Dr. Goldberg lançou a proposta do programa Mussel Watch como o primeiro estágio de um programa mundial de monitoramento do ambiente marinho, utilizando moluscos bivalves como organismos sentinela.

Um organismo pode ser considerado como um bioindicador quando contém informações sobre a qualidade do meio ambiente e como um biomonitor quando traz informações também sobre aspectos quantitativos do meio ambiente (MARKERT et al., 1999).

No que se refere aos moluscos bivalves, particularmente os mexilhões, o uso destes no biomonitoramento da contaminação marinha proporciona uma estimativa da disponibilidade de elementos traço à biomassa de diferentes áreas e localidades. Estes animais representam um dos grupos de organismos aquáticos mais adequados para programas de biomonitoramento (SILVA et al., 2001; LIONETTO et al., 2003) e em estudos toxicológicos (VALBONESI et al., 2003; CORSI et al., 2003). De acordo com Sunila (1987), as vantagens mais evidentes da utilização destes organismos são a sua ampla distribuição geográfica, hábito séssil e habilidade de concentrar compostos químicos em até $10^{2}-10^{5}$ vezes em relação às concentrações detectadas na água. Neste sentido, estes organismos podem bioacumular metais e diversos compostos químicos, orgânicos e inorgânicos, incorporando-os à cadeia trófica e atingindo grande parte dos diferentes estratos que constituem os ecossistemas aquáticos (VIARENGO, 1989). Segundo Yusof et al. (2004), esses moluscos bivalves são capazes de acumular poluentes, sem que ocorra a sua morte. Em especial, o mexilhão Perna perna é um bivalve presente ao longo de uma grande extensão da costa brasileira e apresenta, em princípio, todas as propriedades desejáveis para um biomonitor. Assim, essa espécie é uma boa candidata para o estabelecimento de um programa de biomonitoração em áreas tropicais.

No Brasil, diversos trabalhos têm sido realizados utilizando os organismos marinhos, tais como os mexilhões, os peixes, os copépodos, os anfípodos, as larvas de peixes, os crustáceos, entre outros, como indicadores 
de metais tóxicos e organoclorados. Na maioria desses trabalhos é utilizado o método de biomonitoração passiva, no qual os organismos em seu ambiente natural são coletados e analisados. Ênfase especial tem sido dada à análise de mercúrio e metilmercúrio, devido à particular toxicidade dos compostos orgânicos desse elemento e às descargas industriais que ocorrem, particularmente das indústrias de cloro-álcalis (FURLEY e OLIVEIRA FILHO, 1998; CALLIL, 1998). Além da biomonitoração passiva, pode-se mencionar a biomonitoração ativa que consiste em coletar organismos de uma área limpa, distante de fontes de poluição, e transplantá-los para áreas expostas à contaminação ambiental e por fim analisá-los.

Semmler (2007) determinou os elementos As, $\mathrm{Ca}, \mathrm{Co}, \mathrm{Cr}, \mathrm{Fe}, \mathrm{Na}$, Se e Zn em amostras de mexilhões Perna perna coletados do litoral do estado de São Paulo, após período de exposição em pontos sujeitos à contaminação, pela técnica de análise por ativação com nêutrons instrumental (INAA) e os elementos $\mathrm{Cd}, \mathrm{Hg}$ e $\mathrm{Pb}$ pelo método de espectrometria de absorção atômica (AAS). Foi verificado que, após os transplantes dos mexilhões (biomonitoração ativa) para os pontos de estudo houve um aumento nas concentrações de todos os elementos estudados, indicando assim a boa aplicabilidade do mexilhão Perna perna como organismo biomonitor.

Seo et al. (2007, 2008, 2009, 2010, 2011) empregou a biomonitoração ativa com o uso do molusco bivalve Perna perna para a determinação dos elementos $\mathrm{Br}, \mathrm{Cl}, \mathrm{K}, \mathrm{Mg}, \mathrm{Mn}, \mathrm{U}$ e $\mathrm{V}$ pelo técnica de análise por ativação com nêutrons instrumental (INAA). A partir dos resultados obtidos nas análises das amostras de mexilhões pode-se observar, em geral, um aumento das concentrações desses elementos nas regiões de transplante que estão sujeitas a exposição de poluentes, sobretudo no ponto de São Sebastião (localizado próximo ao TEBAR - Terminal Marítimo Almirante Barroso da Petrobrás)

No presente trabalho, foi empregada a biomonitoração passiva com o uso do molusco bivalve Perna perna com relação aos elementos: bromo, 
cloro, magnésio, manganês, potássio e vanádio. Foram escolhidos estes elementos uma vez que eles podem ser determinados por meio da irradiação curta no reator e também por serem importantes do ponto de vista nutricional ou ambiental.

Sob o ponto de vista nutricional, o consumo de moluscos marinhos geralmente é acompanhado de certa preocupação dos consumidores quanto à origem e qualidade do produto. Este fato está associado à maneira pela qual os animais são consumidos, crus ou levemente cozidos e devido à sua própria biologia, que possibilita sua contaminação por acumulação ou retenção de poluentes ou substâncias tóxicas do meio que habitam (FERREIRA e MAGALHÃES, 2004).

Em contrapartida, sob o ponto de vista ambiental, devido à sua biologia e fisiologia (hábitos sedentários, serem filtradores e sua habilidade de bioconcentrar os poluentes), os moluscos são utilizados em todo mundo em programas de monitoramento ambiental (BEIRAS et al.,2003). O sistema de circulação de água dentro do mexilhão (seu corpo é todo banhado pela água) faz com que partículas se acumulem em seu tecido, podendo exceder de 100 a 1000 vezes a quantidade das partículas presentes na água.

A análise por ativação com nêutrons instrumental (INAA) foi a técnica analítica adotada para a determinação dos elementos de interesse nos tecidos dos mexilhões devido à sua simplicidade, rapidez na análise e disponibilidade da estação pneumática para irradiações curtas no laboratório de análise por ativação neutrônica (LAN) do Instituto de Pesquisas Energéticas e Nucleares (IPEN-CNEN/SP). 


\section{OBJETIVO DO TRABALHO}

\subsection{Objetivo geral}

O objetivo do presente trabalho foi avaliar os teores de $\mathrm{Br}, \mathrm{Cl}, \mathrm{K}, \mathrm{Mg}$, Mn e V em amostras de mexilhões Perna perna (Linnaeus, 1758: Mollusca, Bivalvia) coletados em regiões do litoral de São Paulo sujeitas à contaminação antrópica (Ponta de Itaipu e Ilha das Palmas, em Santos), comparando os valores obtidos nos sítios possivelmente impactados com os valores do sítio controle situado na Praia da Cocanha, em Caraguatatuba.

\subsection{Objetivos específicos}

Para atingir o objetivo geral foram propostos os seguintes objetivos específicos:

- $\quad$ Coletar e preparar as amostras de mexilhões para análise;

- $\quad$ Estabelecer as condições experimentais adequadas para a determinação de elementos por meio de irradiações curtas;

- Avaliar a qualidade analítica dos resultados com relação à exatidão e precisão por meio da análise de materiais de referência certificados;

- $\quad$ Aplicar o método de análise por ativação com nêutrons instrumental (INAA) para determinar as concentrações dos elementos $\mathrm{Br}, \mathrm{Cl}, \mathrm{Mg}, \mathrm{Mg}, \mathrm{K}$ e $\mathrm{V}$ em amostras de mexilhões Perna perna coletados na Praia da Cocanha e na região de Santos (Ponta de Itaipu e Ilha das Palmas) por meio de irradiações curtas no reator;

- Realizar um estudo das variações sazonais das concentrações desses elementos;

- Aplicar tratamentos estatísticos para comparar os valores obtidos nos mexilhões das regiões possivelmente impactadas (Ponta de Itaipu e llha das Palmas) com os valores da região de referência, situada na Praia da Cocanha, em Caraguatatuba. 


\section{IMPORTÂNCIA DOS ELEMENTOS}

\subsection{Bromo}

A determinação de bromo apresenta grande importância em alimentos de origem marinha, pois esse elemento faz parte de compostos como o 2 e 4bromofenol, 2,4 e 2,6 dibromofenol e 2,4,6-tribromofenol, os quais podem produzir, intensificar ou alterar o "flavor" desses alimentos, sendo que a presença desses compostos é considerada relevante na avaliação e controle da qualidade do pescado (MOTA DA SILVA et al., 2007). Segundo esses autores, esses bromofenóis podem ser encontrados em concentrações na ordem de $\mathrm{ng} \mathrm{g}^{-1}$ em peixes marinhos, moluscos e crustáceos, estando fortemente associados ao "flavor" agradável (marinado) ou desagradável (iodofórmico) dependendo da concentração, pois interferem diretamente nas características sensoriais dos alimentos.

A presença de bromofenóis em moluscos marinhos, em seus diferentes estágios de desenvolvimento, parece estar relacionada com a dieta. Assim, as concentrações de bromofenóis mudam em decorrência da variação nas fontes alimentares. Em um estudo realizado por Chung et al. (2003), os bromofenóis foram detectados em todas as amostras de moluscos analisadas com concentração variando na faixa de 10,3 a $246,0 \mathrm{ng} \mathrm{g}^{-1}$ (no peso seco) e também em amostras de ostras com concentração variando na faixa de 13,6 a 75,8 $\mathrm{ng} \mathrm{g}^{-1}$ (no peso seco). 


\subsection{Cloro}

O cloro, por sua vez, é considerado um elemento mineral importante na regulação da pressão osmótica, pois o cloro ionizado juntamente com o sódio mantém o balanço aquoso no organismo. Além disso, participa no equilíbrio ácido - base e na manutenção do pH sanguíneo, na qual o cloro secretado pela mucosa gástrica como ácido clorídrico provoca a acidez necessária para a digestão no estômago e para a ativação de enzimas.

Este elemento é encontrado predominantemente em líquidos extracelulares e intracelulares, sendo absorvido de forma rápida no trato gastrointestinal (GRAY, 2011). A quantidade de cloro no homem adulto normal de $70 \mathrm{~kg}$ corresponde a $0,12 \%$ do peso corporal. A ingestão dietética inadequada de cloro pode acarretar na alcalose metabólica, em contrapartida, o seu excesso pode levar a acidose metabólica, cefaleia, confusão mental e hiperventilação (NAP, 2005). Segundo o Food and Nutrition Board da National Academies Press dos Estados Unidos (2005), recomenda a ingestão dietética adequada estimada (ESADDI) de cloro para indivíduos lactentes (idade 0 a 6 meses) de $180 \mathrm{mg}$ por dia, para lactentes (idade 7 a 12 meses) de $570 \mathrm{mg}$ por dia, para crianças e adolescentes de 1500 a 1900 mg por dia e para adultos de 1500 mg por dia.

\subsection{Magnésio}

O magnésio, por outro lado, é considerado um elemento essencial para os seres humanos e, portanto a sua concentração no organismo deve ser continuamente regulada e a distribuição para as células precisa ser garantida. $O$ valor máximo de ingestão diária desse elemento é de cerca de $400 \mathrm{mg}$ (VORMANN e ANKE, 2002).

Segundo a Food and Nutrition Board da National Academies Press dos Estados Unidos (1997), o magnésio é indispensável na fixação de cálcio nos ossos, podendo causar ou agravar quadros de osteopenia e osteoporose no adulto e dificultar a calcificação correta dos ossos na infância e adolescência. A deficiência de magnésio pode causar perda de apetite, náuseas, vômitos, cãibras, 
espasmos musculares, alteração do sistema nervoso central, tremores, taquicardia e arritmia. Em contrapartida, seu excesso pode acarretar problemas respiratórios, pressão baixa, distúrbios no ritmo cardíaco e inibição da calcificação óssea. Poucos dados existem sobre as concentrações de magnésio em mexilhões Perna perna e portanto essa será também uma contribuição do presente trabalho.

\subsection{Manganês}

O manganês também é um elemento essencial para os seres humanos, sendo encontrado em todos os tecidos e está presente nas dietas em baixas concentrações. Os seres humanos mantêm níveis estáveis de manganês nos tecidos e há um rigoroso controle homeostático da absorção e da excreção (ASCHNER e ASCHNER, 2005; GONZALEZ-REYES et al., 2007). Não há ingestão diária recomendada (RDA) para o manganês, mas o National Research Council dos Estados Unidos estabeleceu a ingestão dietética adequada estimada (ESADDI) de 2 a $5 \mathrm{mg}$ por dia, para adultos. Embora não seja frequente, a ingestão dietética inadequada de manganês pode levar, entre outros efeitos, a baixo crescimento, defeitos ósseos, redução na fertilidade, intolerância à glicose e alterações no metabolismo de lipídios e carboidratos (NAP, 2001).

\subsection{Potássio}

O potássio é o principal cátion intracelular do corpo humano e é necessário para o funcionamento normal das células. Segundo o Food and Nutrition Board da National Academies Press dos Estados Unidos (2005), a ingestão adequada (Al) de potássio é de $4700 \mathrm{mg}$ por dia, para adultos. Esse nível de ingestão dietética é suficiente para manter níveis adequados de pressão arterial, reduzir os efeitos adversos da ingestão de $\mathrm{NaCl}$ na pressão arterial, reduzir o risco de cálculos renais recorrentes e possivelmente diminuir a perda óssea. Com base nos dados disponíveis, as consequências adversas da deficiência de potássio incluem: arritmias cardíacas, fraqueza muscular e intolerância à glicose. Uma ingestão dietética inadequada de potássio pode ainda aumentar o risco de doença cardiovascular, particularmente derrame cerebral. No 
presente trabalho, os dados a serem obtidos para a concentração de potássio no mexilhão Perna perna serão importantes do ponto de vista ambiental e da nutrição.

\subsection{Vanádio}

Entre outros elementos que podem estar presentes na água do mar, menciona-se o vanádio $(\mathrm{V})$, objeto do presente trabalho. As determinações de vanádio são motivo de grande preocupação devido à sua toxicidade (BYRNE e KOSTA, 1978). Por outro lado, o $\mathrm{V}$ se tornou cada vez mais importante na bioquímica clínica por causa de suas propriedades farmacológicas e fisiológicas. Os compostos de $\mathrm{V}$ têm sido estudados para serem utilizados como agentes terapêuticos para a doença de diabetes mellitus, devido ao seu efeito de insulina mimético (KIMURA et al. 2006; HAMEL et al., 1993) ), bem como um agente antitumoral no tratamento do câncer (EVANGELAU, 2002).

Segundo Luz et al. (2003), a maior parte dos efeitos tóxicos dos compostos de $\mathrm{V}$ resulta da ação irritativa local dos olhos e do trato respiratório superior (ao invés de toxicidade sistêmica), caracterizada por rinite, sibilância, hemorragia nasal, conjuntivite, bronquite, tosse e dor torácica, pois os pulmões absorvem bem os óxidos que são as formas solúveis de $\mathrm{V}$.

O V está presente na água do mar em baixas concentrações variando de 0,5 a 2,5 $\mathrm{mg} \mathrm{L}^{-1}$ (STOHS e BAGCHI, 1995). Este elemento pertence ao grupo VB da Tabela Periódica (metal de transição) e existe em diferentes formas químicas dependendo da sua origem, mas acredita-se que o $\mathrm{V}$ esteja presente principalmente como ânion vanadato em água do mar (WEISS et al., 1977). Esse elemento é encontrado em diversos minerais (patronita, vanadinita e carnotita, bauxita, assim como em depósitos que contêm carbono como, por exemplo, no carvão, e óleos de petróleo); é também empregado para fabricação de diferentes tipos de ligas metálicas (BROWN, et al., 2005).

Diversas técnicas de análise estão disponíveis para a determinação de $\checkmark$ tais como: análise por ativação com nêutrons instrumental (INAA) (ZEISLER e STONE, 1988; FUKUSHIMA et al., 2009), espectrometria de absorção atômica 
eletrotérmica (ET-AAS) (SAAVEDRA et al., 2004; LAVILLA et al., 2006), cromatografia líquida de alta eficiência com detecção eletroquímica (NAGAOSA e KIMURA, 1996), espectrometria de massa com fonte de plasma acoplado indutivamente associada à cromatografia líquida (COLINA et al., 2005), espectrometria de absorção atômica (AAS) (ÜNSAL, 1982; TOMINAGA e BANSHO, 1985 SPERLING et al., 2000), voltametria de redissolução adsortiva (AdSV) (SANDER, 1999) e espectrometria de absorção atômica com forno de grafite (GF-AAS) (LUZ et al., 2003; EKINCI e KÖKLÜ, 2000). 


\section{CONSIDERAÇÕES GERAIS SOBRE OS MEXILHÕES}

O Filo Mollusca representa o segundo maior grupo quanto à diversidade animal e, os bivalves marinhos, são os moluscos mais abundantes. Destes, os mexilhões (família Mytilidae) têm conseguido uma impressionante habilidade em dominar os costões rochosos em todos os continentes. Seu sucesso em todo o mundo como organismo dominante é mais pronunciado em locais expostos ou semi-expostos, em regiões tropicais e temperadas, especialmente em substrato rochoso horizontal ou brandamente inclinado. $O$ desenvolvimento de filamentos de bisso para fixação tem permitido a algumas espécies da família Mytilidae, explorar substratos duros e dominar habitats rochosos (RUPPERT et al., 2005; RODRIGUES, 1975).

Os moluscos têm corpo mole, não segmentado, consistindo tipicamente de uma cabeça anterior, um pé ventral e uma massa visceral dorsal. O corpo geralmente é coberto por um manto fino, carnoso e comumente abrigado em uma concha calcária externa. O Filo Mollusca compreende seis classes de aspecto e hábitos diferentes: Gastropoda, Bivalvia, Cephalopoda, Scaphopoda, Polyplacophora e Aplacophora (LOPES e FONSECA, 2008).

A Classe Bivalvia apresenta cerca de 20.000 espécies e também pode ser conhecida pelos nomes de Lamellibranchiata ou Pelecypoda, é formada por moluscos conhecidos por bivalves, sendo os organismos mais conhecidos, as ostras, mexilhões, vieiras e outros mariscos (LOPES e FONSECA, 2008). 
O organismo utilizado neste trabalho foi o mexilhão Perna perna, popularmente conhecido como marisco preto, marisco-das-pedras, ou ostra-depobre, (Figura 4.1) que é um molusco bivalve com a seguinte classificação sistemática (LOPES e FONSECA, 2008):

Filo Mollusca (Linnaeus, 1758)

Classe Bivalvia (Linnaeus, 1758)

Sub-Classe Pteriomorphia (Beurlen, 1944)

Ordem Mytiloida (Férussac, 1822)

Superfamília Mytiloidea (Rafinesque, 1815)

Família Mytilidae (Rafinesque, 1815)

Subfamília Mytilinae (Rafinesque, 1815)

Gênero Perna (Retzius, 1788)

Espécie Perna perna (Linnaeus, 1758)

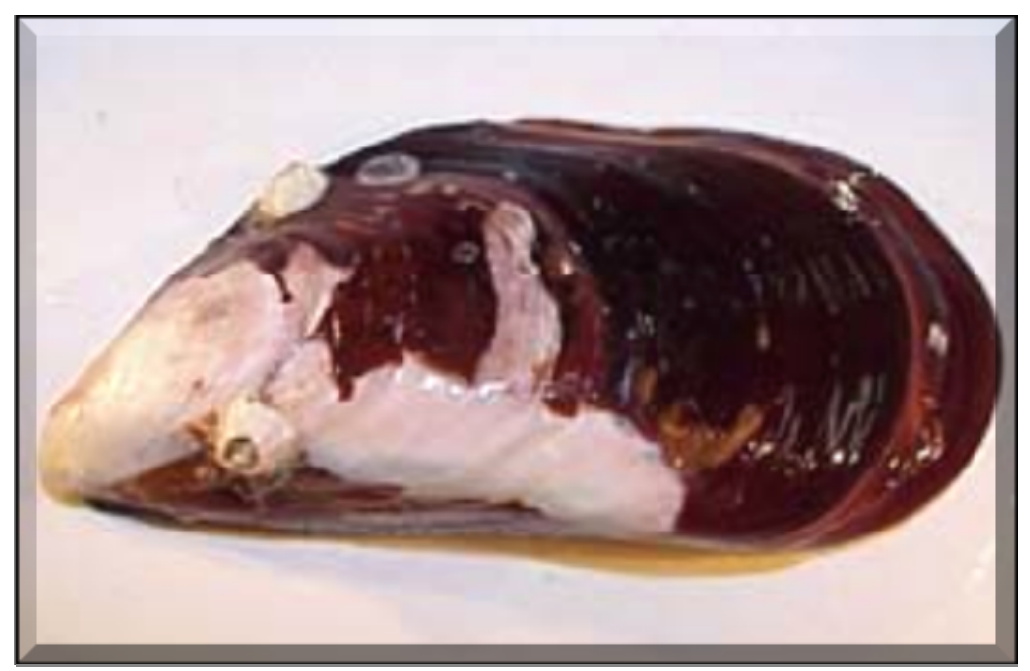

Figura 4.1 Foto da espécie Perna perna - aspecto externo da concha do mexilhão.

Fonte: http://cienciahoje.uol.com.br/noticias/ecologia-e-meio-ambiente/entrandode-gaiato-no-navio/, acessado em 15 de fevereiro de 2012. 
Esta espécie possui uma ampla distribuição geográfica, ocorrendo no Mar Mediterrâneo; na costa atlântica da África, desde o Estreito de Gilbraltar até a Namíbia; no sul e leste da África do Sul até o Mar Vermelho e Madagascar; e no Oceano Índico. Na América do Sul, Perna perna é comumente encontrada na costa oriental da Venezuela, na Península de Paria, Araya, llha Margarita e em Turpialito; no Brasil, ocorre no litoral brasileiro desde a Baía de Vitória, no Estado do Espírito Santo; até Rio Grande, no Rio Grande do Sul e no Uruguai (LOPES e FONSECA, 2008).

Os mexilhões $P$. perna são animais aquáticos que possuem o corpo recoberto por uma concha com duas valvas iguais unidas pelo ligamento elástico. Essas valvas são simétricas e unidas por dois músculos adutores que tendem a mantê-las juntas. Por baixo deste ligamento, encontra-se a charneira, saliência em forma de dentes que se encaixa de forma perfeita em reentrâncias da valva oposta. O manto característico dos moluscos está nos bivalves, totalmente confinado e fixo à concha. A linha paleal das valvas soltas mostra o limite de extensão do corpo mole do organismo (Figura 4.2). Dentro da concha está o corpo mole, formado pela massa visceral (vários órgãos: fígado, estômago, intestino e outros), manto, pé e brânquias (BARNES, 1995; RUPPERT et al., 2005; LOPES e FONSECA, 2008).

A superfície externa de cada valva é marcada pelas linhas de crescimento (Figura 4.3) e nota-se que ocorre demarcação mais forte em animais que sofrem grande estresse ambiental, enquanto que em animais que vivem em locais protegidos e/ou apresentam rápido crescimento, como ocorre em animais de cultivo, estas são suaves e por vezes difíceis de serem notadas (BARNES, 1995; RUPPERT et al., 2005; LOPES e FONSECA, 2008). 


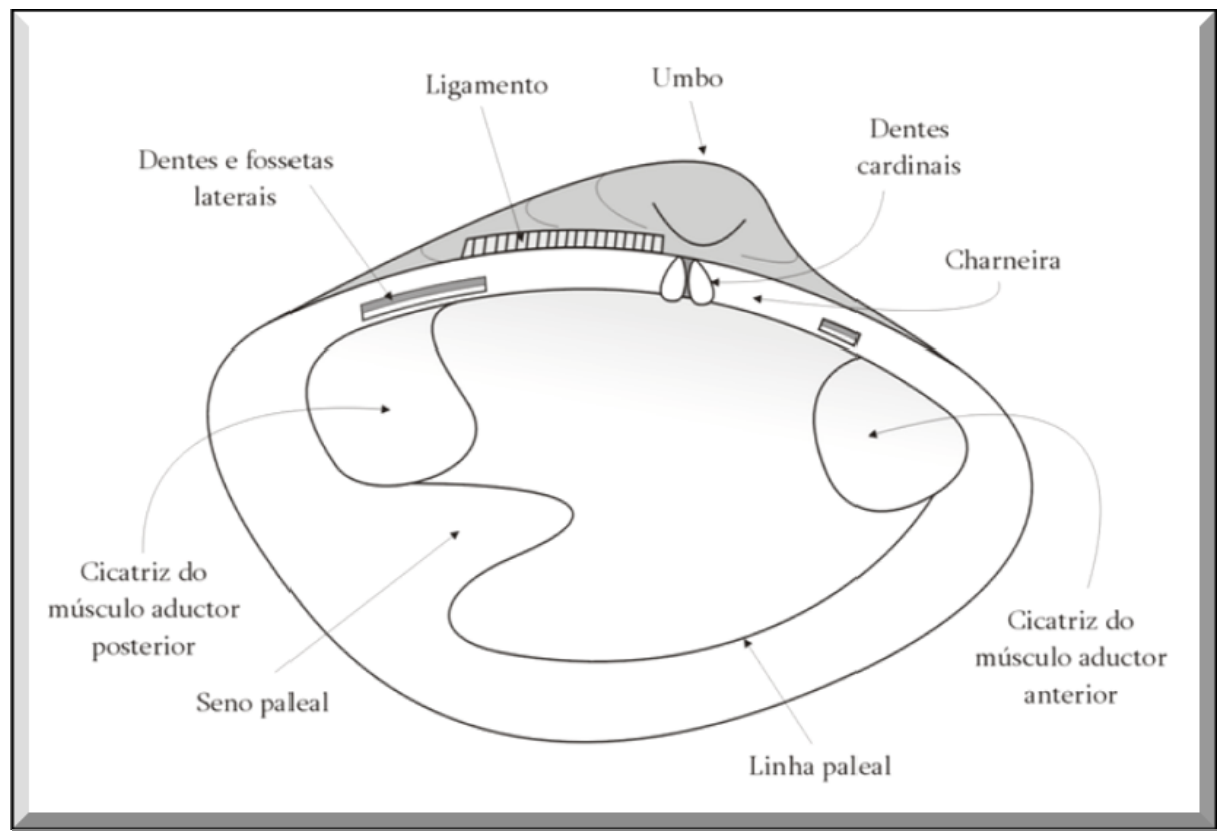

Figura 4.2 Estruturas morfológicas de um mexilhão.

Fonte: http://pt.wikipedia.org/wiki/Imagem:Valva-Vistalnterna.png, acesso em 29 de Junho de 2012.

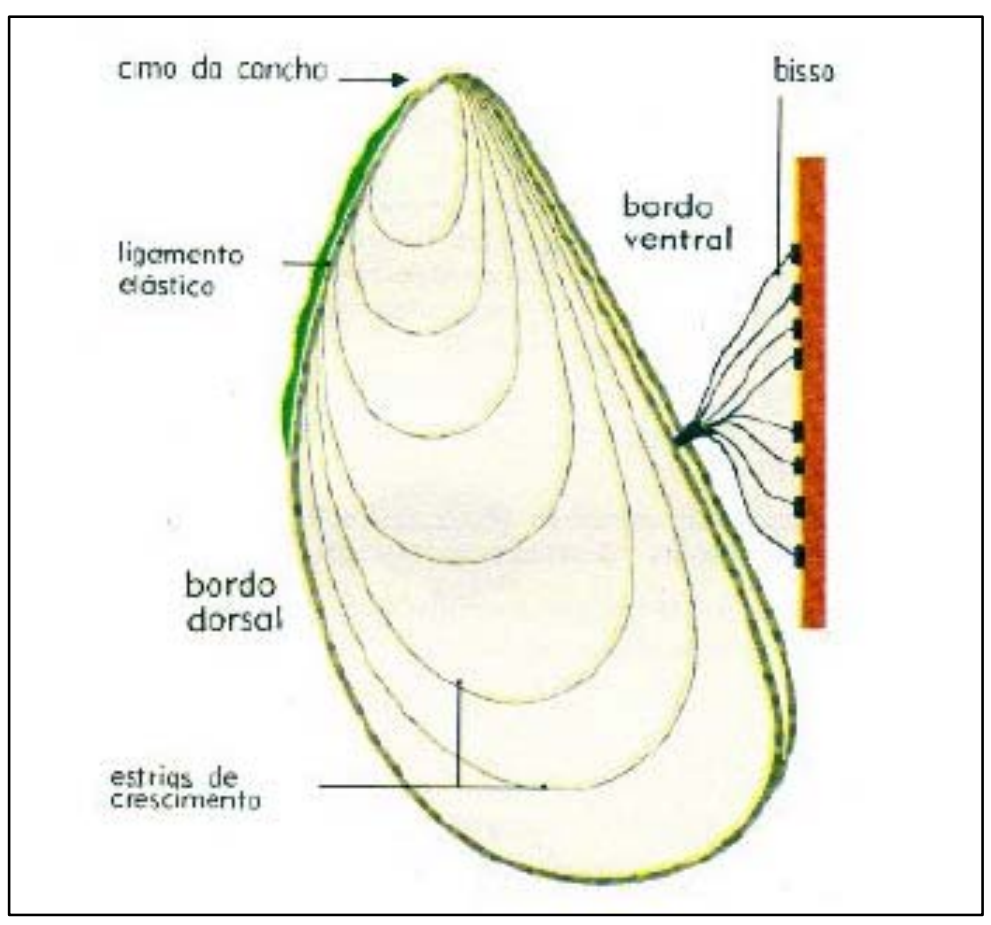

Figura 4.3 Visão geral de um mexilhão.

Fonte: OREUX, 1967. 
Os mexilhões possuem um pé em forma de machado de onde sai o bisso que faz seu suporte de sustentação (Figura 4.4). Suas brânquias são finas e em forma de placas (STORER e USINGER, 1976). Apresenta sifão inalante, abertura por onde a água entra. $\mathrm{O}$ sifão exalante é a estrutura por onde a água sai, e também as pseudofezes (pellets).

A alimentação baseia-se em movimentos ciliares de células presentes nas brânquias que provocam a entrada de água na cavidade do manto. Com um processo de seleção de partículas alimentares, basicamente em função do tamanho, esses animais acabam por ingerir grande quantidade de material orgânico e inorgânico dissolvido na água. As partículas maiores são eliminadas na forma de pseudofezes (compostas por pellets formados pelas partículas rejeitadas associadas a muco protéico). Partículas orgânicas e microrganismos (protozoários e algas), em suspensão na água, constituem o alimento (STORER e USINGER, 1976; LOPES e FONSECA, 2008).

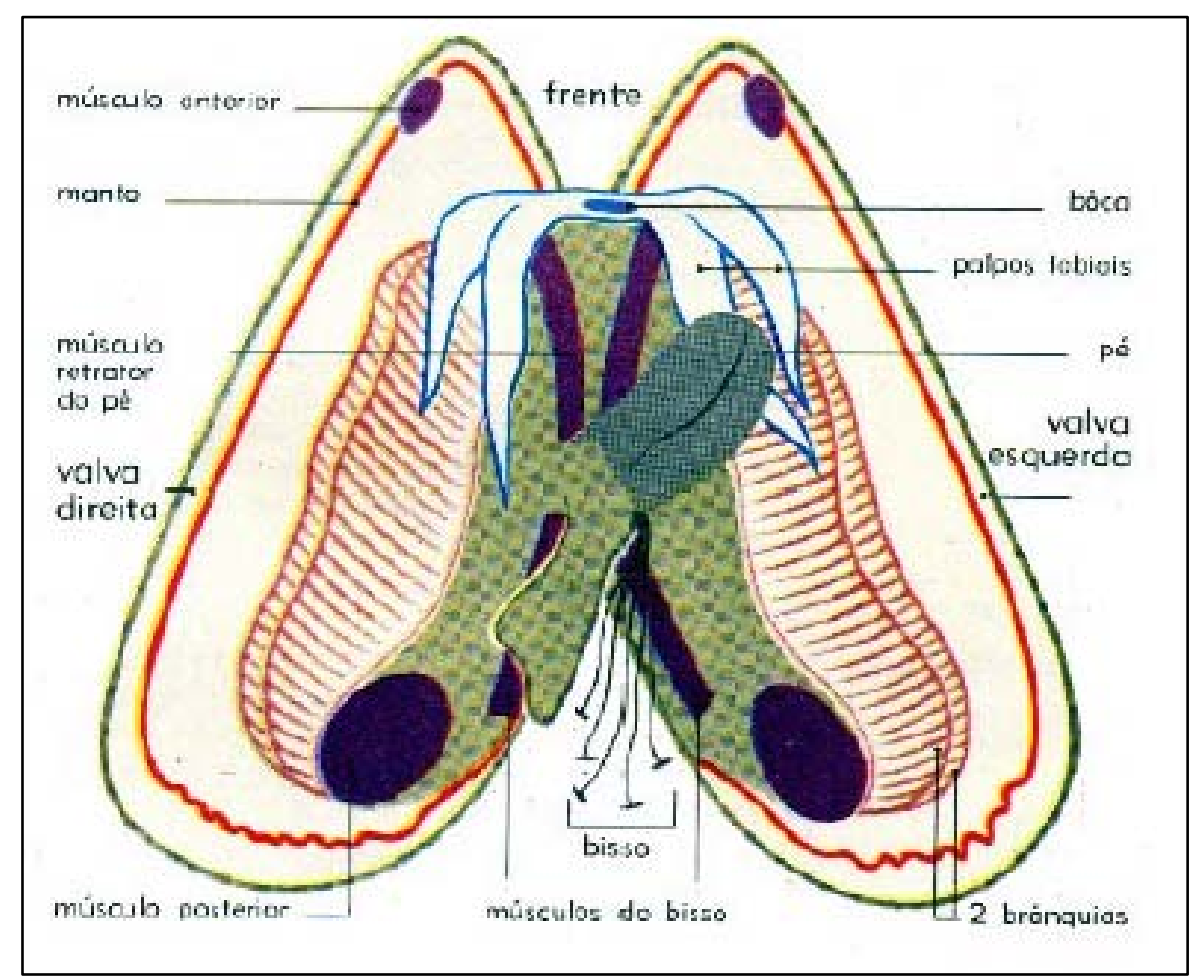

Figura 4.4 Visão interna de um mexilhão.

Fonte: OREUX, 1967. 
Nos mexilhões, os sexos são separados e os machos podem ser distinguidos das fêmeas, internamente, quando estão sexualmente maduros, pela coloração das gônadas como mostra a Figura 4.5.

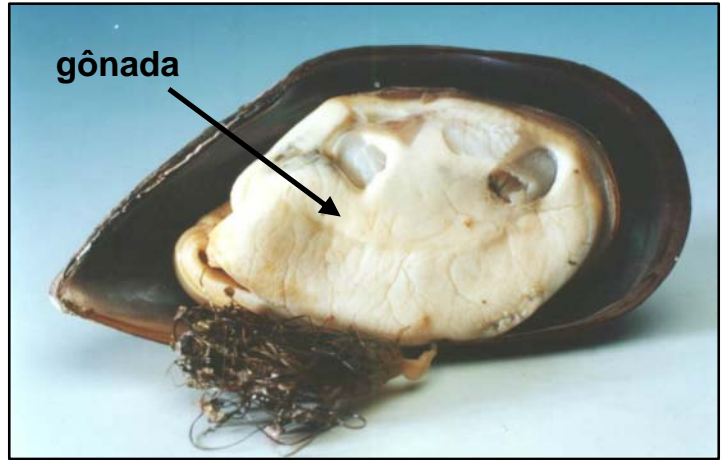

(a)

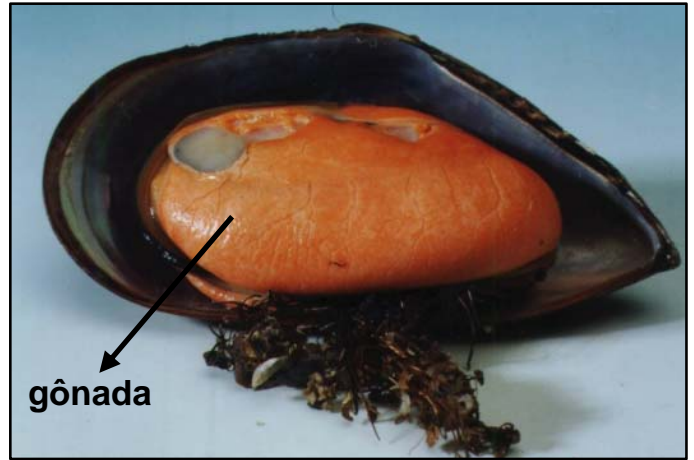

(b)

Figura 4.5 Mexilhão Perna perna. (a) Exemplar macho, mostrando a gônada de cor branca e (b) exemplar fêmea, mostrando a gônada de cor laranja.

Fonte: http://brasilnews1.blogspot.com/2008/08/milicultura-em-floripa.html, acessado em 15 de agosto de 2011.

Nos machos, as gônadas são de cor branca leitosa enquanto que nas fêmeas, são alaranjadas. Para os mexilhões Perna perna raramente ocorre hermafroditismo, sua fecundação ocorre livremente na água. Na região sudeste o ciclo sexual é praticamente contínuo durante todo o ano, sendo que no outono e primavera o período de reprodução encontra-se mais acentuado (LOPES e FONSECA, 2008).

Conforme o Instituto de Planejamento e Economia Agrícola de Santa Catarina (1996) vários fatores interferem no crescimento dos mexilhões Perna perna, tais como:

- Luminosidade: em excesso pode inibir o crescimento; 
- Temperatura: esta espécie possui a capacidade de suportar ampla variação de temperatura (euritérmicos) e sua faixa ótima para crescimento é entre 21 a $28^{\circ} \mathrm{C}$;

- Salinidade: o mexilhão apresenta um bom crescimento com salinidade variando entre 34 a $36 \%$ e resiste à variação entre 19 a $48 \%$;

- Grau de exposição ao ar: quanto mais tempo fora d' água, menos se alimentam, assim, crescem menos;

- Quantidade de alimento: possui influencia direta na taxa de crescimento dos organismos;

- Competidores: podem diminuir a taxa de crescimento;

- Parasitas: mexilhões parasitados apresentam teor de carne inferior aos sadios.

O consumo de moluscos marinhos geralmente é acompanhado de certa preocupação dos consumidores quanto à origem e qualidade do produto. Este fato está associado à maneira pela qual os animais são consumidos, crus ou levemente cozidos e devido à sua própria biologia, que possibilita sua contaminação por acumulação ou retenção de poluentes ou substâncias tóxicas do meio que habitam (BARNES et al., 1995).

Por causa de sua biologia e fisiologia (hábitos sedentários, serem filtradores e sua habilidade de bioconcentrar os poluentes), os moluscos são utilizados em todo o mundo em programas de monitoramento ambiental (ZARONI et al., 2001, BEIRAS et al.,2003). O sistema de circulação de água dentro do mexilhão (seu corpo é todo banhado pela água) faz com que partículas se acumulem em seu tecido, podendo exceder de 100 a 1000 vezes a quantidade das partículas presentes na água. 


\section{5. ÁREAS DE ESTUDO}

A área de estudo do presente trabalho está constituída pelas regiões

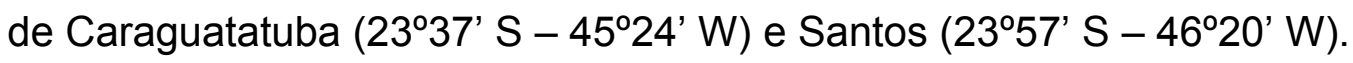

Os locais escolhidos são pontos onde os organismos ficam sujeitos a situações de estresse, devido à proximidade de aporte de efluentes industriais e municipais.

Os pontos de estudo (Figura 5.1), monitorados no litoral de São Paulo, são:

1 - Caraguatatuba: Praia da Cocanha - ponto de referência (cultivo de mexilhões).

2 - Santos: que compreende as regiões de llha das Palmas e Ponta de Itaipu.

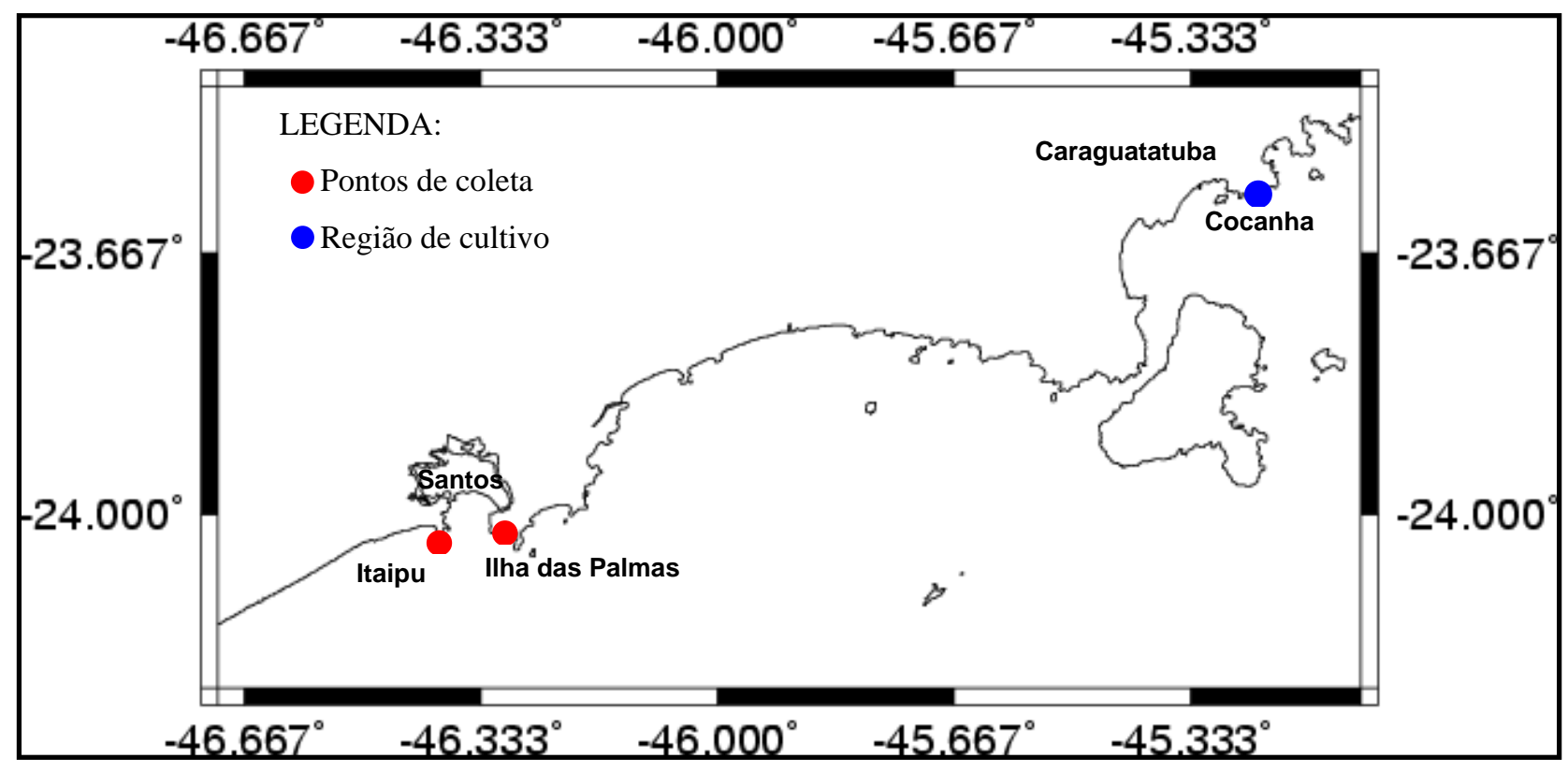

Figura 5.1 Mapa dos pontos de coleta e cultivo de mexilhões Perna perna.

Fonte: Adaptado Google Earth. 
O litoral norte paulista possui uma área de $1943 \mathrm{~km}^{2}$ abrangendo quatro municípios: Ubatuba $\left(711 \mathrm{~km}^{2}\right)$, Caraguatatuba (484 km²), Ilhabela (347 $\mathrm{km}^{2}$ ) e São Sebastião $\left(401 \mathrm{~km}^{2}\right)$. Apresenta planície litorânea estreita, com inúmeras praias intercaladas por costões rochosos $(75 \%$ desses ambientes ocorrem no litoral norte, segundo LAMPARELLI, 1999). Há 41 ilhas, 16 ilhotes e 14 lajes espalhadas pela costa da região; as ilhas são predominantemente rochosas com poucas praias arenosas, das quais se destacam a ilha de São Sebastião, onde se situa o município de Ilhabela; a ilha Anchieta (Ubatuba), que abriga o Parque Estadual da Ilha Anchieta; o arquipélago de Alcatrazes (São Sebastião), abrigando uma Área de Proteção Ambiental municipal.

No que diz respeito ao clima do litoral norte paulista, Monteiro (1973) define o clima do litoral norte do estado de São Paulo como sendo do tipo zonal controlado por massas equatoriais e tropicais, regionalmente caracterizado por alta umidade, resultado da exposição da costa a sistemas tropicais. No que se refere à pluviosidade, segundo Troppmair (2004), no setor de planícies litorâneas a precipitação anual varia de 1800 a 2500 mm; já no setor de serra os índices pluviométricos variam entre 1700 a $2000 \mathrm{~mm}$ anuais.

A população fixa estimada dessa região é de 224.000 habitantes e concentra-se nas principais praias. Essa população pode duplicar nos meses de verão (período de temporada), com aumento em torno de 233.000 pessoas, aumentando de forma excessiva a demanda por água potável, coleta de lixo e coleta de esgotos, nesses municípios. A base da economia local está no setor terciário, devido às atividades ligadas ao turismo, como por exemplo, comércio, hotelaria, construção civil, prestação de serviços, entre outros. A agricultura é inexpressiva na região (CETESB, 2011).

A carência de sistema de coleta e tratamento de esgoto é comum a todos os municípios, resultando na principal fonte de poluição hídrica da região. Os esgotos geralmente são lançados nos corpos d'água locais que deságuam no mar. Esse fato pode alterar consideravelmente a balneabilidade das praias, principalmente nos meses de verão. Os resíduos sólidos domésticos também não são dispostos adequadamente, causando problemas ambientais graves. Outra 
fonte potencialmente poluidora importante está relacionada às atividades do TEBAR (Terminal Almirante Barroso) da Petrobrás, localizado em São Sebastião, devido aos acidentes eventuais já ocorridos durante o manuseio do petróleo e seus derivados (CETESB, 2010).

A Baixada Santista é a mais urbanizada e populosa do litoral, composta pelos municípios de Bertioga, Guarujá, Cubatão, Santos, São Vicente, Praia Grande, Mongaguá. Itanhaém e Peruíbe. É uma área de transição entre o litoral norte, com planície muito estreita e o litoral sul, com planície mais desenvolvida, sendo que sua área territorial é de $2402 \mathrm{~km}^{2}$. As ilhas dessa unidade juntamente com as do litoral sul, são predominantemente sedimentares (LAMPARELLI, 1999). Essa unidade é a que concentra as maiores áreas de manguezal do litoral paulista, principalmente entre Santos e Bertioga.

Nessa região o clima é quente e úmido na maior parte do ano, com média anual superior a $20^{\circ} \mathrm{C}$ de temperatura e pluviosidade anual em torno de 2000 a 2500 mm, com maior incidência nos meses de verão, não havendo uma estação considerada realmente seca na região (LAMPARELLI, 1999).

A população fixa da Baixada Santista é de aproximadamente 1.477.000 habitantes e população flutuante estimada em 947.000 pessoas. Ao todo, são sete estações de tratamento e quatro emissários submarinos (um na Baía de Santos, um no Guarujá e dois em Praia Grande), com percentual médio de cobertura por rede de esgoto de $68,8 \%$ (CESTEB, 2010).

\subsection{Caraguatatuba - Praia da Cocanha}

Caraguatatuba está localizada a $175 \mathrm{~km}$ da capital, entre o Oceano Atlântico e a Serra do Mar, onde nascem os principais rios que deságuam nas praias e onde se situa o Parque Estadual da Serra do Mar. Possui área de 484 $\mathrm{km}^{2}$ e $29 \mathrm{~km}$ de praias e grande parte de sua área ainda é recoberta pela Mata Atlântica, que faz parte do Núcleo Caraguatatuba do Parque Estadual da Serra do Mar, com aproximadamente $138 \mathrm{~km}^{2}$ de área. Além da Mata Atlântica, é possível 
encontrar áreas de manguezais, algumas bastante degradadas pela ocupação humana, destacando-se o manguezal do Rio Juqueriquerê.

O município de Caraguatatuba possui 100.840 habitantes fixos (IBGE, Censo 2011), com população flutuante que predomina nos meses de verão em torno de 93.956 pessoas (Fundação Seade-2000), dobrando a população local nesse período.

A base econômica do município está no comércio e na prestação de serviços, principalmente no setor de turismo. Há também algumas áreas de pesca. O município não apresenta nenhum porto ou atracadouro, apenas uma área de fundeio em águas semiabrigadas, no local denominado Camaroeiro, utilizado por pequenas embarcações de pesca. No Rio Juqueriquerê existem vários atracadouros de barcos de pesca e alguns pontos de comercialização de pescado, além de galpões para abrigo de embarcações de recreio (CETESB, 2010).

A Praia da Cocanha localiza-se ao norte de Caraguatatuba, entre Massaguaçu e Mococa, onde deságua o rio Cocanha. Essa praia possui águas rasas, calmas e cristalinas, sendo ideal para o banho de mar.

De acordo com a CETESB (2011), a qualidade das águas litorâneas no estado de São Paulo, onde em Caraguatatuba 13 praias foram avaliadas, a Praia da Cocanha destaca-se como sendo uma praia de qualidade regular de suas águas. A Tabela 5.1 mostra a classificação das praias de acordo com a porcentagem de ocorrência em cada categoria e qualificação anual.

Na Praia da Cocanha encontra-se uma fazenda de mexilhão (Figura 5.2), com cerca de 2 mil metros quadrados. Os produtores de mexilhão, com apoio da Secretaria de Turismo promovem passeios de barco até o local onde eles são cultivados, a cerca de 500 metros da praia. Cerca de quinze pescadores cultivam o mexilhão em uma espécie de fazenda marinha, situada no ilhote da Cocanha. A Associação dos Pescadores e Maricultores da Praia da Cocanha produz, em média, 80 toneladas de mexilhão por ano. É uma das maiores 
produções deste tipo de molusco no Estado de São Paulo (LITORAL VIRTUAL, 2007).

Tabela 5.1 Classificação das praias de acordo com a porcentagem de ocorrência em cada categoria e qualificação anual (Fonte: CETESB, 2011).

\begin{tabular}{|l|c|c|c|c|c|}
\hline \multicolumn{1}{|c|}{ PRAIA - LOCAL DE AMOSTRAGEM } & EXCELENTE (\%) & $\begin{array}{c}\text { MUITO BOA } \\
(\%)\end{array}$ & $\begin{array}{c}\text { SATISFATÓRIA } \\
(\%)\end{array}$ & $\begin{array}{c}\text { IMPRÓPRIA } \\
(\%)\end{array}$ & $\begin{array}{c}\text { QUALIFICAÇ̃̃O } \\
\text { ANUAL }\end{array}$ \\
\hline TABATINGA (250m RIO TABATINGA) & 17 & 10 & 25 & 48 & RUIM \\
\hline TABATINGA (CONDOM. GAIVOTAS) & 81 & 8 & 12 & 0 & BOA \\
\hline MOCOÓCA & 75 & 12 & 8 & 6 & REGULAR \\
\hline COCANHA & 54 & 10 & 27 & 10 & REGULAR \\
\hline MASSAGUAÇU (R MARIA CARLOTA) & 75 & 8 & 17 & 0 & BOA \\
\hline MASSAGUACU (AV. M. H. CARVALH0) & 100 & 0 & 0 & 0 & OTIMA \\
\hline CAPRICÓRNIO & 96 & 4 & 0 & 0 & BOA \\
\hline LAGOA AZUL & 80 & 13 & 7 & 0 & BOA \\
\hline MARTIM DE SÁ & 67 & 23 & 8 & 2 & REGULAR \\
\hline PRAINHA & 8 & 27 & 35 & 31 & RUIM \\
\hline CENTRO & 21 & 37 & 21 & 21 & REGULAR \\
\hline INDAIÁ & 0 & 17 & 35 & 48 & RUIM \\
\hline PAN BRASIL & 75 & 17 & 8 & 0 & BOA \\
\hline PALMEIRAS & 60 & 33 & 0 & 8 & REGULAR \\
\hline PORTO NOVO & 35 & 19 & 38 & 8 & REGULAR \\
\hline
\end{tabular}

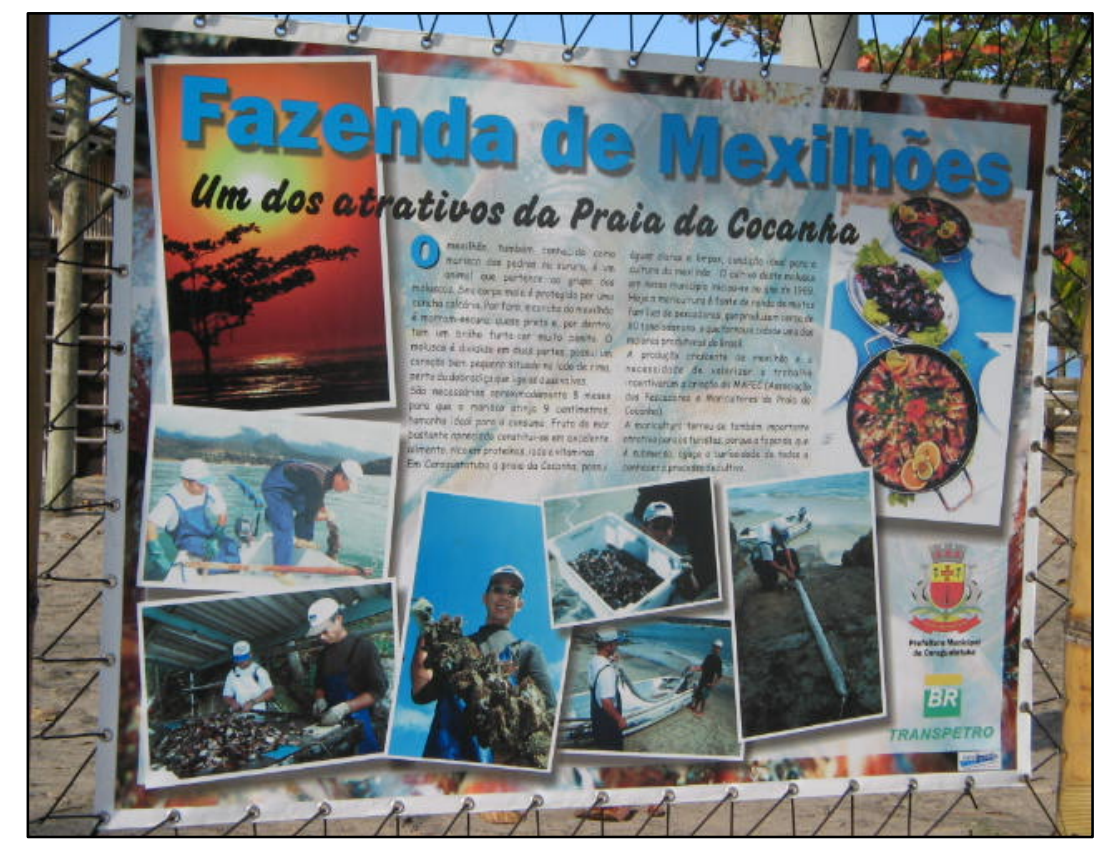

Figura 5.2 Região de cultivo de mexilhões localizada na Praia da Cocanha, em Caraguatatuba.

Fonte: SEMMLER (2007). 


\subsection{Santos - Ilha das Palmas e Ponta de Itaipu}

A Baixada Santista é a área central do litoral paulista compreendida entre Bertioga, a noroeste, e Mongaguá, a sudeste, e Santos, no litoral, estendendo-se até a escarpa da serra do Mar, para o interior. Essa região ocupa uma área de 51.500 ha, onde 5.000 ha correspondem às águas (rios e braços de mar), 6.700 ha às montanhas (morros isolados), 10.800 ha de manguezais $e$ 29.000 ha de áreas remanescentes, inclusive áreas urbanizadas (BOLDRINI, 1990).

A região de Santos apresenta clima quente e úmido, com uma estação chuvosa que vai de outubro a abril, com índices mensais superiores a $170 \mathrm{~mm}$, e um período de secas que se prolonga de maio a setembro. A temperatura média anual é superior a $20^{\circ} \mathrm{C}$ e a pluviosidade é elevada, variando entre 2.000 a 2.500 mm (CETESB, 2011). Os ventos predominantes são de sudeste e escala decrescente de freqüência relativa de sul e sudeste (SABESP, 1997).

Santos possui a maior população fixa do litoral, e a menor taxa de crescimento populacional anual, de apenas 0,3\%. Na temporada, a cidade ainda pode receber aproximadamente 100.000 turistas agravando a situação sanitária do município. Encontra-se uma estação de pré-condicionamento que encaminha seu efluente líquido para o emissário com saída a $4 \mathrm{~km}$ da costa, na Baía de Santos. Esse emissário é o mais antigo do litoral, em funcionamento desde a década de 70 (CETESB, 2011).

O Porto de Santos (Figura 5.3) é um dos maiores complexos portuários da América do Sul e funcionou como base do desenvolvimento regional da Baixada Santista, representando a atividade econômica regional mais importante desde o período colonial. Diariamente, inúmeros navios carregam e descarregam produtos oriundos de vários países, como matérias-primas e produtos industrializados. Muitos desses produtos são armazenados em tanques e comercializados de acordo com a demanda. Essa atividade de tancagem, juntamente com as demais atividades marítimas realizadas no porto, tornam os 
acidentes ambientais comuns, como por exemplo, o derramamento de produtos químicos (TOMMASI, 1979; BONETTI FILHO, 1996; BONETTI, 2000).

O lançamento de esgotos municipais produzidos por Santos, São Vicente, Vicente de Carvalho e Guarujá e os inúmeros efluentes industriais lançados na Baía e no estuário são responsáveis por fazerem deste, um dos locais mais poluídos do Brasil (CETESB, 2011).

A Baía de Santos está situada no lado sul da llha de São Vicente, recebendo todas as águas do estuário e dos efluentes de esgotos municipais produzidos por Santos, São Vicente, Vicente de Carvalho e Guarujá. Dentro da Baía existe um regime de circulação de águas que é governada predominantemente pelo regime de marés (enchente e vazante).

Ao leste da Baía encontra-se a região de llha das Palmas que se encontra próxima à desembocadura do Canal do estuário de Santos. Essa região pode sofrer uma possível contaminação por influência do emissário da SABESP, mas sua principal fonte de contaminação é a água estuarina (efluentes municipais e industriais) trazida em condições de maré vazante. Já no lado oeste da Baía encontra-se a região de Ponta de Itaipu que segue o mesmo padrão de possível contaminação por meio do canal do estuário de São Vicente, também em condições de maré vazante (CETESB, 2011).

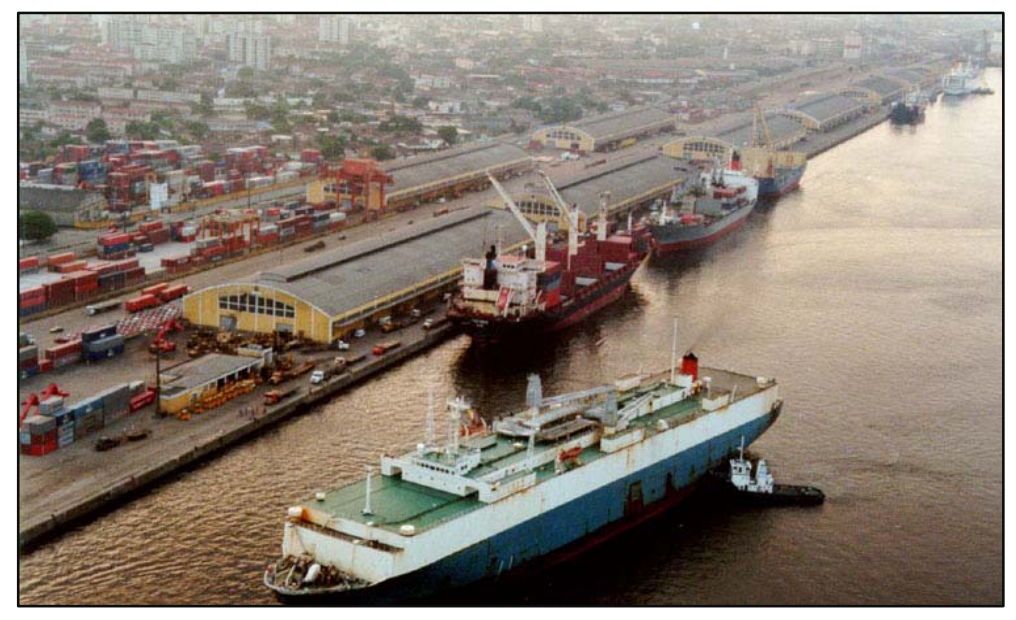

Figura 5.3 Foto do Porto de Santos.

Fonte: http://www.newscomex.com.br/adm/fotos/noticia_13318.jpg, acessado em 2 de janeiro de 2010. 


\section{MÉTODO DE ANÁLISE POR ATIVAÇÃO COM NÊUTRONS (NAA)}

\subsection{Considerações gerais sobre análise por ativação com nêutrons}

O método de análise por ativação com nêutrons baseia-se na produção de radionuclídeos artificiais a partir de elementos estáveis para sua análise qualitativa e quantitativa. As amostras são irradiadas sob um fluxo de nêutrons provenientes de um reator nuclear, que interagem com os núcleos dos isótopos dos elementos presentes na amostra formando os nuclídeos radioativos. Estes nuclídeos radioativos decaem segundo a sua meia-vida emitindo os chamados raios gama de decaimento, os quais são medidos num espectrômetro de raios gama. A análise qualitativa consiste na identificação do elemento que deu origem a este radioisótopo pelas suas energias dos raios gama emitidos e meia-vida. Trata-se de uma técnica analítica bastante sensível e com boa precisão e exatidão, que permite a determinação de vários elementos presentes num determinado tipo de amostra (BODE e DE GOEIJ, 1998).

A descoberta da reação de ativação, isto é, da obtenção de substâncias radioativas a partir do choque entre núcleos dos elementos com partículas ou núcleos de outros elementos, foi feita por Irene e Frédéric Joliot Curie, em 1934. Em 1936, Hevesy e Levi utilizaram nêutrons para bombardear disprósio e európio, sugerindo a aplicação do método de ativação com nêutrons em análises elementares (ALFASSI, 1990).

Desde então a análise por ativação progrediu significativamente, e tornou-se uma ferramenta analítica versátil e sensível para determinação de elementos traço de interesse nas diversas áreas da ciência e tecnologia (BODE e VAN DIJK, 1997). Além das medidas da radioatividade ambiental e do uso de radiotraçadores, a análise dos materiais pôde ser realizada com sua ativação por 
meio de sua irradiação utilizando a fonte de nêutrons mais poderosa - um reator nuclear. Os reatores nucleares de pesquisa são as fontes de nêutrons mais empregadas na NAA, com fluxo variando entre a faixa de $10^{12}$ a $10^{14} \mathrm{n} \mathrm{cm}^{2} \mathrm{~s}^{-1}$ (KELLNER et al., 1998).

De acordo com Aguiar (2001) o uso de reatores na NAA apresenta características favoráveis ao seu uso, a saber:

- Seções de choque dos elementos alvos e taxas de fluência de nêutrons são geralmente altas, possibilitando a detecção de um grande número de elementos;

- Grande poder de penetração dos nêutrons com fluxo homogêneo em vários tipos de materiais, e assim sendo, materiais de espessura volumosa podem ser analisados;

- Produção de calor devido às interações sofridas pela amostra é pequena;

- Irradiação das amostras pode ser realizada paralelamente às outras atividades do reator, sem a ocorrência de interferência.

Os nêutrons podem ser classificados, de acordo com as suas energias, em três componentes básicos caracterizados por suas respectivas energias: nêutrons térmicos, com a energia mais provável de $0,025 \mathrm{eV}$, os nêutrons epitérmicos, com energias que vão desde 0,55 eV até cerca de $1 \mathrm{MeV}$ e os nêutrons rápidos, com energias maiores que $1 \mathrm{MeV}$.

Em geral, a NAA consiste na utilização de rações nucleares para produção de radionuclídeos. Quando o nêutron colide com um núcleo, diversos tipos de reações podem ocorrer, tais como: espalhamento elástico $(n, n)$, espalhamento inelástico $\left(n, n^{\prime}\right)$, captura radioativa $(n, y)$, reações com liberação de partículas $(n, \alpha),(n, p)$ e $(n, 2 n)$, e fissão (n, f) (SANTOS, 2004). Contudo, os nêutrons térmicos e epitérmicos que induzem a reação de captura radioativa $(n, \gamma)$ são considerados os mais importantes na NAA (KUCERA et al., 2004). 


\subsection{Princípio do método de análise por ativação com nêutrons (NAA)}

A análise por ativação com nêutrons baseia-se na interação de um dado material com nêutrons, seguida da medição da radioatividade induzida. Tal fenômeno é possível por meio de uma reação nuclear, que ocorre pelo bombardeamento do núcleo alvo com nêutrons. Desta maneira, pela medida dos radioisótopos formados, é possível realizar uma determinação qualitativa e quantitativa de elementos presentes na amostra. A identificação do radionuclídeo formado é feita pela energia dos raios gama emitidos e pela meia-vida (ALFASSI, 1990).

A sequência de eventos que ocorrem numa reação nuclear típica utilizada na análise por ativação com nêutrons se inicia quando um nêutron interage com um núcleo alvo por meio de uma colisão inelástica, formando um núcleo composto num estado excitado. A energia de excitação do núcleo composto é devida à energia de ligação do nêutron com o núcleo. $O$ núcleo composto formado quase que instantaneamente adquire uma configuração mais estável por meio da emissão de raios gama prontos característicos. Em muitos casos, esta nova configuração produz um núcleo radioativo que também sofre um relaxamento por emissão de um ou mais raios gama de decaimento, mas a uma velocidade mais lenta, de acordo com o tempo de meia-vida do núcleo radioativo (ALFASSI, 1990). Na Figura 3.4.1 é apresentado o esquema de eventos que ocorrem na irradiação de uma amostra com nêutrons.

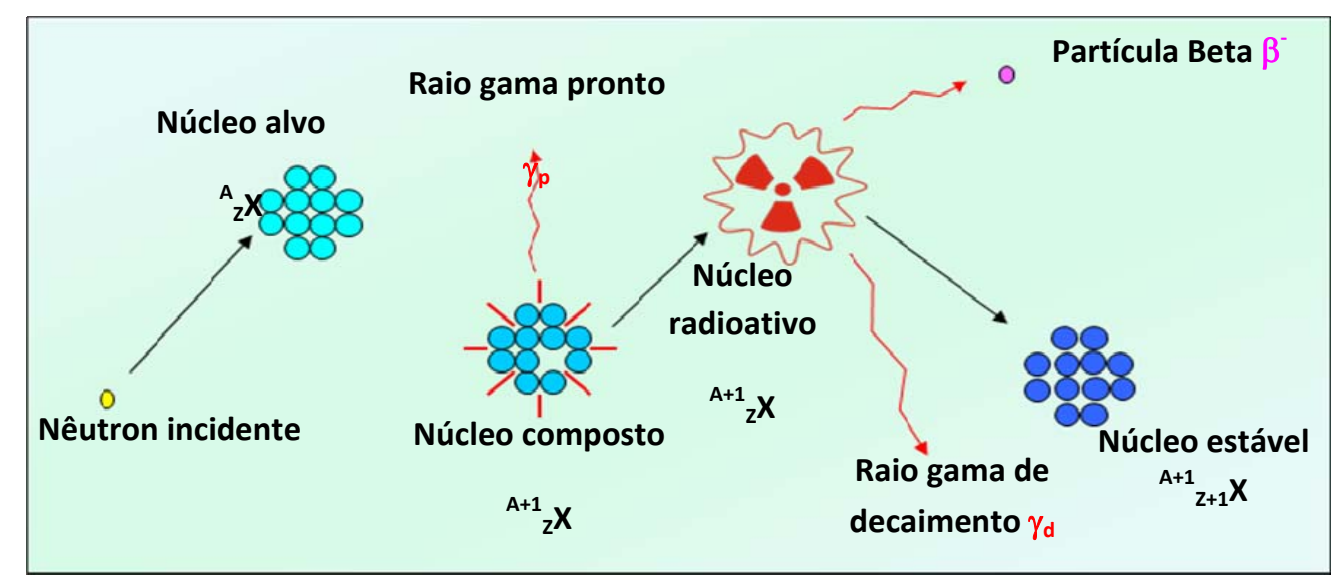

Figura 6.1 Diagrama ilustrativo da seqüência de eventos de uma reação típica (n, Y).

Fonte: Adaptado de IAEA, 1990. 
Para uma melhor compreensão do processo de interação para formação de nuclídeos radioativos, a seguir é apresentado um esquema da reação nuclear (Figura 6.2).

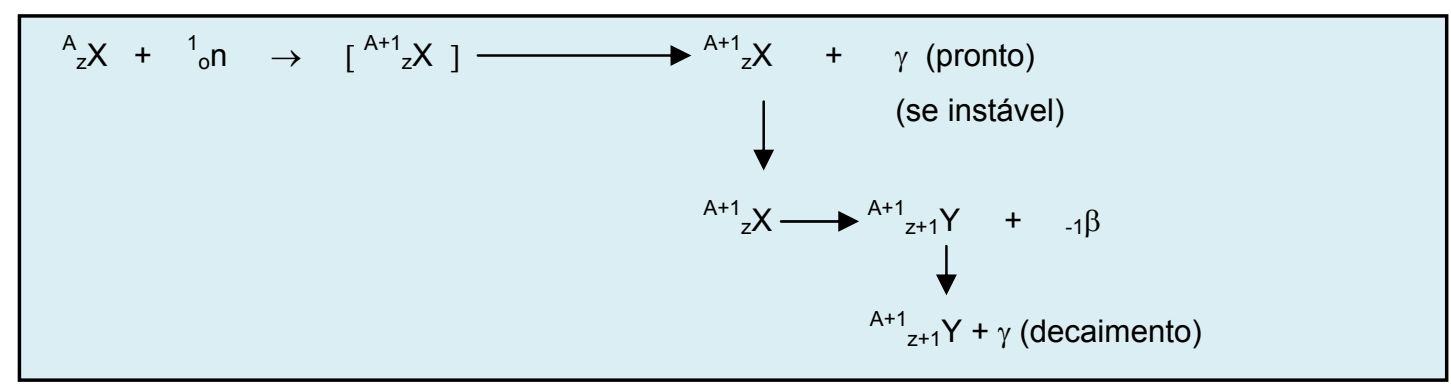

Figura 6.2 Esquema da captura radioativa.

Fonte: Autora do trabalho.

A medição da radiação emitida por ${ }^{A+1}{ }_{Z+1} X$ possibilita a análise qualitativa e quantitativa do elemento que originou este radioisótopo. Como cada radionuclídeo decai com uma meia-vida característica e a maioria deles emite um ou mais raios gama, a identificação do radioisótopo formado é feita por meio da meia-vida e das energias dos raios gama.

Os equipamentos mais utilizados na medição dos raios gama emitidos pelas amostras radioativas são os espectrômetros de radiação gama de alta resolução. Eles são constituídos basicamente de um detector semicondutor, sendo os mais modernos de germânio hiperpuro, e um sistema eletrônico para a amplificação e processamento dos pulsos elétricos gerados. Nos espectros obtidos são discriminados picos de absorção total em energias características, que permitem identificar o radioisótopo presente na amostra. A área sob cada pico é proporcional a quantidade do elemento correspondente.

A sensibilidade do método de NAA depende do tipo de matriz e dos parâmetros de irradiação (fluxo de nêutrons, tempos de irradiação e de decaimento), condições de medição (tempo de medição e eficiência do detector), parâmetros nucleares dos elementos em estudo (abundância isotópica, seção de choque para nêutrons, meia-vidas e abundância de raios gama) (BODE et al., 2000). 


\subsection{Equação fundamental da análise por ativação com nêutrons instrumental}

A atividade induzida em um elemento após determinado tempo de irradiação, que pode ser medida por detector adequado é dada pela seguinte Equação 6.3.1 (DE SOETE et al., 1972):

$$
A=\frac{z \phi \sigma N_{A} m f\left[1-\mathrm{e}^{-0,693 \frac{t_{i}}{t_{1 / 2}}}\right]}{M}
$$

Onde:

$A=$ atividade em taxas de contagens;

$z$ = eficiência do detector;

$\Phi=$ fluxo de nêutrons, em $\mathrm{n} \mathrm{cm}^{-2} \mathrm{~s}^{-1}$;

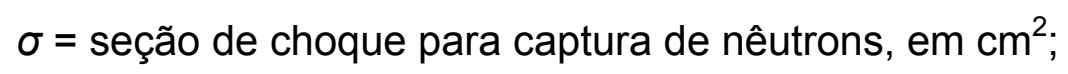

$N_{A}=$ número de Avogadro;

$m=$ massa do elemento;

$f=$ abundância isotópica do nuclídeo alvo;

$M=$ massa atômica do elemento;

$t_{i}=$ tempo de irradiação;

$t_{1 / 2}=$ meia-vida do radionuclídeo formado.

O método de INAA denominado absoluto utiliza a expressão acima para calcular a massa $m$. Para analisar uma amostra por meio do método absoluto é de fundamental importância medir com exatidão a atividade da amostra em estudo. A atividade induzida na amostra pela absorção de nêutrons pelo núcleo pode ser determinada considerando que na análise estão envolvidos os seguintes processos: formação do radionuclídeo, representado por meio de uma reação nuclear $a(n, y) \rightarrow{ }^{*} b$ e decaimento do radionuclídeo formado ( ${ }^{*} b \rightarrow$ c).

Mas, uma vez que não sendo prático conhecer com exatidão todos os parâmetros envolvidos na Equação 6.3.1, tais como o fluxo de nêutrons, a 
eficiência do detector e a secção de choque, é conveniente utilizar o método comparativo da INAA.

\subsection{Método comparativo de análise por ativação}

No método comparativo de análise por ativação, tanto a amostra quanto um padrão do elemento a ser determinado são irradiados sob o mesmo fluxo de nêutrons e medidos com a mesma eficiência de detector ou geometria de medição. Podem-se comparar as atividades induzidas na amostra e no padrão, de forma a determinar a concentração do elemento na amostra, uma vez que a quantidade de radioatividade emitida por um material é função de seu número de átomos alvo. Aplicando-se a Equação 6.3.1 para amostra e padrão, tem-se (KELLER, 1988):

$$
\begin{aligned}
& A_{a}=\frac{z \phi \sigma N_{A} m_{a} f\left[1-\mathrm{e}^{-0,693} \frac{t_{i}}{t_{1 / 2}}\right]}{M} \\
& A_{p}=\frac{z \phi \sigma N_{A} m_{p} f\left[1-\mathrm{e}^{\left.-0,693 \frac{t_{i}}{t_{1 / 2}}\right]}\right.}{M}
\end{aligned}
$$

Onde os índices a e $p$ se referem aos dados para a amostra e o padrão respectivamente.

A razão entre as Equações 6.3.2 e 6.3.3 resulta em:

$$
\frac{A_{a}}{A_{p}}=\frac{m_{a}}{m_{p}}
$$

Na relação (6.3.4), $A_{a}$ e $A_{p}$ se referem às taxas de contagens da amostra e padrão, respectivamente, medidos para o mesmo tempo de decaimento. 
Para o tempo de decaimento $t=0$ pode-se escrever a seguinte relação:

$$
\frac{A_{a(0)}}{A_{p(0)}}=\frac{m_{a}}{m_{p}}
$$

Onde $A_{a(0)}$ e $A_{p}(0)$ são as taxas de contagens da amostra e padrão, respectivamente, para tempo de decaimento $\mathrm{t}=0$.

Segundo a lei do decaimento tem-se:

$A=A_{0} e^{-\lambda t}$

Onde:

$A=$ taxa de contagens para tempo de decaimento $t$;

$A_{0}=$ taxa de contagens para tempo de decaimento $\mathrm{t}=0$;

$t=$ tempo de decaimento.

Escrevendo a relação 6.3.6) para a amostra e padrão tem-se:

$A=A_{a(0)} e^{-\lambda t a}$

$A=A_{a(0)} e^{-\lambda t p}$

Substituindo (6.3.7) e (6.3.8) na relação (6.3.5) tem-se:

$$
\begin{aligned}
& \frac{m_{a}}{m_{p}}=\frac{A_{a} e^{\lambda t a}}{A_{p} e^{\lambda t p}} \\
& m_{a}=\frac{A_{a} m_{p} e^{\lambda(t a-t p)}}{A_{p}}
\end{aligned}
$$


Sendo $C_{a}=\frac{m_{a}}{M_{a}}$

Onde:

$C_{a}=$ concentração do elemento na amostra;

$M_{a}=$ massa total da amostra.

Substituindo a relação (6.3.10) na relação (6.3.11), tem-se a relação (3.4.12):

$$
C_{a}=\frac{A_{a} m_{p} e^{\lambda\left(t_{a}-t_{p}\right)}}{A_{p} M_{a}}
$$

Onde:

$C_{a}=$ concentração do elemento na amostra;

$A_{a}=$ taxa de contagem do radioisótopo na amostra para tempo de decaimento $t_{a}$;

$A_{p}=$ taxa de contagem do radioisótopo no padrão para tempo de decaimento $t_{p}$;

$M_{a}=$ massa total da amostra;

$m_{p}=$ massa do elemento no padrão;

$\lambda$ = constante de decaimento do radionuclídeo;

$t_{a}=$ tempo de decaimento da amostra;

$t_{p}=$ tempo de decaimento do padrão.

A Equação 6.3.12 é utilizada no cálculo da concentração do elemento na amostra no método comparativo de NAA. O termo exponencial leva em consideração a correção do decaimento da amostra e do padrão, uma vez que estes não podem ser medidos simultaneamente num mesmo equipamento. 
A vantagem de se utilizar o método comparativo é que não é necessário conhecer com exatidão os diversos parâmetros nucleares, tais como secção de choque e fluxo de nêutrons.

\subsection{Vantagens e desvantagens do método de análise por ativação}

Ao contrário de outras técnicas bastante utilizadas em análises multielementares como espectrometria de absorção atômica eletrotérmica (ETAAS), espectrometria de emissão atômica com plasma acoplado indutivamente (ICP AES), espectrometria de massas com plasma acoplado indutivamente (ICP MS), espectrometria de absorção atômica com forno de grafite (GF AAS), entre outras, a análise por ativação com nêutrons instrumental (INAA) é um método não-destrutivo, não havendo necessidade de decomposição da amostra, nem tampouco da separação do analito de sua matriz, o que torna muitas vezes a análise simples e rápida, principalmente quando se utilizam radioisótopos de meias-vidas curtas.

Outra grande vantagem da INAA é a não obrigatoriedade de se analisar o branco analítico, pois não há utilização de reagentes para digestão da amostra ou separação de elementos, e não há possibilidade de introdução de contaminantes após a irradiação nas amostras. Além disso, INAA, é uma técnica que se destaca pela universalidade (existem aproximadamente 70 elementos detectáveis por INAA), possibilita análises multielementares e requer quantidades reduzidas de amostras. É também uma técnica bastante seletiva, ou seja, permite a identificação de um elemento mesmo em presença de outros que emitam sinais da mesma natureza.

Entre as desvantagens da técnica estão a dependência da utilização de um reator nuclear e a necessidade de manipulação de material radioativo nas análises. Alguns elementos de baixo número atômico como $\mathrm{H}, \mathrm{He}, \mathrm{Be}, \mathrm{Li}, \mathrm{B}, \mathrm{C}, \mathrm{N}$ e $\mathrm{O}$ e outros de elevado número atômico como $\mathrm{Bi}$, $\mathrm{Tl}$ e $\mathrm{Pb}$ apresentam baixa secção de choque para ativação e/ou seus produtos de ativação têm tempos de meia-vida muito curtos, o que impossibilita a análise destes elementos por ativação neutrônica (BODE e GOEIJ, 1998). Além disso, a análise por ativação 
não permite a identificação da forma química em que um elemento é encontrado na amostra por se tratar de um método baseado em reações que acontecem no nível do núcleo atômico e não de sua esfera eletrônica, e é necessário disponibilidade ou acesso a um reator nuclear de pesquisa. 


\section{PARTE EXPERIMENTAL}

O procedimento experimental deste estudo consistiu de seguintes etapas:

- Coleta dos organismos;

- Tratamento das amostras;

- Ensaios preliminares (verificação da calibração do balão volumétrico

e verificação da calibração do pipetador automático);

- Preparação de padrões sintéticos dos elementos a serem analisados;

- Análise dos materiais de referência certificados;

- Determinação da percentagem da perda de umidade nas amostras e em materiais de referência certificados;

- Procedimento de análise por ativação com nêutrons instrumental e;

- Análise estatística.

Este trabalho foi financiado pelo Conselho Nacional de Desenvolvimento Científico e Tecnológico (CNPq), sob $\mathrm{n}^{0}$ do Processo 304509/2009 - 4 (Bolsa de Produtividade em Pesquisa), intitulado como "Biomonitoração de contaminação por meio de organismos marinhos", e também foi submetido ao Instituto Brasileiro do Meio Ambiente e dos Recursos Naturais Renováveis (IBAMA), conforme autorização de n 16305-1, de 17/07/2008.

\subsection{Coleta dos organismos}

A coleta dos organismos estudados, mexilhões Perna perna (Figuras 7.1a e 7.1b), foi realizada em colaboração com o Laboratório de Ecotoxicologia, coordenado pela Profa. Dra. Eduinetty Ceci Pereira Moreira de Sousa do Instituto Oceanográfico da Universidade de São Paulo (IO-USP). 

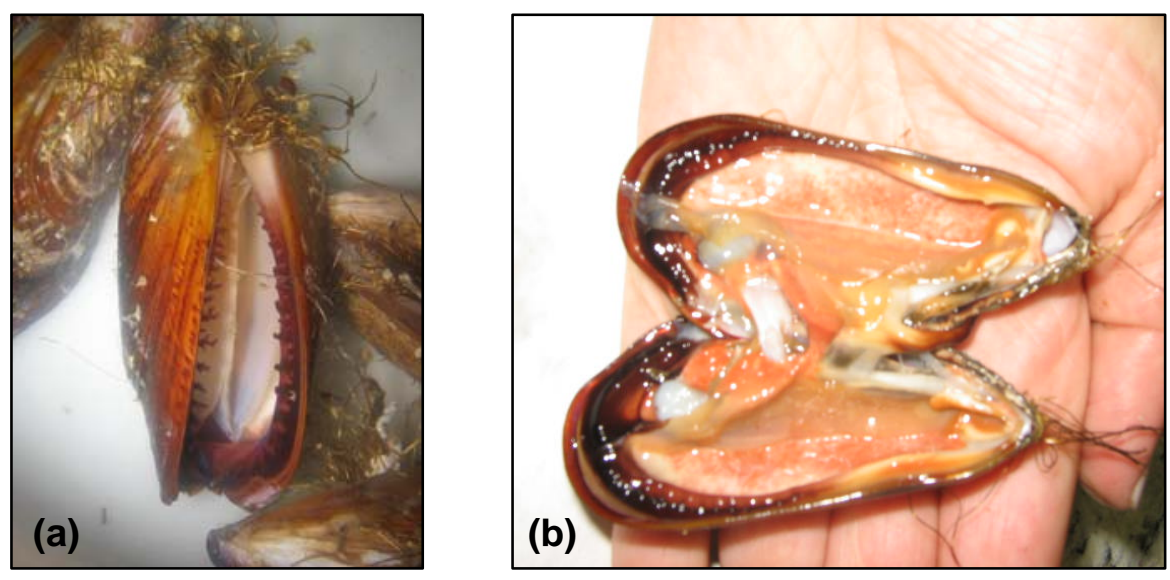

Figura 7.1 (a) Mexilhão Perna perna em água salina. (b) Mexilhão Perna perna aberto.

Fonte: Autora do trabalho.

A área de estudo do presente trabalho é constituída pela região de Caraguatatuba $\left(23^{\circ} 37^{\prime} \mathrm{S}-4^{\circ} 24^{\prime} \mathrm{W}\right)$ e Santos $\left(23^{\circ} 57^{\prime} \mathrm{S}-4^{\circ} 26^{\prime} \mathrm{W}\right)$. Para o ponto de referência dos mexilhões, os organismos foram adquiridos em um cultivo situado na Praia da Cocanha, em Caraguatatuba. Com relação aos pontos supostamente contaminados, os organismos foram coletados em dois locais situados na região de Santos, sendo a Ilha das Palmas e Ponta de Itaipu (Figura $7.2)$.

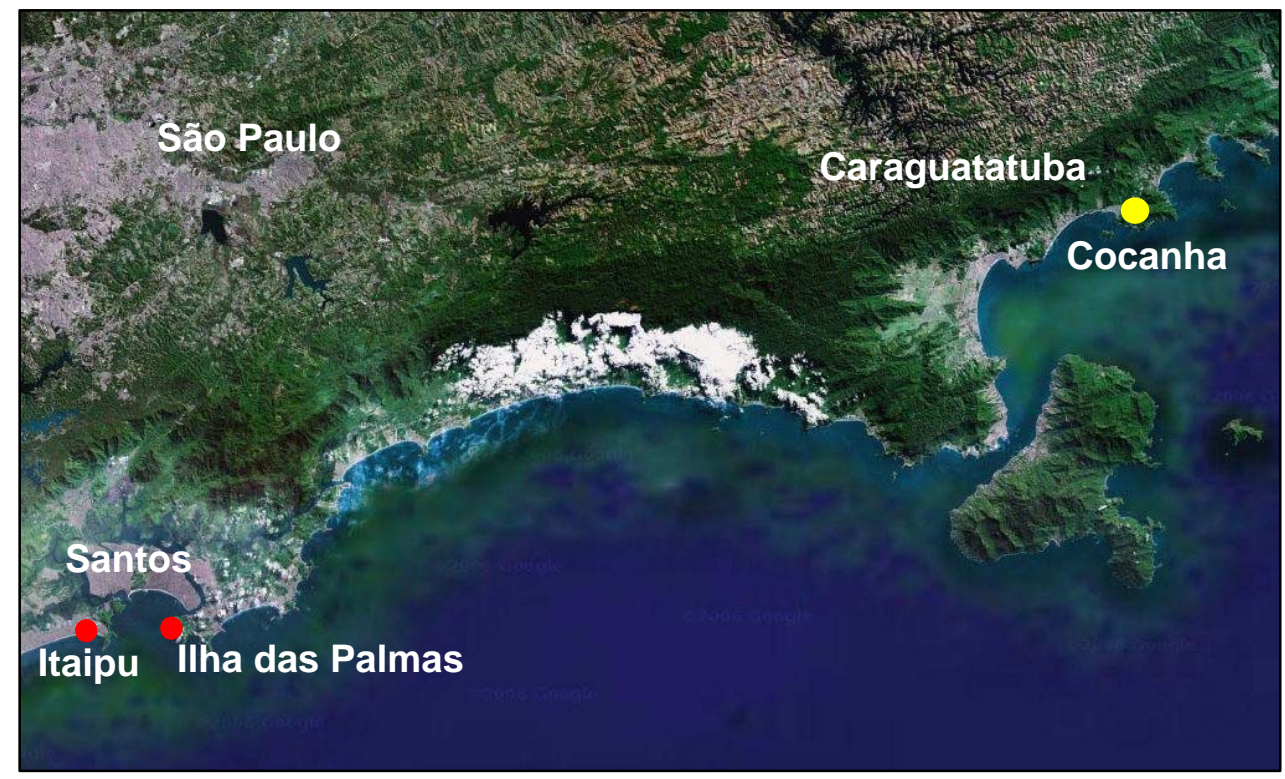

Figura 7.2 Área de estudo no litoral paulista.

Fonte: Google Earth, modificado pela autora. 
Estes locais (Ilha das Palmas e Ponta de Itaipu) situam-se em pontos estratégicos da região de Santos, ou seja, os dois lados da Baía de Santos. A Ilha das Palmas localiza-se próximo à desembocadura do canal do estuário de Santos, cujas águas estuarinas sofrem influência de emissários industriais cujos efluentes são trazidos em condições de maré vazante, tornando-se a principal fonte de contaminação para este ponto, além daquelas advindas do emissário da Sabesp. A Ponta de Itaipu apresenta o mesmo padrão de possível contaminação do canal do estuário de São Vicente, também em condições de maré vazante.

A coleta dos organismos foi realizada em todas as estações do ano, com início na primavera de 2008 e término no inverno de 2009.

Os locais, períodos de coleta das amostras e os códigos dados às amostras estão apresentados na Tabela 7.1.

Tabela 7.1 Código, período de coleta e procedência das amostras de mexilhão.

\begin{tabular}{ccc}
\hline $\begin{array}{c}\text { Código das } \\
\text { amostras }\end{array}$ & $\begin{array}{c}\text { Período de coleta } \\
\text { (estação e ano) }\end{array}$ & Procedência das amostras \\
\hline CP & Primavera / 2008 & Praia da Cocanha, Caraguatatuba \\
CV & Verão / 2009 & Praia da Cocanha, Caraguatatuba \\
CO & Outono / 2009 & Praia da Cocanha, Caraguatatuba \\
CI & Inverno /2009 & Praia da Cocanha, Caraguatatuba \\
ITAp & Primavera / 2008 & Ponta de Itaipu, Santos \\
ITAv & Verão / 2009 & Ponta de Itaipu, Santos \\
ITAo & Outono /2009 & Ponta de Itaipu, Santos \\
ITAi & Inverno / 2009 & Ponta de Itaipu, Santos \\
PALp & Primavera / 2008 & Ilha das Palmas, Santos \\
PALv & Verão / 2009 & Ilha das Palmas, Santos \\
PALo & Outono / 2009 & Ilha das Palmas, Santos \\
PALi & Inverno / 2009 & Ilha das Palmas, Santos \\
\hline
\end{tabular}


A coleta dos moluscos bivalves situados em Santos (Ilha das Palmas e Ponta de Itaipu) foi realizada com o auxílio de uma espátula de titânio uma vez que os organismos se encontram fixos a rochas.

Após a retirada dos mexilhões dos pontos de estudo, esses foram transportados para o laboratório da base norte do Instituto Oceanográfico da USP em Ubatuba, onde ficaram acondicionados em tanques contendo água do mar, sob aeração. Os mexilhões permaneceram por aproximadamente 3 horas nos tanques para a sua recuperação, visto que durante a retirada destes dos pontos de estudo, eles permaneceram fora d'água.

\subsection{Tratamento das amostras}

Após o período de recuperação dos organismos, estes foram retirados do tanque e levados para o Laboratório de Ecotoxicologia no Instituto Oceanográfico da USP (IO-USP).

Para o tratamento das amostras, inicialmente foram selecionados 90 mexilhões de tamanhos diferentes (pequenos, médios e grandes).

Em seguida, foram retirados com uma faca de titânio algas e outros organismos que ficam impregnados nas conchas. Após a remoção desses organismos cada mexilhão foi lavado com água do mar e em seguida realizou-se a biometria dos mesmos (medição do comprimento e da largura das conchas) com um paquímetro, conforme mostra a Tabela 7.2.

Ao término das medidas, os tecidos dos mexilhões retirados das suas conchas foram triturados e homogeneizados em um liquidificador com lâminas de titânio. Após a homogeneização, essas amostras, colocadas em potes de plástico, foram pesadas, armazenadas no freezer e congeladas para posterior secagem por liofilização. A Figura 7.3 (a, b, c) ilustra o procedimento adotado.

Este procedimento de processamento das amostras de mexilhões foi realizado no Laboratório de Ecotoxicologia do IO-USP/SP para as amostras 
coletadas em Caraguatatuba (Praia da Cocanha). As demais amostras coletadas em Santos (Ponta de Itaipu e llha das Palmas) foram processadas na base norte do IO-USP localizada em Ubatuba.

Tabela 7.2 Biometria (médias dos comprimentos e das larguras) das conchas dos mexilhões.

\begin{tabular}{ccc}
\hline $\begin{array}{c}\text { Código das } \\
\text { amostras }\end{array}$ & Comprimento (cm) & Largura (cm) \\
\hline CP & 7,9 & 2,9 \\
CV & 8,4 & 4,6 \\
CO & 8,2 & 4,3 \\
CI & 7,1 & 3,6 \\
ITAp & 5,3 & 2,7 \\
ITAv & 6,9 & 2,9 \\
ITAo & 6,1 & 2,6 \\
ITAi & 5,3 & 2,3 \\
PALp & 5,7 & 2,8 \\
PALV & 5,8 & 2,6 \\
PALo & 5,2 & 2,5 \\
PALi & 6,6 & 3,3 \\
\hline
\end{tabular}

Para as análises pelo método de ativação com nêutrons, é necessário que as amostras estejam na forma mais seca possível, para que não ocorram reações de radiólise da água durante a irradiação. Um dos métodos de secagem mais usados para materiais biológicos analisados por análise por ativação com nêutrons instrumental (INAA) é a liofilização, pois para muitos elementos o risco de perdas por volatilização é menor.

As amostras de mexilhões foram transportadas em caixas térmicas com gelo para posterior liofilização, no laboratório de Análise por Ativação Neutrônica-LAN do IPEN-CNEN/SP para as análises químicas dos elementos. 


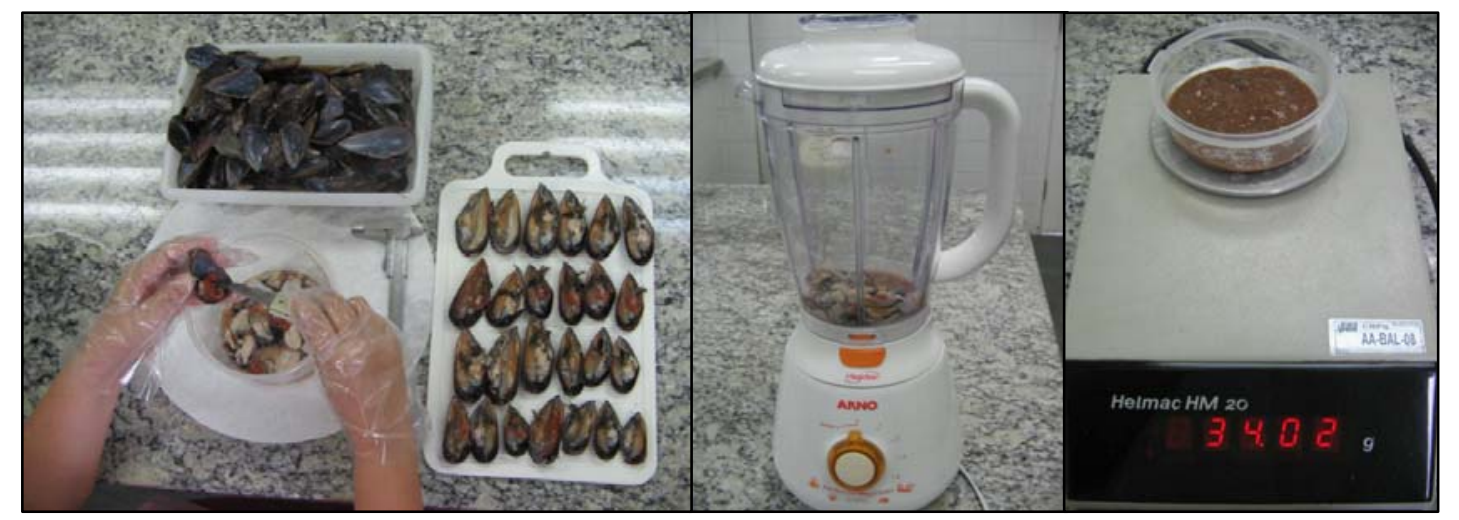

(a)

(b)

(c)

Figura 7.3 llustração do procedimento adotado: (a) remoção dos tecidos de mexilhão, (b) trituração e homogeneização, (c) pesagem das amostras de mexilhão.

Fonte: Autora do trabalho.

Para a liofilização das amostras foi utilizado o liofilizador (Figura 7.4) de marca Thermo Electron Corporation, modelo Modulyo D-115, do Laboratório de Análise por Ativação Neutrônica, que é adequado para a secagem de pequenas quantidades de amostras.

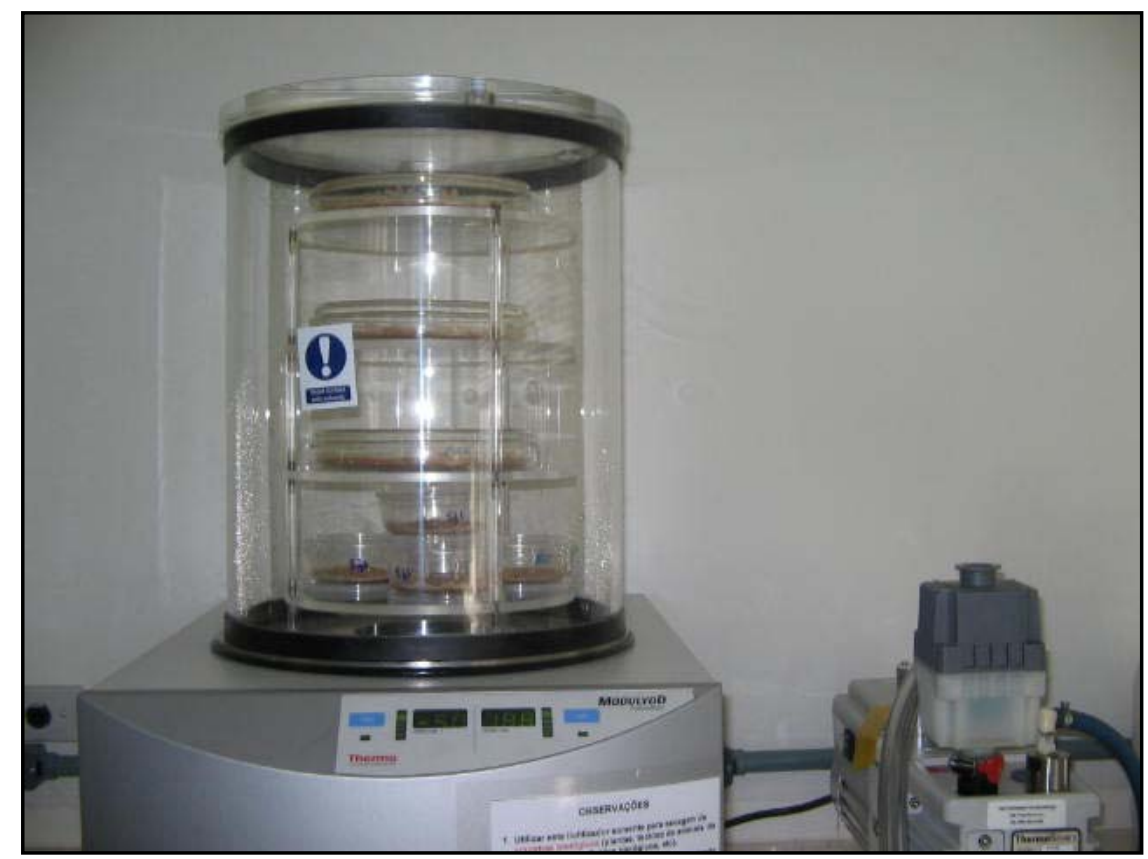

Figura 7.4 Liofilizador da marca Thermo Electron Corporation, modelo Modulyo D-115.

Fonte: Autora do trabalho. 
As amostras foram liofilizadas separadamente por pontos de estudo e estações do ano, com o objetivo de evitar eventual contaminação. O período de liofilização foi de cerca de $48 \mathrm{~h}$, à temperatura de $-52{ }^{\circ} \mathrm{C}$ e pressão de $74 \mu \mathrm{bar}$. Em seguida, as amostras foram novamente pesadas afim de avaliar a percentagem de umidade perdida na liofilização, conforme mostra a Tabela 7.3.

Ao término desta secagem, as amostras foram trituradas em almofariz de ágata e peneiradas em peneira de nylon de 100 mesh. Finalmente, as amostras na forma de pó foram armazenadas em frascos plásticos, etiquetadas e guardadas em freezer para posteriores análises. A Figura $7.5(\mathrm{a}, \mathrm{b})$ ilustra o procedimento adotado.

Tabela 7.3 Porcentagens da perda de umidade $(P)$ nas secagens das amostras de mexilhões por liofilização.

\begin{tabular}{cc}
\hline Amostras de mexilhões & $\mathbf{P}(\%)$ \\
\hline Cocanha Primavera & 84,7 \\
Cocanha Verão & 84,2 \\
Cocanha Outono & 85,3 \\
Cocanha Inverno & 85,5 \\
Itaipu Primavera & 85,5 \\
Itaipu Verão & 80,3 \\
Itaipu Outono & 85,6 \\
Itaipu Inverno & 88,1 \\
Palmas Primavera & 84,7 \\
Palmas Verão & 77,9 \\
Palmas Outono & 86,7 \\
Palmas Inverno & 84,3 \\
\hline
\end{tabular}




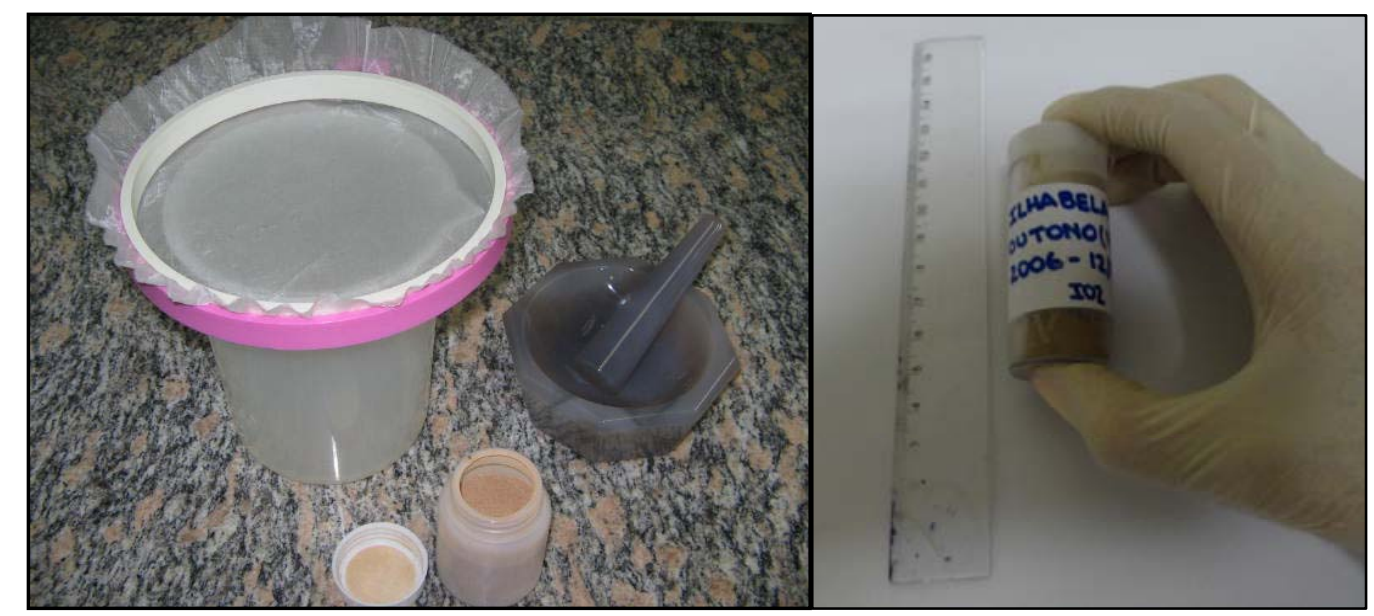

(a)

(b)

Figura 7.5 llustração do procedimento adotado: (a) amostras trituradas em almofariz de ágata e peneiradas em peneira de nylon de 100 mesh, (b) amostras na forma de pó foram armazenadas em frascos plásticos e etiquetadas.

Fonte: Autora do trabalho.

\subsection{Ensaios preliminares}

\subsubsection{Verificação da calibração do balão volumétrico}

Os balões volumétricos utilizados na diluição da solução padrão foram verificados quanto a sua calibração, bem como para avaliação da incerteza na diluição.

Para proceder à verificação da calibração, os balões e a água purificada MilliQ foram deixados na sala de pesagem em um tempo suficiente (cerca de uma hora) para que os materiais estivessem em equilíbrio térmico com o meio. A temperatura da água purificada foi medida durante a aferição para se obter o valor da densidade da água na temperatura do experimento. Para a pesagem, foi utilizada uma balança analítica da marca Shimadzu Libor, modelo AEL-40S com precisão de 0,00001g.

Pesaram-se os balões volumétricos vazios de $10 \mathrm{~mL}$ e $25 \mathrm{~mL}$ com as tampas (Figura 7.6). Mediu-se a temperatura da água e encheram-se os 
respectivos balões de água purificada até o menisco evitando que houvesse erro de paralaxe.

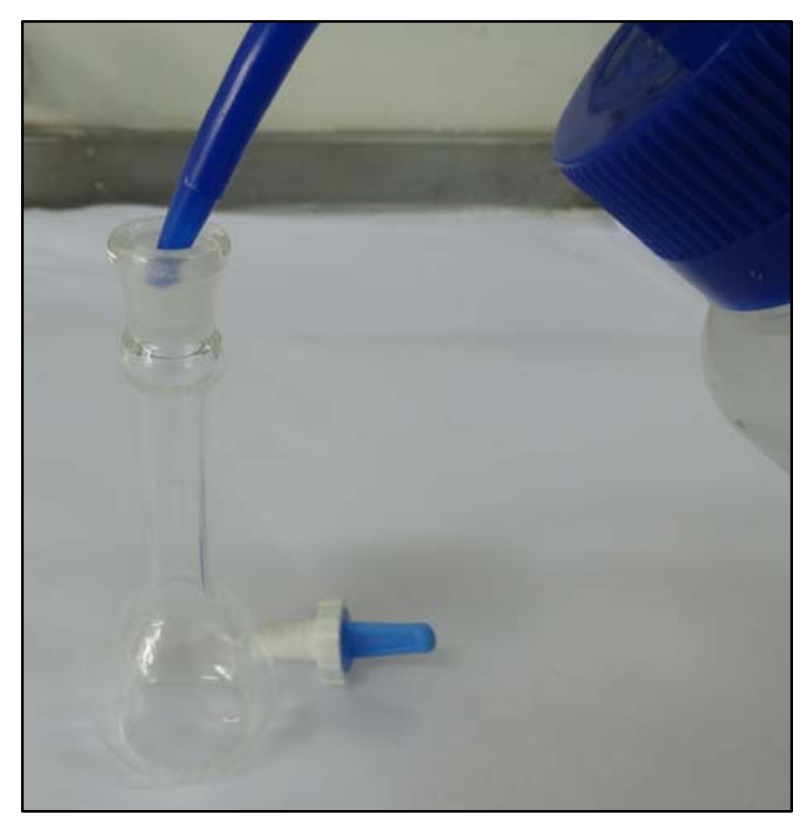

Figura 7.6 Foto apresentando a etapa da adição de água no balão volumétrico para a verificação da calibração.

Fonte: Autora do trabalho.

Depois do balão cheio com água, ele foi pesado com tampa. Por meio da diferença entre a massa do balão cheio e vazio, obteve-se a massa da água.

Obtendo-se a massa da água até o menisco, o volume correspondente foi calculado usando o fator de correção apresentado por Basset et al.(1981), que considera a densidade da água e o coeficiente de dilatação do vidro pyrex à temperatura medida.

Aos resultados obtidos na verificação da calibração dos materiais volumétricos foram determinados os parâmetros, a saber, desvio padrão individual, desvio padrão relativo e erro relativo percentual.

A repetitividade na tomada de alíquotas foi avaliada calculando-se o desvio padrão individual, aplicando-se a relação 7.1: 


$$
\mathrm{DP}=\left[\Sigma(\overline{\mathrm{X}}-\mathrm{Xi})^{2} / \mathrm{n}-1\right]^{1 / 2}
$$

Onde:

$\mathrm{DP}=$ desvio padrão;

$\bar{X}=$ média aritmética dos valores dos volumes obtidos;

$\mathrm{X} \mathrm{i}=$ são os valores dos volumes obtidos;

$\mathrm{N}$ = número de determinações.

O cálculo do desvio padrão relativo (DPR) foi efetuado aplicando a seguinte relação 7.2 :

$$
\mathrm{DPR}=100 . \mathrm{DP} / \overline{\mathrm{X}}
$$

O erro relativo percentual (ER) que nos diz sobre a exatidão da determinação foi calculado pela seguinte relação:

$$
E R=(\bar{X}-\mu) \cdot 100 / \mu
$$

Onde:

$\bar{X}=$ média aritmética dos valores dos volumes obtidos;

$\mu=$ valor real ou nominal da grandeza.

\subsubsection{Verificação da calibração do pipetador automático}

O pipetador automático também foi verificado quanto à sua calibração e também para avaliar a incerteza na diluição da solução padrão.

O procedimento para a verificação da calibração do pipetador consistiu em realizar medições para cada volume pré-estabelecido de água purificada pipetada em um pesa-filtro utilizando uma balança analítica da marca Shimadzu Libror, modelo $A E L-40 S M$ com precisão de 0,0001 g. Foram realizadas verificações para capacidades de $50 \mu \mathrm{L}, 75 \mu \mathrm{L}$ e $500 \mu \mathrm{L}$, conforme a indicação 
dos fabricantes contida na embalagem do pipetador. Na verificação dos materiais volumétricos, os materiais utilizados nesta calibração e a água purificada foram mantidos na sala de balanças para o estabelecimento do seu equilíbrio térmico. A temperatura da água foi também medida, e foi utilizada na obtenção do valor da densidade da água, para cálculo do volume.

Durante a tomada de alíquotas procurou-se evitar a formação de bolhas na água pipetada bem como a tomada das alíquotas foi realizada com o pipetador mantido na posição vertical. Tendo a massa do pesa-filtro vazio e o com água purificada pipetada, pela diferença calculou-se a massa da água pipetada.

Tendo o valor da densidade da água à temperatura da água medida, calculou-se o volume da água, utilizando-se a relação 7.4 :

$$
d=m / V
$$

Onde:

$\mathrm{d}$ = densidade da água na temperatura da água utilizada na calibração;

$\mathrm{m}$ = massa da água purificada MilliQ;

$\mathrm{V}=$ volume da água purificada MilliQ.

\subsection{Procedimento para as análises}

\subsubsection{Preparação de padrões sintéticos dos elementos a serem analisados}

Para a preparação dos padrões sintéticos dos elementos foram utilizadas soluções padrão de elementos certificados adquiridas da Spex CertiPrep USA, pipetador automático da marca Eppendorf e balões volumétricos previamente verificados quanto a sua calibração. A partir dessas soluções padrão estoque, foram preparadas soluções mais diluídas contendo um elemento, as quais após a sua preparação foram conservadas à temperatura de aproximadamente $14{ }^{\circ} \mathrm{C}$ e em recipiente de polietileno da marca Nalgene, com suas tampas vedadas com parafilme. Para o uso dessas soluções, mantidas no 
refrigerador, elas foram retiradas deste e mantidas à temperatura ambiente para que ocorresse o equilíbrio térmico antes do uso. A preparação dos padrões sintéticos de elementos consistiu em pipetar $30 \mu \mathrm{L}$ da solução padrão obtida codificada de "VA", 50 LL das soluções padrão codificadas de "Br9", "Mn9" e 100 $\mu \mathrm{L}$ das soluções padrão codificadas de "Mg9", "Cl9", "K9" sobre tiras de papel de filtro Whatman $n^{\circ} 40$. A massa do elemento presente em cada solução padrão está apresentada na Tabela 7.4.

Tabela 7.4 Massas dos elementos presentes nos padrões sintéticos de elementos.

\begin{tabular}{|c|c|c|c|c|c|}
\hline $\begin{array}{l}\text { Código da } \\
\text { solução padrão }\end{array}$ & $\begin{array}{l}\text { Elemento } \\
\text { químico }\end{array}$ & $\begin{array}{l}\text { Concentração } \\
\qquad\left(\mu g \mathrm{~mL}^{-1}\right)\end{array}$ & $\begin{array}{l}\text { Massa em } \\
30 \mu \mathrm{L}(\mu \mathrm{g})\end{array}$ & $\begin{array}{l}\text { Massa em } \\
50 \mu \mathrm{L}(\mu \mathrm{g})\end{array}$ & $\begin{array}{c}\text { Massa em } \\
100 \mu \mathrm{L} \\
(\mu \mathrm{g})\end{array}$ \\
\hline Br9 & $\mathrm{Br}$ & 99,70 & & 4,985 & \\
\hline $\mathrm{Cl} 9$ & $\mathrm{Cl}$ & 10000,0 & & & 1000,0 \\
\hline K9 & K & 10010,0 & & & 1001,0 \\
\hline Mg9 & $\mathrm{Mg}$ & 9979,0 & & & 997,9 \\
\hline Mn9 & $\mathrm{Mn}$ & 79,84 & & 3,992 & \\
\hline VA & V & 1002,0 & 30,06 & & \\
\hline
\end{tabular}

As tiras de papel filtro contendo alíquotas das soluções pipetadas foram colocadas no dessecador, por aproximadamente $24 \mathrm{~h}$, para a secagem à temperatura ambiente. O papel de filtro Whatman foi cortado conforme apresentado na Figura 7.7.

Posteriormente estas tiras foram dobradas e colocadas em invólucros de polietileno, os quais foram selados com ferro elétrico para solda. Os plásticos para a preparação dos invólucros foram previamente lavados com solução de ácido nítrico p. a. diluída e água purificada, seguida de secagem à temperatura ambiente, tomando-se o cuidado para que não ocorresse contaminação. 

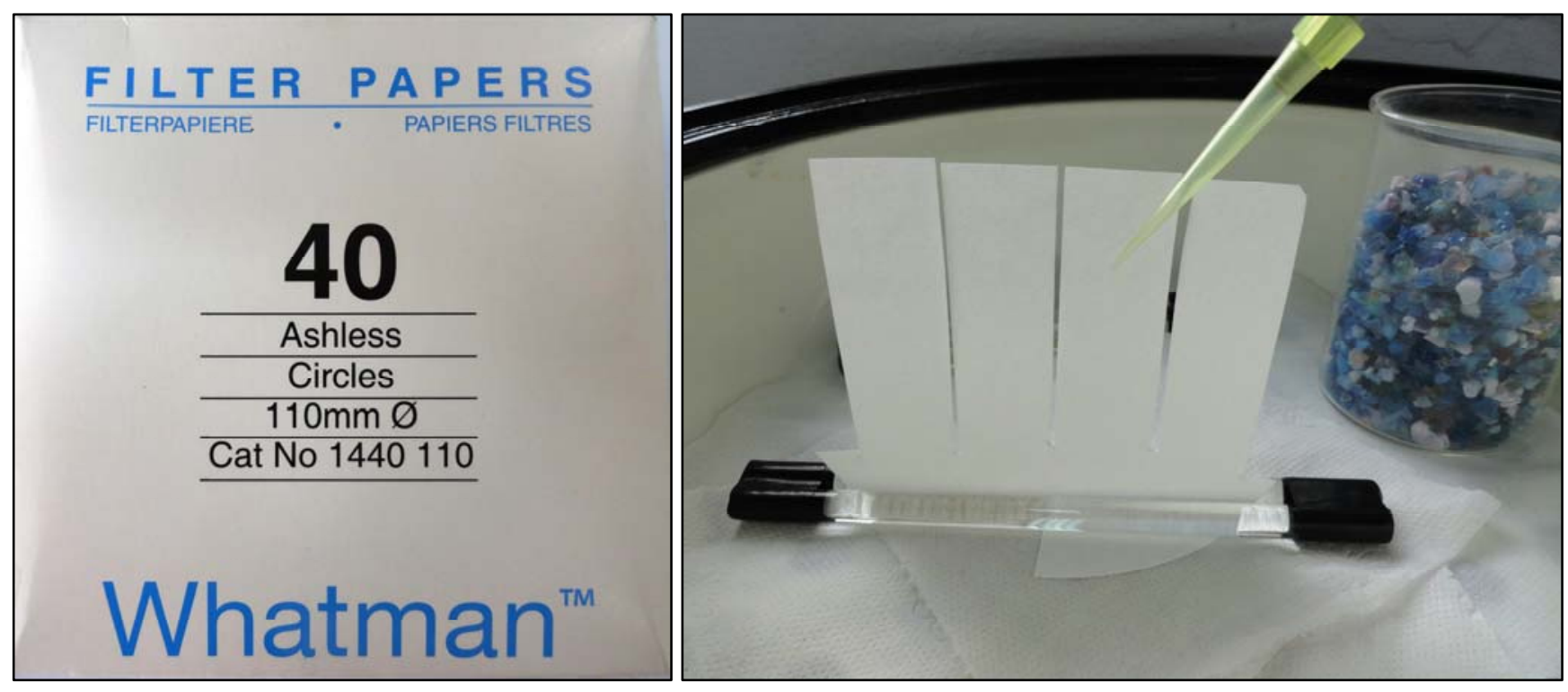

Figura 7.7 Foto da pipetagem de solução padrão em tiras de papel filtro Whatman $\mathrm{n}^{\circ} 40$.

Fonte: Autora do trabalho.

\subsubsection{Análise dos materiais de referência certificados}

Os materiais de referência (MR) são substâncias que têm um ou mais valores de propriedade que são suficientemente homogêneos e bem estabelecidos para serem usados na calibração de um aparelho, de um método de medição ou na atribuição de valores ao material. Quando os valores de propriedade são certificados por um processo bem estabelecido com rastreabilidade à obtenção exata da unidade na qual os valores de propriedade são expressos, o MR passa a ser denominado material de referência certificado (MRC). O valor de propriedade deve ser acompanhado por uma incerteza para um nível de confiança estabelecido. No caso de MRC de composição química, o valor de propriedade certificado é a concentração dos diversos elementos no material (ABNT, 2000).

Devido à alta confiabilidade dos valores certificados, os materiais de referência certificados apresentam uma grande aplicabilidade. Mesmo as técnicas instrumentais mais sofisticadas utilizadas na atual química analítica, notoriamente 
reconhecida por produzir resultados de medição com altíssima precisão ou repetitividade, necessitam de materiais de referência certificados para a obtenção de resultados de medição exatos (OLIVEIRA JUNIOR, 2008).

A finalidade do uso de materiais de referência refere-se à calibração dos instrumentos analíticos, e os materiais de referência certificados podem ser utilizados no desenvolvimento e validação da metodologia.

A análise do material de referência certificado assegura a confiabilidade dos resultados obtidos nas determinações com relação à exatidão e precisão da técnica analítica empregada.

Os materiais de referência certificados analisados no presente trabalho foram: NIST SRM 1566b Oyster Tissue e NIST SRM 2976 Mussel Tissue (NIST, 2001; NIST, 1998), procedentes do National Institute of Standards and Technology, USA. Esses materiais foram guardados em recipientes de polietileno com a tampa vedada com parafilme, dentro de um dessecador à temperatura ambiente, de cerca de $25^{\circ} \mathrm{C}$.

7.4.3 Determinação da percentagem da perda de umidade nas amostras e em materiais de referência certificados

Para expressar os resultados das análises na base seca foi feita a determinação de perda de umidade nas amostras de mexilhão e nos materiais de referência certificados, secando cerca de $200 \mathrm{mg}$ de cada uma das amostras, pesadas em pesafiltros, em estufa da marca Fabber Primar a $85^{\circ} \mathrm{C}$ por $24 \mathrm{~h}$. As amostras de mexilhões e os materiais de referência antes e após a secagem foram pesados em uma balança analítica da marca Shimadzu à temperatura ambiente.

As porcentagens de perda de massa na secagem das amostras de mexilhão e dos materiais de referência foram calculadas por meio da seguinte relação dada por: 


$$
P=\frac{m i-m f}{m i} \cdot 100
$$

Onde:

$P$ é a porcentagem de perda de massa;

mi é a massa inicial da amostra antes da secagem;

$m f$ é a massa final da amostra após a secagem.

Os valores de $\mathrm{P}$ encontrados foram usados para expressar as concentrações dos elementos $\mathrm{Br}, \mathrm{Cl}, \mathrm{K}, \mathrm{Mg}, \mathrm{Mn}$ e $\mathrm{V}$ destes materiais na sua base seca. Esses valores estão apresentados na Tabela 7.5.

Tabela 7.5 Porcentagens da perda de umidade $(P)$ nas secagens dos materiais de referência certificados e das amostras de mexilhões.

\begin{tabular}{cc}
\hline Amostras e Materiais de Referência & P (\%) \\
Certificados & 3,9 \\
NIST SRM 1566b Oyster Tissue & 3,7 \\
NIST SRM 2976 Mussel Tissue & 7,2 \\
Cocanha Primavera & 7,9 \\
Cocanha Verão & 4,4 \\
Cocanha Outono & 10,4 \\
Cocanha Inverno & 7,1 \\
Itaipu Primavera & 5,8 \\
Itaipu Verão & 5,7 \\
Itaipu Outono & 9,1 \\
Itaipu Inverno & 6,1 \\
Palmas Primavera & 5,6 \\
Palmas Verão & 6,7 \\
Palmas Outono & 10,5 \\
Palmas Inverno & \\
\hline
\end{tabular}


7.4.4 Procedimento de análise por ativação com nêutrons instrumental

O procedimento experimental para determinação dos elementos $\mathrm{Br}, \mathrm{Cl}$, $\mathrm{K}, \mathrm{Mg}, \mathrm{Mn}$ e $\mathrm{V}$ consistiu em irradiar cerca de $180 \mathrm{mg}$ de cada amostra de mexilhão Perna perna ou do material de referência certificado juntamente com os padrões sintéticos de elementos no reator IEA-R1 do IPEN-CNEN/SP.

Para irradiação curta no reator, cada uma das amostras de mexilhão ou do material de referência e os padrões sintéticos de elementos embalados em invólucros de polietileno foram colocados juntos em um novo invólucro de polietileno, o qual foi inserido em um dispositivo de polietileno, conhecido como "coelho" (Figura 7.8).

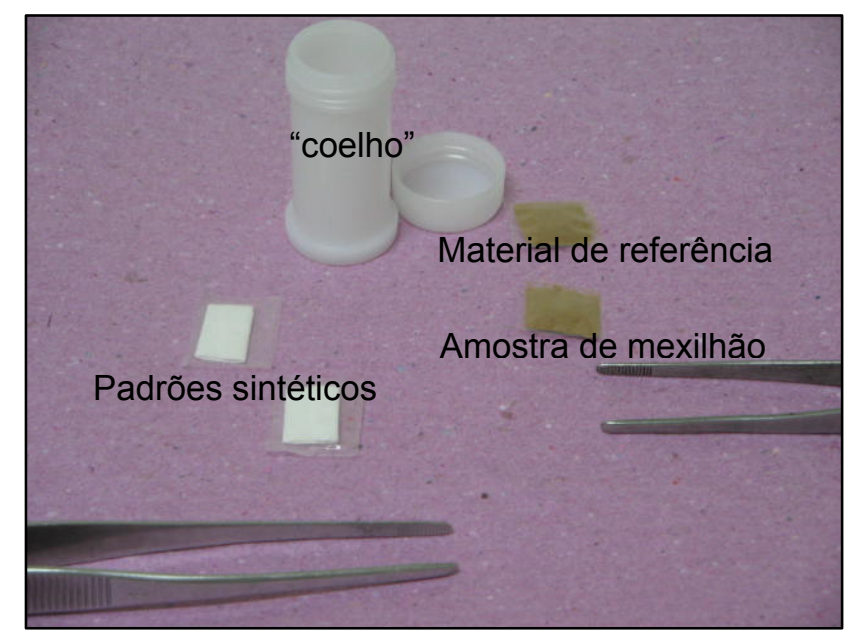

Figura 7.8 llustração do "coelho", da amostra de mexilhão, do material de referência e do padrão sintético em invólucros de polietileno para irradiação curta.

Fonte: Autora do trabalho.

Este conjunto foi submetido a uma irradiação curta na Estação Pneumática $\mathrm{n}^{\circ} 4$ do reator de pesquisa IEA-R1 do IPEN-CNEN/SP sob um fluxo de nêutrons térmicos de cerca de $6,6 \times 10^{12} \mathrm{n} \mathrm{cm}^{-2} \mathrm{~s}^{-1}$ por um período de $8 \mathrm{a} 10 \mathrm{~s}$.

A Figura $7.10(a, b)$ mostra o painel de controle para envio das amostras a serem irradiadas no reator IEA-R1 do IPEN-CNEN/SP e a cabine de envio e recebimento da amostra na Estação Pneumática $n^{\circ} 4$, respectivamente. 
Na Figura 7.9 está apresentado o esquema da sequência para o preparo das amostras para irradiação.

Para as medições, a amostra e os padrões sintéticos irradiados foram montados individualmente em suportes de aço inoxidável (conhecidos por "panelinhas"), utilizando fita adesiva.

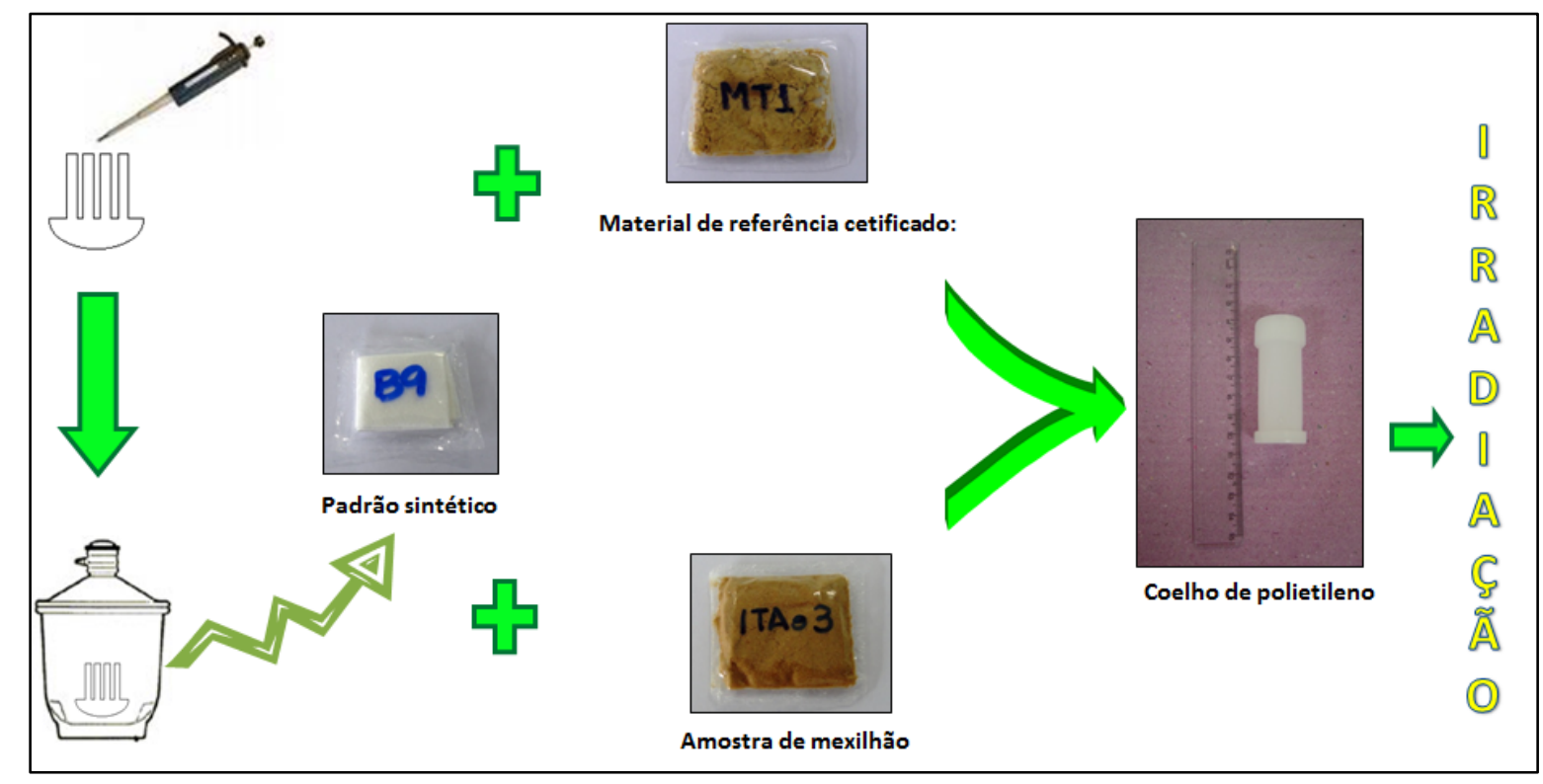

Figura 7.9 Esquema de preparo das amostras para irradiação.

Fonte: Autora do trabalho.

Após cerca de 3 a 5 min de decaimento, as medições das atividades gama das amostras e padrão foram feitas utilizando um detector semi condutor de Ge hiperpuro modelo GC2018 da marca Canberra ligado ao analisador de espectro digital DAS-1000 também da Canberra e sistema eletrônico associado (Figura 7.11). A resolução (FWHM) do sistema utilizado foi de $1,01 \mathrm{keV}$ para 0 pico de $121,49 \mathrm{keV}$ do ${ }^{57} \mathrm{Co}$ e de $1,75 \mathrm{keV}$ para o pico $1332,97 \mathrm{keV}$ do ${ }^{60} \mathrm{Co}$.

Foram realizadas duas medições da amostra e padrões para diferentes tempos de decaimento. O tempo de contagem da amostra e do padrão na $1^{a}$ medição foi de $300 \mathrm{~s}$. Usando um cronômetro foram também registrados os tempos iniciais de medição da amostra e dos padrões para posterior cálculo de tempos de decaimento. Para a aquisição dos dados espectrais utilizou-se o programa Genie 2000 versão 3.1 da Canberra. A $2^{\mathrm{a}}$ medição foi feita por cerca de 
90 min de decaimento e o tempo de contagem utilizado foi de $600 \mathrm{~s}$ tanto para amostra como para os padrões.

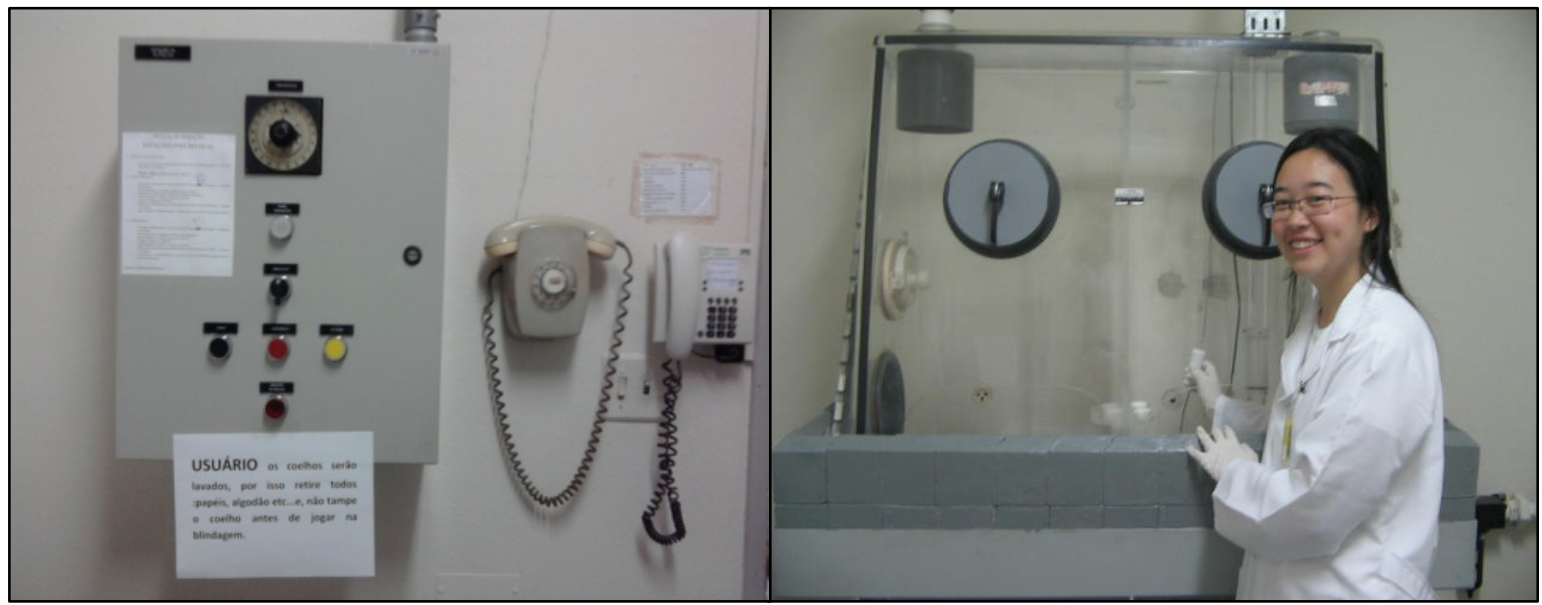

(a)

(b)

Figura 7.10 (a) Foto do painel de controle para envio das amostras a serem irradiadas no reator IEA-R1 do IPEN-CNEN/SP. (b) Foto da cabine para envio e recebimento de amostra na Estação Pneumática $n^{\circ} 4$.

Fonte: Autora do trabalho.

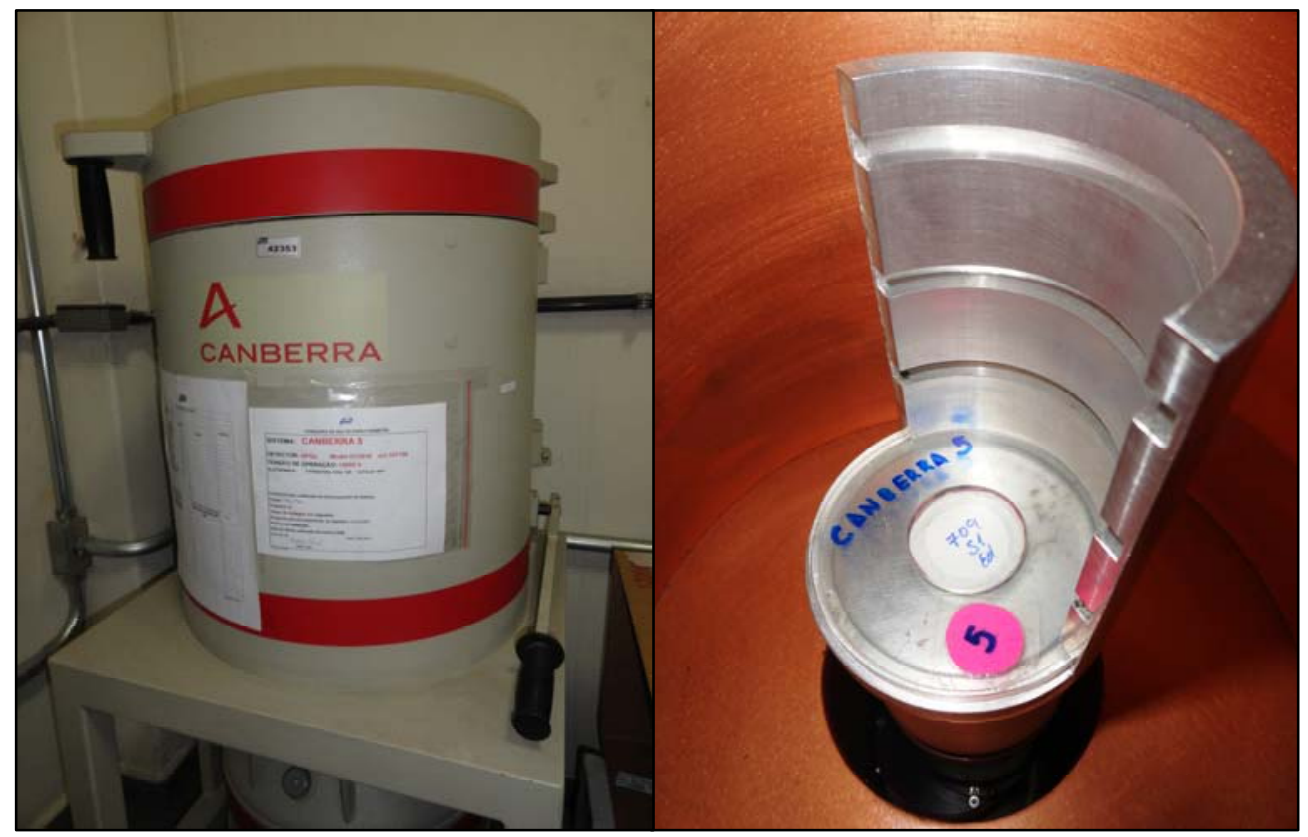

Figura 7.11 Foto da blindagem de detector de Ge hiperpuro e da amostra sobre o detector.

Fonte: Autora do trabalho. 
Posteriormente, a análise dos espectros gama foi feita usando um programa de computação Gamma Acquisition Analysis da Canberra, onde foram obtidos as taxas de contagens e o valor da energia dos raios gama dos radioisótopos formados. Por meio das energias dos raios gama e tempos de meias-vida foi feita a identificação de cada radioisótopo formado. Os radioisótopos medidos com suas respectivas energias de raios gama e tempos de meia-vida podem ser verificados na Tabela 7.6.

Conhecendo - se a meia - vida do radioisótopo, tempos de decaimento, taxas de contagens e massa total da amostra e do elemento presente no padrão, foram calculadas as concentrações de cada elemento presente na amostra pelo método comparativo, aplicando - se a seguinte relação (De SOETE et al., 1972):

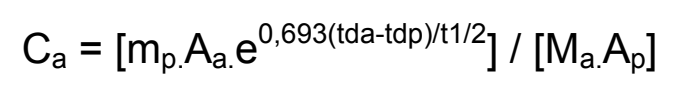

Onde:

Os índices a e p indicam amostra e padrão respectivamente;

A é a taxa de contagem do radioisótopo considerado;

$M_{\mathrm{a}}$ é a massa total da amostra;

$\mathrm{t}_{1 / 2}$ é a meia-vida do radioisótopo;

$m_{p}$ é a massa do elemento no padrão;

$\mathrm{C}_{\mathrm{a}}$ é a concentração do elemento na amostra;

tda e tdp são os tempos de decaimento da amostra e padrão, respectivamente. Os tempos de decaimento foram calculados considerando $o$ decaimento durante o tempo de medição.

A Figura 7.12 (a, b) ilustra o "coelho" contendo amostra a ser submetido à irradiação e a montagem das amostras irradiadas nas "panelinhas", respectivamente. 
Tabela 7.6 Dados relativos à identificação de cada radioisótopo formado.

\begin{tabular}{cccc}
\hline Elementos & Radioisótopos & $\begin{array}{c}\text { Energias de raios gama } \\
\mathbf{( k e V )}\end{array}$ & $\begin{array}{c}\text { Tempos de meia-vida } \\
\text { (min ou hora) }\end{array}$ \\
\hline $\mathrm{Br}$ & ${ }^{80} \mathrm{Br}$ & 616,30 & $17,68 \mathrm{~min}$ \\
$\mathrm{Cl}$ & ${ }^{38} \mathrm{Cl}$ & 1642,7 & $37,24 \mathrm{~min}$ \\
$\mathrm{~K}$ & ${ }^{42} \mathrm{~K}$ & 1524,6 & $12,36 \mathrm{~h}$ \\
$\mathrm{Mg}$ & ${ }^{27} \mathrm{Mg}$ & 843,$8 ; 1014,4$ & $9,46 \mathrm{~min}$ \\
$\mathrm{Mn}$ & ${ }^{6} \mathrm{Mn}$ & 846,$8 ; 1810,7$ & $2,58 \mathrm{~h}$ \\
$\mathrm{~V}$ & ${ }^{52} \mathrm{~V}$ & 1434,08 & $3,75 \mathrm{~min}$ \\
\hline
\end{tabular}

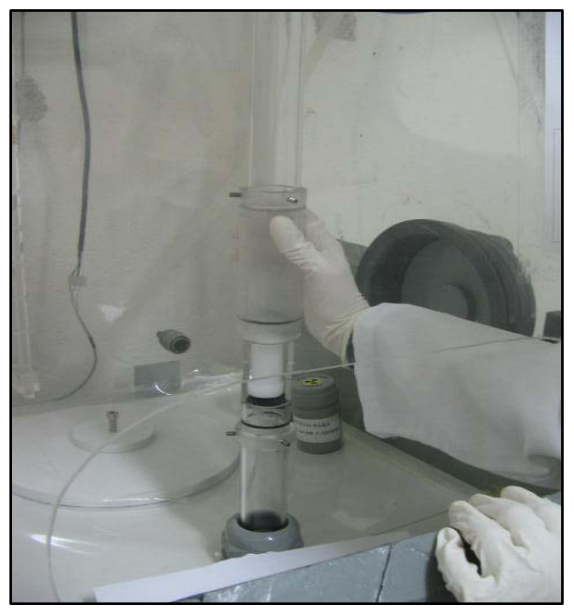

(a)

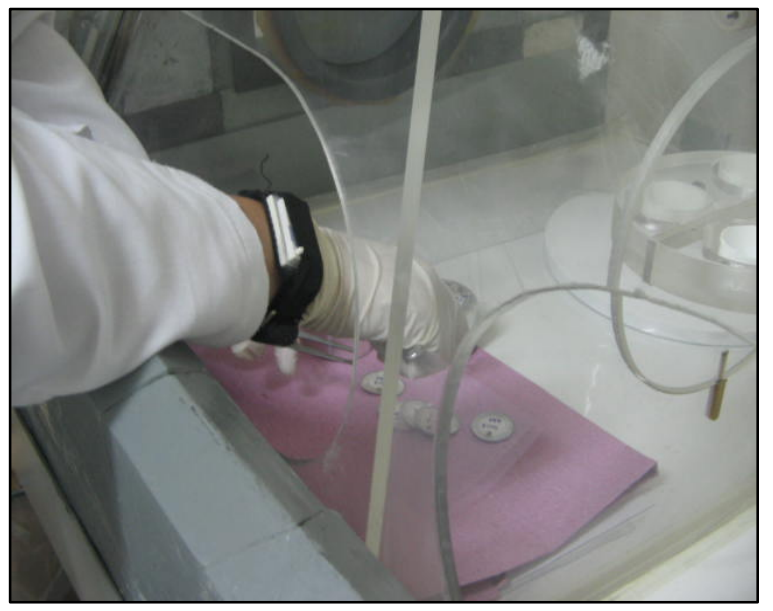

(b)

Figura 7.12 (a) Foto do envio do "coelho" para irradiação, (b) montagem das amostras irradiadas nos suportes.

Fonte: Autora do trabalho.

\subsection{Análise estatística}

As variações das concentrações dos elementos obtidos entre os pontos de coleta e estações do ano foram avaliados por meio da análise de variância (ANOVA) e teste de Tukey $(p<0,05)$, utilizando o software Origin, versão 7.5 (VIEIRA, 1999). 


\section{RESULTADOS E DISCUSSÃO}

\subsection{Ensaios preliminares}

8.1.1 Verificação da calibração do balão volumétrico e do pipetador automático

Os resultados obtidos da calibração do balão volumétrico e do pipetador automático são apresentados nas Tabelas 8.1 e 8.2, respectivamente.

Tabela 8.1 Resultados obtidos das verificações da calibração dos balões volumétricos.

\begin{tabular}{lcccc}
\hline Balão volumétrico & $\begin{array}{c}\text { Capacidade* } \\
(\mathbf{m L})\end{array}$ & $\begin{array}{c}\text { Média } \pm \text { DP }(\mathbf{n}) \\
(\mathbf{m L})\end{array}$ & DPR (\%) & ER (\%) \\
\hline 1 & $10,000 \pm 0,025$ & $9,87 \pm 0,04(\mathrm{n}=9)$ & 0,4 & 1,3 \\
2 & $25,00 \pm 0,03$ & $24,7 \pm 0,1(\mathrm{n}=9)$ & 0,4 & 1,2 \\
\hline$\left(^{*}\right)=$ Descrição da capacidade apresentada na vidraria; & \\
$(\mathrm{n})=$ número de determinações; \\
$(\mathrm{DPR})=$ desvio padrão relativo; \\
$(\mathrm{ER})=$ erro relativo percentual.
\end{tabular}

Os resultados obtidos da verificação dos balões volumétricos de 10 e $25 \mathrm{~mL}$ indicaram uma boa precisão com desvios padrão relativos inferiores a $0,4 \% \mathrm{e}$ erros relativos menores que $1,3 \%$. É possível observar na Tabela 8.1 , que comparando os valores da verificação obtida com as capacidades apresentadas nas vidrarias, os dois balões apresentam variações dentro do limite tolerado. 
Tabela 8.2 Resultados das médias de volumes obtidos na verificação da calibração do pipetador automático.

\begin{tabular}{cccc}
\hline $\begin{array}{c}\text { Capacidade } \\
(\mathbf{m L})\end{array}$ & $\begin{array}{c}\text { Média } \pm \text { DP }(\mathbf{n}) \\
(\mathbf{m L})\end{array}$ & DPR (\%) & ER (\%) \\
\hline $50,00 \pm 0,15$ & $50,05 \pm 0,25(\mathrm{n}=30)$ & 0,5 & 0,1 \\
$75,0 \pm 0,2$ & $75,2 \pm 0,8(\mathrm{n}=30)$ & 1,1 & 0,3 \\
$500 \pm 0,003$ & $499,1 \pm 2,2(\mathrm{n}=30)$ & 0,4 & 0,2 \\
\hline$\left.{ }^{*}\right)=$ Descrição da capacidade apresentada na pipetador; & \\
$(\mathrm{n})=$ número de determinações; & \\
(DPR) = desvio padrão relativo; & \\
(ER) = erro relativo percentual.
\end{tabular}

Com relação à verificação do pipetador automático, para os volumes de 50,75 e $500 \mu \mathrm{L}$, foram obtidos desvios padrão relativos e percentagens de erros relativos inferiores $1,1 \%$ e $0,4 \%$, respectivamente. A comparação entre o resultado obtido para a capacidade de $50 \mu \mathrm{L}$, com o valor apresentado no catálogo do pipetador, mostrou que o resultado médio do volume calibrado está dentro da faixa de variação. Os valores apresentados pelo catálogo do pipetador são de $1 \%$ para a percentagem de erro sistemático e de $\leq 0,3 \%$ para erro aleatório (coeficiente de variação). Os resultados obtidos para a capacidade de $500 \mu \mathrm{L}$, comparado ao valor apresentado no catálogo do pipetador, também estiveram dentro da faixa de variação de $1 \%$ para percentagem de erro sistemático e de $\leq 0,2 \%$ para o erro aleatório. $O$ certificado do pipetador não possui um valor de imprecisão para o volume de $75 \mu \mathrm{L}$, entretanto apresenta um valor para o intervalo da pipetagem de 50 a $100 \mu \mathrm{L}$, com valor de $0,8 \%$ para a percentagem de erro sistemático e de $\leq 0,2 \%$ para o erro aleatório.

\subsection{Análise dos materiais de referência certificados}

Nas Tabelas 8.3 e 8.4 são apresentados os resultados das concentrações dos elementos $\mathrm{Br}, \mathrm{Cl}, \mathrm{Mg}, \mathrm{Mn}, \mathrm{K}$ e $\mathrm{V}$ obtidos nas análises dos materiais de referência certificados NIST SRM 1566b Oyster Tissue e NIST SRM 
2976 Mussel Tissue respectivamente, juntamente com os valores dos certificados (NIST, 2001; NIST, 1998).

Os resultados de concentração obtidos também foram submetidos a um controle estatístico calculando os valores de z-score ou de diferença padronizada (THOMPSON, 2000). No caso do material de referência NIST SRM 2876 Mussel Tissue foram calculados o erro relativo (ER) e índice z-score a partir de valores de referência e não valores certificados.

Tabela 8.3 Concentrações de elementos, em $\mathrm{mg} \mathrm{kg}^{-1}$, no material de referência certificado NIST SRM 1566b Oyster Tissue.

\begin{tabular}{|c|c|c|c|c|c|}
\hline Elementos & Média $\pm D P^{a}\left(n^{b}\right)$ & $\mathrm{DPR}^{\mathrm{c}}, \%$ & $E r^{d}, \%$ & z-score & $\begin{array}{l}\text { Valores do } \\
\text { certificado }\end{array}$ \\
\hline $\mathrm{Cl}$ & $5094 \pm 65(5)$ & 1,28 & 0,89 & $-0,20$ & $5140 \pm 100$ \\
\hline $\mathrm{K}$ & $6451 \pm 531(7)$ & 8,23 & 1,06 & $-0,25$ & $6520 \pm 90$ \\
\hline $\mathrm{Mg}$ & $1101 \pm 64(13)$ & 5,81 & 1,47 & 0,26 & $1085 \pm 23$ \\
\hline $\mathrm{Mn}$ & $18,1 \pm 0,8(12)$ & 4,42 & 2,16 & $-0,21$ & $18,5 \pm 0,2$ \\
\hline V & $0,567 \pm 0,032(20)$ & 5,64 & 1,73 & $-0,10$ & $0,577 \pm 0,023$ \\
\hline
\end{tabular}

Tabela 8.4 Concentrações de elementos, em mg kg ${ }^{-1}$, no material de referência certificado NIST SRM 2976 Mussel Tissue.

\begin{tabular}{|c|c|c|c|c|c|}
\hline Elementos & Média $\pm D P^{a}\left(n^{b}\right)$ & $\mathrm{DPR}^{\mathrm{c}}, \%$ & $E R^{d}, \%$ & z-score & $\begin{array}{l}\text { Valores de } \\
\text { referência }\end{array}$ \\
\hline $\mathrm{Br}$ & $338 \pm 23(10)$ & 6,80 & 2,74 & 0,40 & $329 \pm 15$ \\
\hline $\mathrm{Cl}$ & $57888 \pm 2664(9)$ & 4,60 & 1,56 & 0,50 & $57000 \pm 5000$ \\
\hline $\mathrm{K}$ & $9617 \pm 375(6)$ & 3,90 & 0,86 & $-0,21$ & $9700 \pm 1000$ \\
\hline $\mathrm{Mg}$ & $5078 \pm 250(12)$ & 4,92 & 4,19 & $-0,99$ & $5300 \pm 500$ \\
\hline $\mathrm{Mn}$ & $34 \pm 1(10)$ & 2,94 & 3,03 & 0,31 & $33 \pm 2$ \\
\hline
\end{tabular}


A comparação da média dos resultados das concentrações dos elementos obtidos com os valores dos certificados indica uma boa concordância, demonstrando que o procedimento de análise por ativação com nêutrons aplicado é adequado para determinação dos elementos. Foi obtida a porcentagem de erro relativo inferior a $4,2 \%$. Com relação à precisão, os resultados obtidos apresentaram uma boa reprodutibilidade com desvios-padrão relativos inferiores a $8,2 \%$.

Os resultados das concentrações de elementos obtidos foram também submetidos a um controle estatístico calculando os valores de z-score ou de diferença padronizada (THOMPSOM, 2000). O valor obtido da diferença padronizada ou $\mid z$-score $\mid<1$ indica que o resultado obtido está dentro da faixa do valor do certificado em um nível de confiança de $68 \%$.

\subsection{Análise das amostras de mexilhões Perna perna}

Nas Tabelas 8.5 a 8.10 são apresentados os resultados obtidos das concentrações dos elementos $\mathrm{Br}, \mathrm{Cl}, \mathrm{K}, \mathrm{Mg}, \mathrm{Mn}$ e $\mathrm{V}$ nas amostras de mexilhões Perna perna coletados em Santos (Ponta de Itaipu e llha das Palmas) e também os da região de referência (Praia da Cocanha), que foram amostrados em diferentes períodos. Podem-se observar nas Figuras 8.1 e 8.2 as médias das concentrações dos elementos obtidos nos mexilhões coletados nos três pontos de estudo para as quatro estações do ano, juntamente com as análises de variação espacial e sazonal.

\section{- Bromo}

Conforme mostra a Tabela 8.5, as concentrações de $\mathrm{Br}$ nos mexilhões variaram na faixa de 173,80 a $358,99 \mathrm{mg} \mathrm{kg}^{-1}$ (na base seca). Os resultados indicam que os mexilhões coletados em llha das Palmas na estação inverno apresentaram maior acúmulo deste elemento que nos demais pontos de coleta. 
Comparando os valores obtidos nos sítios possivelmente impactados (Ponta de Itaipu e llha das Palmas) com o valor do sítio controle situado na Praia da Cocanha em Caraguatatuba, pode-se observar na Figura 8.1, que os mexilhões coletados durante a estação verão apresentam diferenças significativas em relação ao ponto de referência (Cocanha) com aqueles coletados em Palmas. Para a estação inverno, pode-se verificar uma diferença significativa nos teores de Br para o sítio controle e os pontos de Itaipu e Palmas.

Quanto à análise sazonal (Figura 8.2), os resultados das análises dos mexilhões coletados em Ponta de Itaipu durante as estações outono e inverno apresentaram um aumento significativo em relação às outras estações do ano. No ponto de estudo llha das Palmas, pode-se verificar uma diferença significativa na concentração de $\mathrm{Br}$ durante as estações verão e outono. Já para Praia da Cocanha, não houve diferença significativa entre as estações do ano.

Os bromofenóis presentes em organismos marinhos, como os moluscos, estão fortemente associados ao "flavor" agradável (marinado) ou desagradável (iodofórmico) dependendo da concentração, pois interferem diretamente nas características sensoriais dos alimentos. Em altas concentrações ocasionam um aroma desagradável e são associados à má qualidade do alimento. Entretanto, quando presentes em baixas concentrações estes compostos orgânicos de bromo agregam valor ao alimento devido à melhora do aroma e sabor característico das espécies marinhas. Verificou-se que os teores de $\mathrm{Br}$ presentes nos tecidos dos mexilhões analisados no presente estudo $\left(173,80\right.$ a $358,99 \mathrm{mg} \mathrm{kg}^{-1}$, na base seca) foram muito superiores aos de bromofenóis normalmente encontrados em moluscos (10,3 a 246,0 $\mathrm{ng} \mathrm{g}^{-1}$, no peso seco), e também em amostras de ostras (13,6 a 75,8 $\mathrm{ng} \mathrm{g}^{-1}$, no peso seco), o que pode indicar que o $\mathrm{Br}$ estaria presente também em outras formas químicas, como por exemplo íons brometos (CHUNG et al., 2003).

Segundo mostra a Tabela 8.11, comparando esses resultados com aqueles obtidos em um estudo anterior que fez uso da biomonitoração ativa com mexilhões Perna perna (SEO et al., 2007), pode-se verificar que as concentrações 
de $\mathrm{Br}$ apresentaram a mesma ordem de grandeza (219 a $418 \mathrm{mg} \mathrm{kg}^{-1}$, na base seca).

\section{- Cloro}

Os resultados obtidos na Tabela 8.6 para o elemento $\mathrm{Cl}(4,6$ a $10,9 \%$, na base seca) mostram que os mexilhões amostrados na llha das Palmas durante a estação primavera apresentaram altas concentrações quando comparadas às obtidas para os demais pontos. Em contrapartida, é possível observar que as concentrações deste elemento foram inferiores nas amostras coletadas para este mesmo local durante a estação verão. Tal fato possivelmente pode ter ocorrido devido à variação de salinidade da água com a estação do ano, uma vez que sabe-se que o fator salinidade pode variar conforme a topografia do rio/mar, estação do ano e fluxo da quantidade de água (RECHI, 2012).

Conforme mostra a Figura 8.1, os resultados obtidos nos mexilhões na estação primavera apresentaram diferenças significativas em relação ao ponto de referência (Cocanha) com aqueles coletados na llha das Palmas. Para estação verão, pode-se notar diferenças significativas na concentração de $\mathrm{Cl}$ nos moluscos bivalves coletados nos pontos de Ponta de Itaipu e Ilha das Palmas. Por fim, para a estação outono, os resultados obtidos para os mexilhões apresentaram diferenças significativas para o ponto localizado na llha das Palmas.

Na análise sazonal (Figura 8.2), os resultados dos mexilhões coletados em Ponta de Itaipu e Ilha das Palmas durante a estação inverno apresentaram um aumento significativo em relação às demais estações do ano. Em contrapartida, para estes mesmos locais de estudo, durante a estação verão houveram um decréscimo significativo comparado às outras estações do ano.

Na Tabela 8.11 é possível notar a comparação dos resultados obtidos para $\mathrm{Cl}$ em mexilhões no presente trabalho com outros valores da literatura. A partir desses resultados, verificou-se que as concentrações de $\mathrm{Cl}$ 
presentes nos tecidos dos mexilhões analisados neste trabalho (4,6 a 10,9\%, na base seca) foram da mesma ordem de grandeza (5,7 a 11,5\%, na base seca) comparadas as encontradas em mexilhões Perna perna transplantados de uma região de referência (Praia da Cocanha) para locais supostamente contaminados (Ilhabela, São Sebastião, Ponta de Itaipu e llha das Palmas), conforme Seo et al. (2007).

\section{- Potássio}

Os resultados das concentrações de $\mathrm{K}$ das análises dos mexilhões obtidos na base seca para diferentes períodos de coleta são apresentados na Tabela 8.7. Os valores de K observados variaram de $7043 \pm 856$ a $12506 \pm 675$ $\mathrm{mg} \mathrm{kg}^{-1}$. Nota-se que houve maior acúmulo deste elemento nos organismos coletados na Praia da Cocanha durante a estação primavera do que nos demais pontos de coleta.

Com base na Figura 8.1, é possível verificar que as concentrações de $\mathrm{K}$ obtidas nas amostras de mexilhões coletados na estação primavera apresentaram diferenças significativas em relação ao ponto de referência (Cocanha) para aqueles coletados nos demais pontos situados em Ponta de Itaipu e llha das Palmas. Para a estação outono, pode-se observar uma diferença significativa na concentração deste elemento para o ponto de Ponta de Itaipu. Já para a estação inverno, nota-se diferença significativa para todos os pontos de coleta (Ponta de Itaipu e llha das Palmas).

Quanto à análise sazonal (Figura 8.2), os resultados dos mexilhões coletados em Ponta de Itaipu durante as estações verão, outono e inverno apresentaram um aumento significativo em relação à estação primavera. Já em Ilha das Palmas foi observada diferença significativa para os períodos verão e outono.

Comparando esses resultados $(0,70$ a $1,25 \%$, na base seca) com aqueles obtidos em um estudo anterior (SEO et al., 2007), pode-se verificar que 
as concentrações de $\mathrm{K}$ apresentaram a mesma ordem de grandeza $(0,78$ a $1,35 \%$, na base seca), conforme mostra a Tabela 8.11 .

\section{- Magnésio}

Na Tabela 8.8 é possível observar que os teores de Mg encontrados nos mexilhões analisados variaram de $2774 \pm 211$ a $5691 \pm 717 \mathrm{mg} \mathrm{kg}^{-1}$ (na base seca). Estes resultados indicam que os mexilhões expostos em Ponta de Itaipu na estação inverno apresentaram maior acúmulo de $\mathrm{Mg}$ que nos demais pontos de coleta.

Comparando os valores obtidos nos pontos localizados na Ponta de Itaipu e na llha das Palmas com o valor do sítio controle situado na Praia da Cocanha em Caraguatatuba, pode-se observar na Figura 8.1, que os mexilhões coletados durante a estação outono apresentam diferenças significativas em relação ao ponto de referência (Cocanha) com aqueles coletados em Itaipu e Palmas. Para a estação inverno, pode-se verificar uma diferença significativa nos teores de Mg para os organismos coletados em Itaipu.

Quanto à análise sazonal (Figura 8.2), os resultados das análises dos mexilhões coletados em Ponta de Itaipu durante as estações verão e outono apresentaram diferenças significativas em relação às outras estações do ano. No ponto de estudo llha das Palmas, pode-se verificar uma diferença significativa na concentração de $\mathrm{Mg}$ durante as estações verão e inverno. Na Praia da Cocanha foi observada diferença significativa para os períodos de coleta verão, outono e inverno, sendo as mais altas concentrações de $\mathrm{Mg}$ obtidas nos mexilhões coletados na estação inverno.

Verificou-se também na Tabela 8.11 que os teores de Mg presentes nos tecidos dos mexilhões analisados no presente estudo (2774 a $5691 \mathrm{mg} \mathrm{kg}^{-1}$, na base seca) foram da mesma ordem de grandeza (2121 a $5699 \mathrm{mg} \mathrm{kg}^{-1}$, na base seca) em relação aos organismos da mesma espécie transplantados por biomonitoração ativa (SEO et al., 2009). 


\section{- Manganês}

Conforme mostra a Tabela 8.9, as concentrações de Mn obtidas nos mexilhões variaram de 7,01 $\pm 0,30$ a 29,74 $\pm 3,32 \mathrm{mg} \mathrm{kg}^{-1}$ (na base seca). Estes resultados mostram que as amostras expostas em llha das Palmas na estação verão apresentaram concentrações de $\mathrm{Mn}$ mais elevadas do que nos demais pontos.

Na Figura 8.1 é possível observar que os resultados obtidos nos mexilhões na estação primavera apresentaram diferenças significativas em relação ao ponto de referência (Cocanha) com aqueles coletados na Ponta de Itaipu e na Ilha das Palmas. Para as estações verão e outono, pode-se notar diferenças significativas na concentração de Mn nos moluscos bivalves coletados em Palmas. Já para a estação inverno, os resultados obtidos para os mexilhões apresentaram diferenças significativas para o ponto localizado em Ponta de Itaipu.

$\mathrm{Na}$ análise sazonal (Figura 8.2), os resultados dos mexilhões coletados em Ponta de Itaipu durante as estações verão e outono apresentaram um aumento significativo em relação às outras estações do ano. No ponto de estudo Ilha das Palmas, pode-se observar uma diferença significativa na concentração de Mn durante a estação verão. Na região de referência localizada na Praia da Cocanha não foi observada diferença significativa para todos os períodos de coleta.

$\mathrm{Na}$ Tabela 8.11 é possível observar a comparação dos resultados obtidos para Mn em mexilhões no presente trabalho com outros valores da literatura. Comparando os resultados obtidos para Mn nos mexilhões Perna perna $\left(7,01 \pm 0,30\right.$ a $29,74 \pm 3,32 \mathrm{mg} \mathrm{kg}^{-1}$, na base seca) com os da literatura, verifica se que a faixa de resultados obtidos neste estudo é da mesma ordem de grandeza daqueles obtidos para mexilhões Mytilus galloprovincialis coletados no litoral de Safi, Marrocos, de 14,70 a 25,30 $\mathrm{mg} \mathrm{kg}^{-1}$ na base seca (MAANAN, 2007) e para mexilhões Perna perna coletados no litoral do Estado de São Paulo, Brasil, de 7,1 a 29,2 $\mathrm{mg} \mathrm{kg}^{-1}$ na base seca (SEO et al., 2010), em um experimento de biomonitoração ativa. Entretanto as concentrações obtidas neste trabalho foram 
superiores as concentrações obtidas para esta mesma espécie de mexilhão coletada na llha de Santana, RJ, de 6,69 a $9,52 \mathrm{mg} \mathrm{kg}^{-1}$, em peso seco (CARVALHO et al., 2001).

Com relação aos trabalhos existentes sobre a determinação de $\mathrm{Mn}$ em organismos marinhos, tem - se o de Maanan (2007) que determinou as concentrações de vários metais tóxicos, tais como, $\mathrm{Hg}, \mathrm{Cd}, \mathrm{Pb}, \mathrm{Zn}, \mathrm{Cu}, \mathrm{Ni}, \mathrm{Mn}$ e Cr por meio da espectrometria de absorção atômica (AAS) em mexilhões Mytilus galloprovincialis coletados no litoral de Safi, no Marrocos. As concentrações de $\mathrm{Mn}$ obtidas nos mexilhões variaram de 7,2 a 27,5 mg kg-1 (na base seca).

Outro trabalho, realizado no Brasil, é o de Carvalho et al. (2001) que avaliaram a contaminação do ambiente costeiro próximo à cidade de Macaé - SE, por meio da análise dos elementos $\mathrm{Al}, \mathrm{Fe}, \mathrm{Mn}, \mathrm{Ca}, \mathrm{Cr}, \mathrm{Cu}, \mathrm{Ni}, \mathrm{Pb}$ e $\mathrm{Zn}$ em mexilhões Perna perna pelo método de espectrometria de emissão atômica com fonte de plasma acoplado indutivamente (ICP AES). As concentrações de $\mathrm{Mn}$ obtidas nos mexilhões variaram de 6,69 a 9,52 $\mathrm{mg} \mathrm{kg}^{-1}$ (na base seca).

\section{- Vanádio}

$\mathrm{Na}$ Tabela 8.10 são apresentados os resultados obtidos das concentrações de $\mathrm{V}$ nos mexilhões coletados em Santos (Ponta de Itaipu e llha das Palmas) e também os da região de controle (Praia da Cocanha) durante diferentes períodos de coleta. Os resultados obtidos mostram níveis de $\mathrm{V}$ mais elevados (variando de $0,77 \pm 0,02$ a $3,43 \pm 0,28 \mathrm{mg} \mathrm{kg}^{-1}$ ) em mexilhões coletados na Praia da Cocanha durante o período de primavera quando comparados aos demais locais de coleta.

A Figura 8.1 mostra que as concentrações de $V$ obtidas nas amostras de mexilhões coletados na estação verão apresentaram diferenças significativas em relação ao ponto de referência (Cocanha) para os demais pontos situados em Ponta de Itaipu e llha das Palmas. Para a estação outono, pode-se observar diferenças significativas na concentração deste elemento para todos os pontos de 
coleta (Ponta de Itaipu e llha das Palmas). Já para a estação inverno, nota-se diferença significativa para o ponto localizado em Ponta de Itaipu.

Quanto à análise sazonal (Figura 8.2), os resultados das análises dos mexilhões coletados na Praia da Cocanha e nos demais pontos de estudo Ponta de Itaipu e llha das Palmas apresentaram diferenças significativas entre as quatro estações do ano, sendo as mais altas concentrações de $\vee$ obtidas na estação primavera para todos os pontos.

Nota-se na Tabela 8.11 a comparação dos resultados obtidos para $V$ em mexilhões no presente trabalho com outros valores da literatura. Pode-se verificar que os mexilhões analisados no presente trabalho apresentaram níveis superiores aos obtidos para os mexilhões coletados na Baía de Onagawa $(0,20-$ $0,62 \mathrm{mg} \mathrm{kg}^{-1}$ na base seca), no Japão e no litoral Português (<0,34 - 2,50 $\mathrm{mg} \mathrm{kg}^{-1}$ na base seca), em Portugal. No entanto, é possível observar que os mexilhões Perna perna analisados neste estudo também apresentaram níveis mais baixos de $\mathrm{V}$ quando comparados aos mexilhões provenientes da região do Golfo (2,0 $5,1 \mathrm{mg} \mathrm{kg}^{-1}$ na base seca), Hong Kong (1,0 - 5,8 $\mathrm{mg} \mathrm{kg}^{-1}$ na base seca), na China e no litoral de São Paulo $\left(2,60-6,76 \mathrm{mg} \mathrm{kg}^{-1}\right.$, na base seca), no Brasil (FOWLER et al., 1993; CASTRO et al., 2004; LIU e KUEH, 2005; FUKUSHIMA et al., 2009; SEO et. al., 2011).

Dentre os estudos sobre vanádio, a seguir serão relacionados aqueles sobre a determinação deste elemento em mexilhões. Fukushima et al. (2009) determinaram as concentrações de $\mathrm{V}$ em organismos marinhos, a saber, algas, ostras, plâncton, ascídias e mexilhões pelo método de análise por ativação com nêutrons instrumental (INAA). Tais organismos foram coletados na Baía de Onagawa, em Miyagi, Japão, durante os anos de 2005 a 2008. O método de INAA mostrou que esta técnica permite a obtenção de resultados precisos e exatos. Comparando os resultados obtidos para os diferentes organismos marinhos analisados foi verificado que as concentrações de $V$ mais baixas estão presentes nas amostras de ostras e mexilhões. Os resultados de $V$ obtidos para mexilhões Mytilus sp. variaram de 0,12 a $0,62 \mu \mathrm{g} \mathrm{g}^{-1}$, sendo que os teores de $\mathrm{V}$ mais 
elevados foram obtidos para amostras coletadas durante a estação de primavera e sobretudo em novembro.

Saavedra et al. (2004) avaliaram os níveis de $\mathrm{V}$ em mexilhões coletados na costa da Galícia, na Espanha, pelo método de espectrometria de absorção atômica eletrotérmica (ET-AAS). Os resultados de $V$ obtidos para o material de referência certificado NIST SRM 1566b Oyster Tissue foram satisfatórios. O limite de detecção de $V$ foi de $0,03 \mathrm{mg} \mathrm{kg}^{-1}$ (em peso seco), indicando que o método de ET-AAS é adequado para a análise de mexilhões. As concentrações de $V$ obtidas nos mexilhões variaram de $0,104 \pm 0,002$ a 0,516 \pm $0,006 \mathrm{mg} \mathrm{kg}^{-1}$, na base seca.

Colina et al. (2005) analisaram sedimentos, mexilhões e tecidos da musculatura de peixes coletados no Lago de Maracaibo, Venezuela, para determinar as concentrações de $\mathrm{V}$ presentes nestas amostras pelo método de espectrometria de massa com fonte de plasma acoplado indutivamente associada a cromatografia líquida. Com base nos resultados obtidos, estes pesquisadores verificaram que a aplicabilidade do método é simples e adequada. Os resultados de $\mathrm{V}$ obtidos na base seca para as amostras de sedimento variaram de 1,4 a 2,3

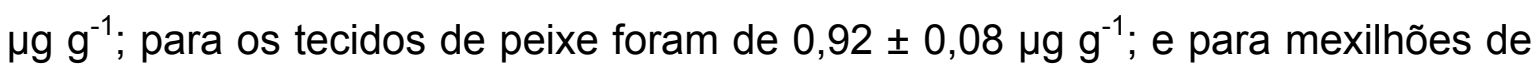
$1,52 \pm 0,16 \mu \mathrm{g} \mathrm{g}^{-1}$.

Sperling et al. (2000) determinaram as concentrações de $\mathrm{V}$ pelo método de espectrometria de absorção atômica (AAS) em mexilhões Mytilus edulis e algas Fucus vesiculosus coletados na costa da Alemanha. O resultado da análise do material de referência certificado $\left(7,96 \mu \mathrm{g} \mathrm{g}^{-1}\right)$ foi concordante com o valor do certificado $\left(8,1 \pm 0,18 \mu \mathrm{g} \mathrm{g}^{-1}\right)$ e as concentrações de $V$ obtidas para os mexilhões variaram de 1,3 a $3,8 \mu^{-1} g^{-1}$ (em peso seco), sendo que as mais altas concentrações desse elemento foram encontradas em amostras coletadas nas regiões próximas de estaleiros e rotas marítimas as quais são afetadas pelo aporte de óleos e combustíveis fósseis.

Liu e Kueh (2005) determinaram 12 metais (Al, As, Cd, Cr, Cu, Fe, Hg, $\mathrm{Mn}, \mathrm{Ni}, \mathrm{Pb}, \mathrm{Zn}$ e V) e compostos orgânicos (DDTs, PCBs, PAHs e dioxinas) em 
tecidos de mexilhões Perna viridis coletados em cinco regiões de Hong Kong, China durante os anos de 1998 a 2003. Os metais foram determinados pelas técnicas de espectrometria de massa com fonte de plasma acoplado indutivamente (ICP-MS) e espectrometria de emissão atômica com fonte de plasma de argônio induzido (ICP-AES). Já os compostos orgânicos foram determinados por diversos métodos, entre eles o método WC-OR-15 \& WC-OR15 (A) baseado no método USEPA 3545 e 3547, 1997 ;e método WC-OR-14 baseado no método USEPA 8082, 1996. Os resultados obtidos para $V$ variaram de 2,3 a 4,0 mg kg-1 (na base seca) para as amostras do período de 1998 e 2003. Os teores mais elevados de $\mathrm{V}$ foram registrados para amostras de mexilhões da região de Tai Tam, localizada ao sul de Hong Kong $\left(2,4\right.$ a $\left.5,8 \mathrm{mg} \mathrm{kg}^{-1}\right)$ e na região de Wu Kai Sha, localizada próximo a Tolo Harbour $\left(1,0\right.$ a $\left.5,0 \mathrm{mg} \mathrm{kg}^{-1}\right)$. Em contrapartida, as concentrações mais baixas de $\mathrm{V}$ foram obtidas em amostras de Tsim Sha Tsui, localizado próxima a Victoria Harbour, onde foram obtidas concentrações de 1,0 a $2,0 \mathrm{mg} \mathrm{kg}^{-1}$.

Com relação aos trabalhos sobre a ingestão de $\mathrm{V}$ por alimentos marinhos, tem-se o de Bu-Olayan e Al-Yakoob (1998) que determinaram as concentrações de $\mathrm{Pb}$, $\mathrm{Ni}$ e $\mathrm{V}$ em alimentos de origem marinha (peixes e camarões) pela técnica de espectrometria de absorção atômica (AAS) e avaliaram os potenciais riscos que estes elementos causam à saúde. As concentrações de $\mathrm{V}$ obtidas em alimentos de origem marinha variaram de 0,49 a $1,48 \mathrm{\mu g} \mathrm{g}^{-1}$ (em peso seco), sendo que as maiores concentrações para esse elemento foram encontradas em peixes. 
Tabela 8.5 Concentrações de $\mathrm{Br}$, em mg kg-1 (base seca), em amostras de mexilhões Perna perna coletados na Praia da Cocanha, llha das Palmas e Ponta de Itaipu para as quatro estações do ano.

\begin{tabular}{|c|c|c|c|c|c|c|c|c|c|c|c|c|}
\hline \multirow{2}{*}{ Determinação } & \multirow[b]{2}{*}{ Primavera } & \multicolumn{2}{|c|}{ Praia da Cocanha } & \multicolumn{5}{|c|}{ Ilha das Palmas } & \multirow[b]{2}{*}{ Primavera } & \multicolumn{3}{|c|}{ Ponta de Itaipu } \\
\hline & & Verão & Outono & Inverno & Primavera & Verão & Outono & Inverno & & Verão & Outono & Inverno \\
\hline \multirow{2}{*}{1} & $222^{*}$ & 220 & 282 & 210 & 264 & 169 & 294 & 391 & 226 & 280 & 276 & 338 \\
\hline & $30^{* *}$ & 29 & 56 & 25 & 36 & 22 & 41 & 66 & 30 & 35 & 28 & 44 \\
\hline \multirow{2}{*}{2} & 299 & 229 & 300 & 208 & 257 & 166 & 231 & 356 & 227 & 234 & 298 & 330 \\
\hline & 47 & 24 & 51 & 30 & 36 & 20 & 30 & 51 & 24 & 26 & 36 & 42 \\
\hline \multirow{2}{*}{3} & 244 & 238 & 283 & 208 & 206 & 186 & 259 & 331 & 210 & 208 & 265 & 327 \\
\hline & 27 & 27 & 48 & 28 & 23 & 22 & 28 & 49 & 28 & 23 & 26 & 36 \\
\hline \multirow{2}{*}{4} & 240 & 271 & 240 & 265 & 249 & 164 & 288 & 358 & 263 & 237 & 357 & 333 \\
\hline & 28 & 38 & 33 & 35 & 34 & 22 & 32 & 69 & 39 & 32 & 44 & 38 \\
\hline \multirow{2}{*}{5} & 298 & 214 & 286 & 274 & 298 & 184 & 332 & & 261 & 269 & 333 & 330 \\
\hline & 39 & 22 & 40 & 46 & 35 & 20 & 45 & & 38 & 37 & 44 & 45 \\
\hline \multirow{2}{*}{6} & & & 272 & 247 & & & 345 & & & & 364 & 381 \\
\hline & & & 34 & 36 & & & 42 & & & & 38 & 49 \\
\hline \multirow{2}{*}{7} & & & & 214 & & & 281 & & & & & \\
\hline & & & & 27 & & & 40 & & & & & \\
\hline \multirow{2}{*}{8} & & & & 277 & & & 312 & & & & & \\
\hline & & & & 43 & & & 35 & & & & & \\
\hline Média Geral*** & 261 & 234 & 277 & 238 & 255 & 174 & 293 & 359 & 237 & 246 & 316 & 340 \\
\hline DP & 36 & 22 & 20 & 31 & 33 & 10 & 37 & 25 & 23 & 29 & 42 & 21 \\
\hline DPR & 13,8 & 9,4 & 7,2 & 13,0 & 12,9 & 5,7 & 12,6 & 7,0 & 9,7 & 11,8 & 13,3 & 6,2 \\
\hline
\end{tabular}

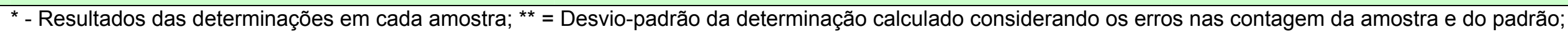

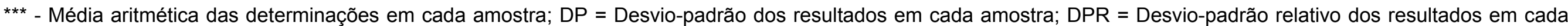
amostra. 
Tabela 8.6 Concentrações de $\mathrm{Cl}$, em mg kg${ }^{-1}$ (base seca), em amostras de mexilhões Perna perna coletados na Praia da Cocanha, Ilha das Palmas e Ponta de Itaipu para as quatro estações do ano.

\begin{tabular}{|c|c|c|c|c|c|c|c|c|c|c|c|c|}
\hline \multirow{2}{*}{ Determinação } & \multirow[b]{2}{*}{ Primavera } & \multicolumn{2}{|c|}{ Praia da Cocanha } & \multicolumn{5}{|c|}{ Ilha das Palmas } & \multirow[b]{2}{*}{ Primavera } & \multicolumn{3}{|c|}{ Ponta de Itaipu } \\
\hline & & Verão & Outono & Inverno & Primavera & Verão & Outono & Inverno & & Verão & Outono & Inverno \\
\hline \multirow{2}{*}{1} & $84491^{*}$ & 74269 & 80860 & 83284 & 108238 & 45439 & 103091 & 80456 & 86801 & 69403 & 81194 & 96342 \\
\hline & $1939^{* *}$ & 2177 & 2075 & 2989 & 3108 & 1252 & 3063 & 2003 & 2074 & 1810 & 2135 & 2476 \\
\hline \multirow{2}{*}{2} & 85019 & 92333 & 80970 & 84064 & 109446 & 46477 & 109587 & 93282 & 72543 & 60001 & 80917 & 97234 \\
\hline & 2148 & 2285 & 3657 & 2103 & 3156 & 1083 & 3200 & 2404 & 1886 & 1592 & 2159 & 3650 \\
\hline \multirow{2}{*}{3} & 75026 & 90367 & 83870 & 83820 & 109813 & 42526 & 106956 & 81559 & 82027 & 57639 & 85858 & 93055 \\
\hline & 1902 & 2589 & 2427 & 2230 & 3465 & 1869 & 2958 & 1940 & 2428 & 1526 & 2441 & 3562 \\
\hline \multirow{2}{*}{4} & & 76520 & & 84140 & & 45047 & 95030 & 90908 & & 54637 & 76253 & \\
\hline & & 2043 & & 2361 & & 1806 & 2907 & 2363 & & 1306 & 2180 & \\
\hline \multirow{2}{*}{5} & & 75836 & & & & 46695 & 98787 & 80297 & & 61366 & 75326 & \\
\hline & & 1890 & & & & 1115 & 2914 & 1996 & & 1809 & 1983 & \\
\hline \multirow{2}{*}{6} & & & & & & 47762 & & 104078 & & & & \\
\hline & & & & & & 1516 & & 3336 & & & & \\
\hline Média Geral"** & 81512 & 81865 & 81900 & 83827 & 109166 & 45658 & 102690 & 88430 & 80457 & 60609 & 79910 & 95573 \\
\hline DP & 5623 & 8725 & 1707 & 387 & 824 & 1811 & 5912 & 9503 & 7257 & 5540 & 4255 & 2218 \\
\hline DPR & 6,9 & 10,7 & 2,1 & 0,5 & 0,8 & 4,0 & 5,8 & 10,8 & 9,0 & 9,1 & 5,3 & 2,3 \\
\hline
\end{tabular}

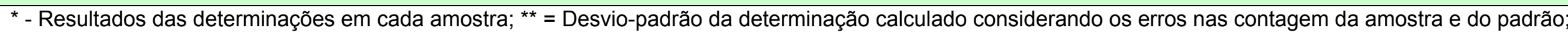

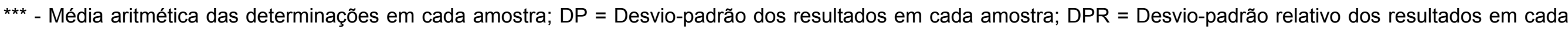
amostra. 
Tabela 8.7 Concentrações de $\mathrm{K}$, em mg kg $^{-1}$ (base seca), em amostras de mexilhões Perna perna coletados na Praia da Cocanha, Ilha das Palmas e Ponta de Itaipu para as quatro estações do ano.

\begin{tabular}{|c|c|c|c|c|c|c|c|c|c|c|c|c|}
\hline \multirow{2}{*}{ Determinação } & \multirow[b]{2}{*}{ Primavera } & \multicolumn{2}{|c|}{ Praia da Cocanha } & \multicolumn{5}{|c|}{ Ilha das Palmas } & \multirow[b]{2}{*}{ Primavera } & \multicolumn{3}{|c|}{ Ponta de Itaipu } \\
\hline & & Verão & Outono & Inverno & Primavera & Verão & Outono & Inverno & & Verão & Outono & Inverno \\
\hline \multirow{2}{*}{1} & $15013^{*}$ & 9796 & 13324 & 13104 & 9114 & 10776 & 11751 & 10354 & 6055 & 11049 & 9000 & 9866 \\
\hline & $1818^{* *}$ & 1442 & 2213 & 1831 & 1400 & 987 & 1536 & 1581 & 1205 & 1539 & 1304 & 1472 \\
\hline \multirow{2}{*}{2} & 12423 & 10711 & 9938 & 11248 & 7771 & 10365 & 13264 & 8350 & 7502 & 10946 & 8533 & 8958 \\
\hline & 1583 & 1695 & 1498 & 1663 & 1517 & 1002 & 2035 & 1698 & 1266 & 1216 & 1218 & 1884 \\
\hline \multirow{2}{*}{3} & 14988 & 9150 & 11257 & 12948 & 8572 & 10082 & 10519 & 8346 & 7571 & 10426 & 8340 & 8500 \\
\hline & 2288 & 1256 & 1792 & 1780 & 1432 & 1491 & 1795 & 1718 & 928 & 1520 & 1211 & 1551 \\
\hline \multirow{2}{*}{4} & & 9573 & 10703 & 12345 & 8161 & 10772 & & 8668 & & & & \\
\hline & & 1188 & 1670 & 1640 & 1455 & 1275 & & 1609 & & & & \\
\hline \multirow{2}{*}{5} & & & 12635 & 12847 & & & & & & & & \\
\hline & & & 1564 & 1502 & & & & & & & & \\
\hline \multirow{2}{*}{6} & & & & 12545 & & & & & & & & \\
\hline & & & & 1773 & & & & & & & & \\
\hline Média Geral*** & 14141 & 9808 & 11571 & 12506 & 8405 & 10498 & 11845 & 8929 & 7043 & 10807 & 8624 & 9108 \\
\hline DP & 1488 & 659 & 1390 & 675 & 575 & 338 & 1375 & 961 & 856 & 334 & 340 & 695 \\
\hline DPR & 10,5 & 6,7 & 12,0 & 5,4 & 6,8 & 3,2 & 11,6 & 10,8 & 12,2 & 3,1 & 3,9 & 7,6 \\
\hline
\end{tabular}

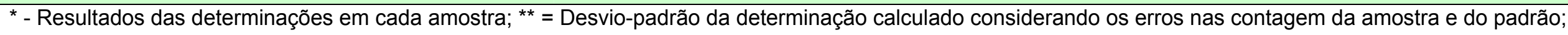

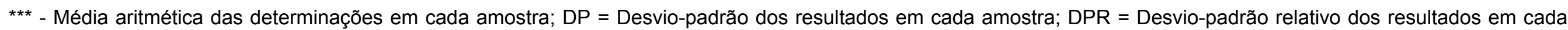
amostra. 
Tabela 8.8 Concentrações de Mg, em mg kg ${ }^{-1}$ (base seca), em amostras de mexilhões Perna perna coletados na Praia da Cocanha, Ilha das Palmas e Ponta de Itaipu para as quatro estações do ano.

\begin{tabular}{|c|c|c|c|c|c|c|c|c|c|c|c|c|}
\hline \multirow{2}{*}{ Determinação } & \multirow[b]{2}{*}{ Primavera } & \multicolumn{2}{|c|}{ Praia da Cocanha } & \multicolumn{5}{|c|}{ Ilha das Palmas } & \multicolumn{4}{|c|}{ Ponta de Itaipu } \\
\hline & & Verão & Outono & Inverno & Primavera & Verão & Outono & Inverno & Primavera & Verão & Outono & Inverno \\
\hline 1 & $3194^{*}$ & 3090 & 3928 & 4389 & 2895 & 2395 & 3703 & 4362 & 4254 & 3354 & 3570 & 5429 \\
\hline \multirow{2}{*}{2} & 3238 & 3027 & 4532 & 4404 & 3249 & 2977 & 3531 & 4047 & 3742 & 3440 & 3824 & 4534 \\
\hline & 379 & 307 & 426 & 450 & 318 & 146 & 349 & 384 & 315 & 746 & 348 & 380 \\
\hline \multirow{2}{*}{3} & 3827 & 2643 & 4431 & 4511 & 3621 & 2816 & 3984 & 3675 & 3120 & 2715 & 3877 & 4926 \\
\hline & 388 & 325 & 423 & 460 & 388 & 167 & 358 & 359 & 302 & 137 & 346 & 435 \\
\hline \multirow{2}{*}{4} & 3672 & 3100 & 4379 & 4057 & 3841 & 2686 & 3085 & 3899 & 3594 & 2812 & 4574 & 5664 \\
\hline & 470 & 321 & 440 & 381 & 346 & 159 & 335 & 382 & 340 & 311 & 420 & 491 \\
\hline \multirow{2}{*}{5} & 3547 & 3134 & 4821 & 4137 & 2912 & 2876 & 3331 & 3959 & 4043 & 2445 & 3326 & 6464 \\
\hline & 399 & 414 & 405 & 423 & 322 & 161 & 268 & 396 & 445 & 741 & 378 & 529 \\
\hline 6 & & 2612 & 3974 & 4780 & & 2654 & 3402 & 4390 & 3218 & 3233 & 3945 & 6617 \\
\hline \multirow{2}{*}{7} & & & 4852 & & & 2713 & 3810 & 4163 & & 3366 & & 6041 \\
\hline & & & 463 & & & 141 & 420 & 368 & & 194 & & 453 \\
\hline \multirow{2}{*}{8} & & & 3825 & & & 3072 & & 5385 & & 2971 & & 5850 \\
\hline & & & 445 & & & 202 & & 541 & & 206 & & 547 \\
\hline Média Geral"*** & 3496 & 2934 & 4343 & 4380 & 3303 & 2774 & 3549 & 4235 & 3745 & 3042 & 3853 & 5691 \\
\hline DP & 274 & 240 & 398 & 261 & 422 & 211 & 307 & 522 & 390 & 362 & 421 & 717 \\
\hline DPR & 7,9 & 8,2 & 9,2 & 6,0 & 12,8 & 7,6 & 8,7 & 12,3 & 10,4 & 11,9 & 10,9 & 12,6 \\
\hline
\end{tabular}

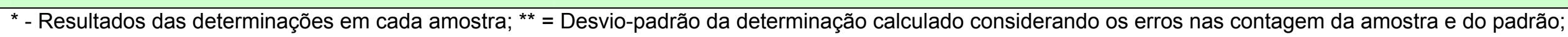

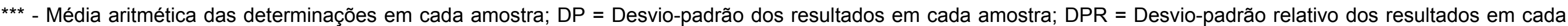
amostra. 
Tabela 8.9 Concentrações de Mn, em mg kg ${ }^{-1}$ (base seca), em amostras de mexilhões Perna perna coletados na Praia da Cocanha, Ilha das Palmas e Ponta de Itaipu para as quatro estações do ano.

\begin{tabular}{|c|c|c|c|c|c|c|c|c|c|c|c|c|}
\hline \multirow{2}{*}{ Determinação } & \multirow[b]{2}{*}{ Primavera } & \multicolumn{2}{|c|}{ Praia da Cocanha } & \multicolumn{5}{|c|}{ Ilha das Palmas } & \multirow[b]{2}{*}{ Primavera } & \multicolumn{3}{|c|}{ Ponta de Itaipu } \\
\hline & & Verão & Outono & Inverno & Primavera & Verão & Outono & Inverno & & Verão & Outono & Inverno \\
\hline \multirow{2}{*}{1} & $11,63^{*}$ & 10,67 & 10,19 & 13,81 & 14,18 & 29,44 & 16,39 & 13,83 & 7,35 & 9,63 & 12,5 & 9,10 \\
\hline & $0,75^{\star *}$ & 0,65 & 0,87 & 0,84 & 0,84 & 1,38 & 0,95 & 0,92 & 0,56 & 0,63 & 1,07 & 1,09 \\
\hline \multirow{2}{*}{2} & 11,19 & 12,60 & 9,42 & 12,76 & 13,01 & 29,22 & 14,51 & 11,83 & 6,77 & 11,74 & 10,05 & 7,71 \\
\hline & 0,71 & 0,76 & 0,76 & 0,81 & 0,81 & 1,01 & 1,14 & 0,84 & 0,64 & 0,66 & 1,03 & 1,12 \\
\hline \multirow{2}{*}{3} & 13,21 & 14,71 & 10,82 & 11,17 & 13,14 & 30,63 & 14,64 & 13,04 & 6,92 & 11,61 & 10,60 & 8,47 \\
\hline & 0,79 & 0,81 & 1,07 & 1,14 & 0,80 & 1,37 & 0,89 & 0,87 & 0,58 & 0,81 & 0,66 & 1,00 \\
\hline \multirow{2}{*}{4} & & 13,15 & 9,88 & 11,27 & 15,15 & 28,29 & 15,58 & 14,90 & & 11,24 & 9,96 & \\
\hline & & 0,98 & 0,78 & 1,07 & 0,80 & 1,24 & 0,89 & 1,04 & & 0,91 & 0,63 & \\
\hline \multirow{2}{*}{5} & & 14,02 & 11,59 & 13,71 & 15,75 & 33,49 & & & & & & \\
\hline & & 0,80 & 0,84 & 0,87 & 0,90 & 0,89 & & & & & & \\
\hline \multirow{2}{*}{6} & & & 8,46 & 13,07 & & 23,30 & & & & & & \\
\hline & & & 0,60 & 1,00 & & 0,98 & & & & & & \\
\hline \multirow{2}{*}{7} & & & & 14,13 & & 34,00 & & & & & & \\
\hline & & & & 0,96 & & 1,39 & & & & & & \\
\hline \multirow{2}{*}{8} & & & & & & 29,53 & & & & & & \\
\hline & & & & & & 1,45 & & & & & & \\
\hline Média Geral*** & 12,01 & 13,03 & 10,06 & 12,85 & 14,25 & 29,74 & 15,28 & 13,40 & 7,01 & 11,05 & 10,78 & 8,43 \\
\hline DP & 1,06 & 1,55 & 1,09 & 1,20 & 1,21 & 3,32 & 0,88 & 1,29 & 0,30 & 0,97 & 1,18 & 0,70 \\
\hline DPR & 8,8 & 11,9 & 10,8 & 9,4 & 8,5 & 11,2 & 5,8 & 9,7 & 4,3 & 8,8 & 11,0 & 8,3 \\
\hline
\end{tabular}

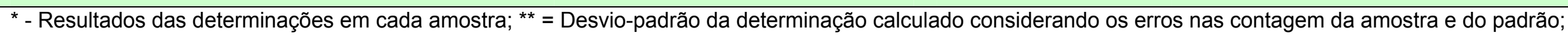

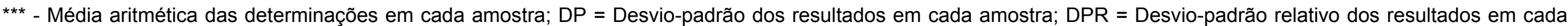
amostra. 
Tabela 8.10 Concentrações de $\mathrm{V}$, em mg kg${ }^{-1}$ (base seca), em amostras de mexilhões Perna perna coletados na Praia da Cocanha, Ilha das Palmas e Ponta de Itaipu para as quatro estações do ano.

\begin{tabular}{|c|c|c|c|c|c|c|c|c|c|c|c|c|}
\hline \multirow{2}{*}{ Determinação } & \multirow[b]{2}{*}{ Primavera } & \multicolumn{2}{|c|}{ Praia da Cocanha } & \multicolumn{5}{|c|}{ Ilha das Palmas } & \multicolumn{4}{|c|}{ Ponta de Itaipu } \\
\hline & & Verão & Outono & Inverno & Primavera & Verão & Outono & Inverno & Primavera & Verão & Outono & Inverno \\
\hline \multirow{2}{*}{1} & $3,41^{*}$ & 2,78 & 0,89 & 0,74 & 3,44 & 1,40 & 2,05 & 0,76 & 3,33 & 1,26 & 2,42 & 0,88 \\
\hline & $0,40^{* *}$ & 0,37 & 0,01 & 0,01 & 0,06 & 0,21 & 0,31 & 0,01 & 0,04 & 0,23 & 0,30 & 0,01 \\
\hline \multirow{2}{*}{2} & 3,43 & 2,67 & 0,82 & 0,78 & 3,19 & 1,16 & 2,04 & 0,78 & 3,16 & 1,20 & 2,85 & 0,94 \\
\hline & 0,43 & 0,36 & 0,01 & 0,01 & 0,04 & 0,21 & 0,31 & 0,01 & 0,06 & 0,21 & 0,36 & 0,01 \\
\hline \multirow{2}{*}{3} & 3,08 & 2,41 & 0,78 & 0,80 & 3,44 & 1,33 & 1,81 & 0,81 & 3,05 & 1,28 & 2,39 & 0,93 \\
\hline & 0,42 & 0,38 & 0,01 & 0,01 & 0,04 & 0,25 & 0,33 & 0,01 & 0,04 & 0,23 & 0,35 & 0,01 \\
\hline \multirow{2}{*}{4} & 3,78 & 2,60 & 0,72 & 0,77 & & 1,40 & 2,14 & 0,85 & 3,02 & 1,18 & 2,67 & 0,90 \\
\hline & 0,46 & 0,30 & 0,01 & 0,01 & & 0,21 & 0,40 & 0,01 & 0,04 & 0,24 & 0,35 & 0,01 \\
\hline Média Geral*** & 3,43 & 2,62 & 0,80 & 0,77 & 3,36 & 1,32 & 2,01 & 0,80 & 3,14 & 1,23 & 2,58 & 0,91 \\
\hline DP & 0,28 & 0,16 & 0,07 & 0,02 & 0,14 & 0,11 & 0,14 & 0,04 & 0,14 & 0,05 & 0,22 & 0,03 \\
\hline DPR & 8,3 & 6,0 & 8,9 & 3,0 & 4,2 & 8,6 & 7,1 & 4,8 & 4,6 & 3,7 & 8,5 & 3,1 \\
\hline
\end{tabular}

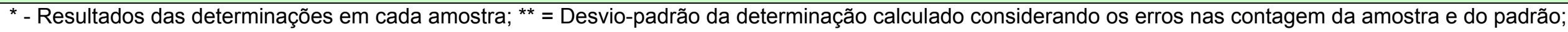

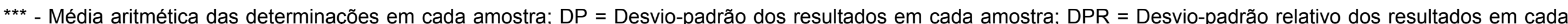
amostra. 


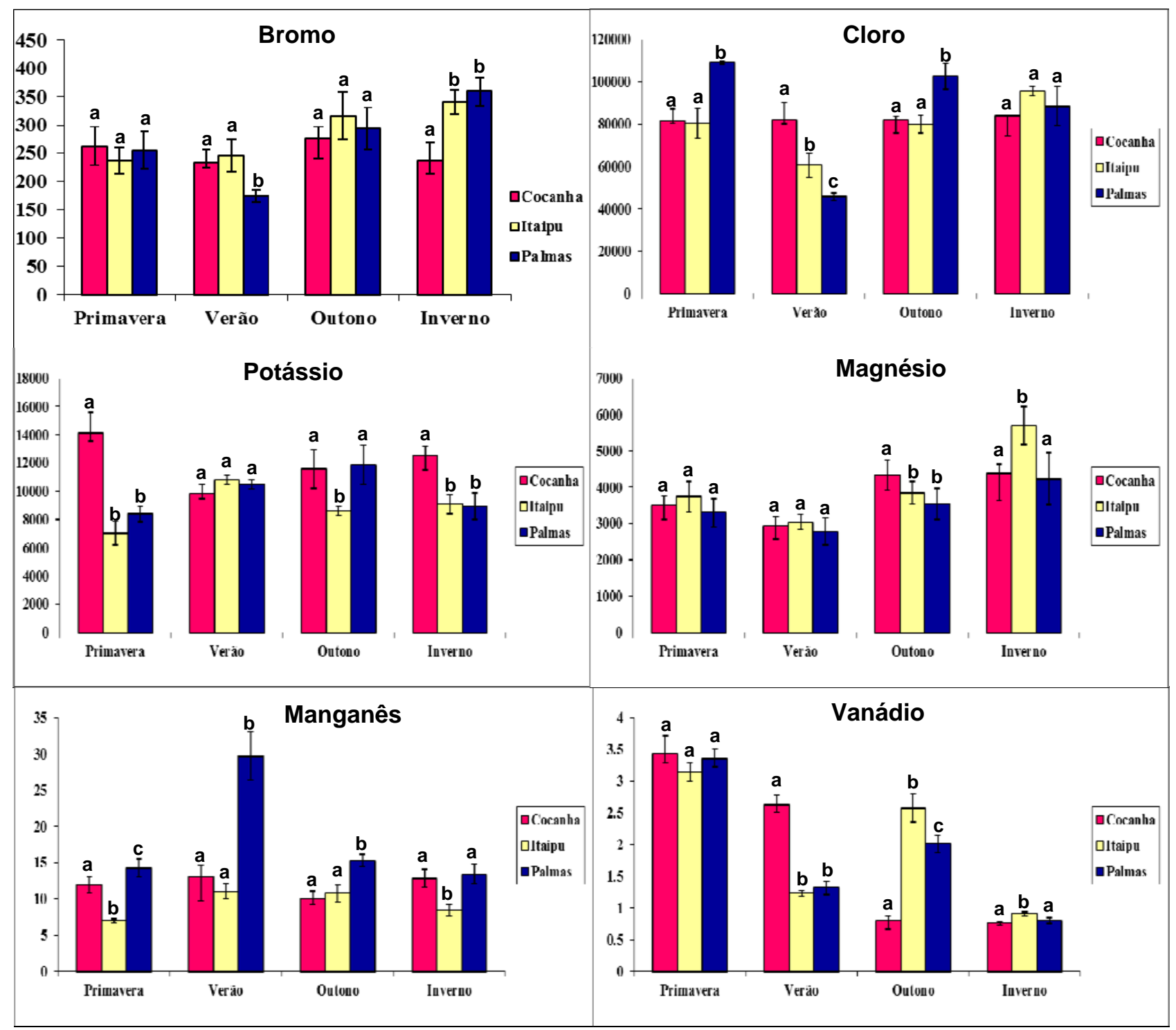

Figura 8.1 Médias das concentrações dos elementos em $\mathrm{mg} \mathrm{kg}^{-1}$ nas amostras de mexilhões (em base seca) coletados em diferentes pontos nas quatro estações do ano. Médias com letra minúscula igual indicam que os resultados não diferem pelo teste de Tukey $(p<0,05)$ na análise espacial. 


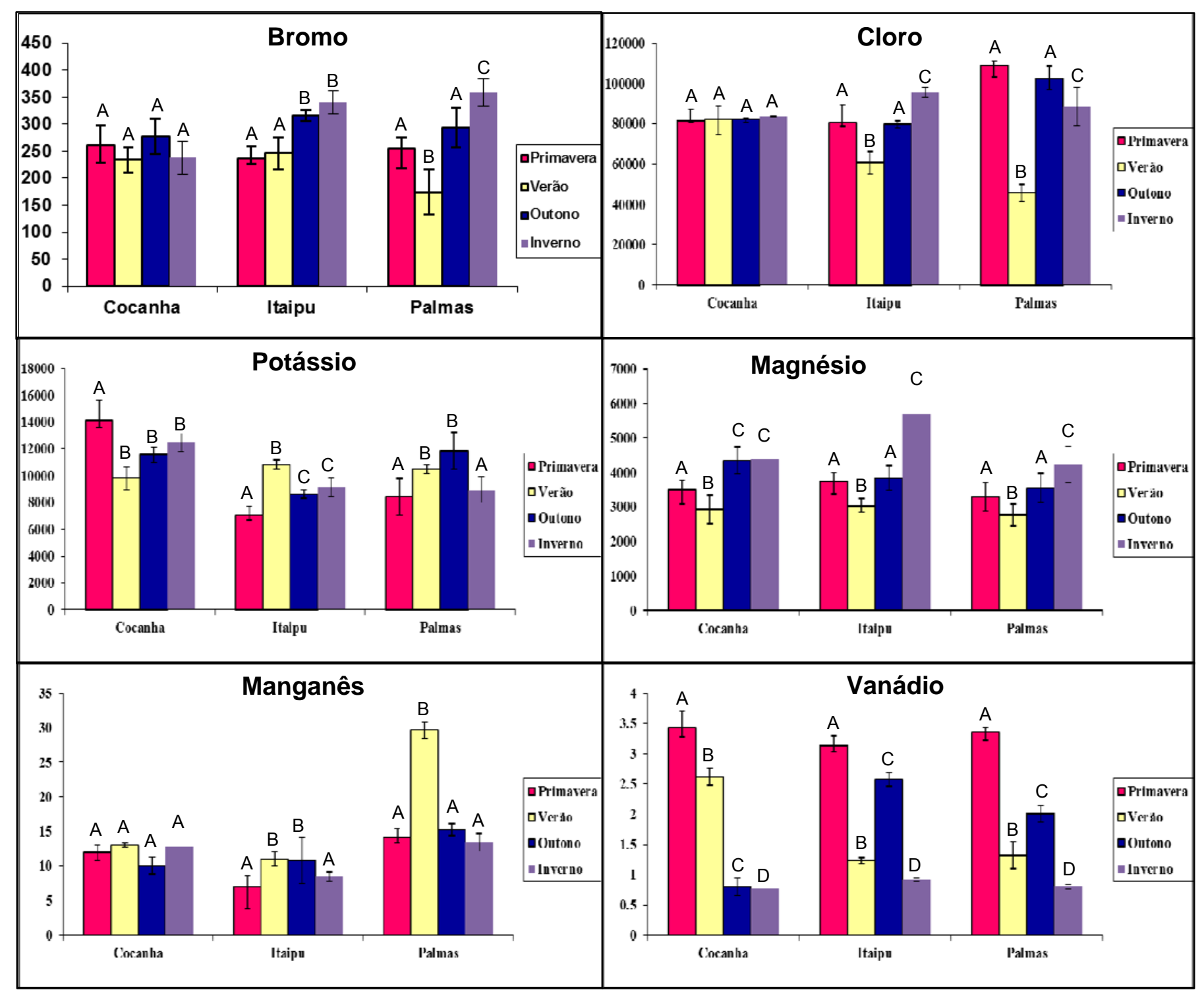

Figura 8.2 Médias das concentrações dos elementos em $\mathrm{mg} \mathrm{kg}^{-1}$ nas amostras de mexilhões (em base seca) coletados em diferentes pontos nas quatro estações do ano. Médias com letra maiúscula igual indicam que os resultados não diferem pelo teste de Tukey $(p<0,05)$ na análise sazonal. 
Tabela 8.11 Comparação das determinações dos elementos em mexilhões com os valores da literatura (na base seca).

\begin{tabular}{|c|c|c|}
\hline Elementos & Este trabalho & Trabalhos anteriores \\
\hline \multirow{3}{*}{$\mathrm{Br}$} & \multirow{3}{*}{$173,80-358,99 \mathrm{mg} \mathrm{kg}^{-1}$} & 219 a $418 \mathrm{mg} \mathrm{kg}^{-1}$ (SEO et al., 2007) \\
\hline & & 0,0103 a 0,246 $\mathrm{mg} \mathrm{kg}^{-1}$ (CHUNG et al., 2003) \\
\hline & & 0,0136 a $0,0758 \mathrm{mg} \mathrm{kg}^{-1}$ (CHUNG et al., 2003) \\
\hline $\mathrm{Cl}$ & $4,6-10,9 \%$ & 5,7 a $11,5 \%$ (SEO et al., 2007) \\
\hline K & $0,70-1,25 \%$ & $0,78$ a $1,35 \%$ (SEO et al., 2007$)$ \\
\hline \multirow[t]{2}{*}{$\mathrm{Mg}$} & $2774-5691 \mathrm{mg} \mathrm{kg}^{-1}$ & 2121 a $5699 \mathrm{mg} \mathrm{kg}^{-1}$ (SEO et al., 2009) \\
\hline & & 7,1 a $29,2 \mathrm{mg} \mathrm{kg}^{-1}$ (SEO et al., 2010) \\
\hline \multirow[t]{4}{*}{$\mathrm{Mn}$} & $7,01-29,74 \mathrm{mg} \mathrm{kg}^{-1}$ & 14,70 a $25,30 \mathrm{mg} \mathrm{kg}^{-1}$ (MAANAN, 2007) \\
\hline & & 6,69 a $9,52 \mathrm{mg} \mathrm{kg}^{-1}$ (CARVALHO et al., 2001) \\
\hline & & $0,20-0,62 \mathrm{mg} \mathrm{kg}^{-1}$ (FUKUSHIMA et al., 2009) \\
\hline & & $<0,34-2,50 \mathrm{mg} \mathrm{kg}^{-1}$ (CASTRO et al., 2004) \\
\hline \multirow[t]{3}{*}{ V } & $0,77-3,43 \mathrm{mg} \mathrm{kg}^{-1}$ & $2,0-5,1 \mathrm{mg} \mathrm{kg}^{-1}$ (FOWLER et al., 1993) \\
\hline & & $1,0-5,8 \mathrm{mg} \mathrm{kg}^{-1}$ (LIU e KUEH, 2005) \\
\hline & & $2,60-6,768 \mathrm{mg} \mathrm{kg}^{-1}$ (SEO et al., 2011) \\
\hline
\end{tabular}




\section{CONCLUSÕES}

1. Os resultados obtidos permitiram concluir que o procedimento adotado para o tratamento das amostras e o método analítico de análise por ativação com nêutrons instrumental (INAA) foram adequados para determinação dos elementos $\mathrm{Br}, \mathrm{Cl}, \mathrm{Mg}, \mathrm{Mn}, \mathrm{K}$ e $\vee$ em tecidos de mexilhões Perna perna por meio de irradiações curtas no reator nuclear IEA-R1 do IPEN-CNEN/SP.

2. A vantagem da técnica aplicada (INAA) está na rapidez da análise e as condições experimentais estabelecidas foram de irradiação curta a $10 \mathrm{~s}$, seguida de 2 contagens das amostras de mexilhões. Para o nível de concentração dos elementos, em $\mathrm{mg} \mathrm{kg}^{-1}$, é aceitável um DPR da ordem de $15 \%$.

3. As análises dos materiais de referência certificados indicaram uma boa qualidade dos resultados com relação à precisão e exatidão. Os desviospadrão relativos foram inferiores a $8,2 \%$ para os elementos e os resultados apresentaram uma boa concordância com os valores certificados com percentagens de erros relativos inferiores a $4,2 \%$.

4. Com relação às análises das amostras de mexilhões Perna perna, esperava-se que as concentrações obtidas para os elementos não fossem elevadas para os organismos coletados na Praia da Cocanha (em Caraguatatuba), uma vez que este local trata-se de um cultivo de mexilhões, considerado como ponto de referência. Já para os pontos de estudo localizados no canal de Santos (Ponta de Itaipu e llha das Palmas) esperava-se que os níveis de concentração dos elementos analisados fossem superiores devido à localização próxima de emissários industriais (como por exemplo, indústrias de fertilizantes), emissários da Sabesp, descargas domésticas e a circulação de navios provenientes dos portos. No entanto, os resultados obtidos para as amostras de mexilhões Perna perna analisados no presente estudo, mostraram 
que, em geral, o acúmulo de elementos presentes nos tecidos destes organismos foi acentuado na região da Praia da Cocanha, sobretudo durante a estação de primavera, que é considerada uma das estações do ano cujos mexilhões estão em época reprodutiva. Tal fato possivelmente pode ter ocorrido devido ao aporte de embarcações (barcos dos pescadores e navios portuários) na região, o que poderia ser visto como um evento local.

5. Comparando os resultados obtidos no presente estudo (biomonitoração passiva) com aqueles obtidos em trabalhos anteriores (biomonitoração ativa), pode-se verificar que nas amostras de mexilhões transplantadas as concentrações de $\mathrm{Br}, \mathrm{Cl}$ e $\mathrm{Mg}$ foram superiores em Ilhabela, os níveis de $\mathrm{K}$ e $\mathrm{Mn}$ foram elevados em Ilha das Palmas, e por fim, as concentrações de $V$ foram superiores na região de São Sebastião, próximo ao TEBAR (terminal petrolífero de São Sebastião). Em contrapartida, neste trabalho as concentrações dos elementos, em geral, foram acentuadas na região da Praia da Cocanha, conforme mencionado anteriormente.

6. Os teores de $\mathrm{Br}$ presentes nos tecidos dos mexilhões analisados no presente estudo foram muito superiores aos de bromofenóis normalmente encontrados em moluscos e também em amostras de ostras, o que pode indicar que o $\mathrm{Br}$ estaria presente também em outras formas químicas, como por exemplo íons brometos.

7. Os resultados obtidos para $\mathrm{Mg}$ indicaram que os mexilhões são ricos neste elemento, que é considerado essencial, e cuja ingestão diária humana para prover as necessidades recomendadas nutricionalmente é de cerca de $400 \mathrm{mg}$.

8. A partir dos resultados obtidos pode - se concluir que os mexilhões da espécie Perna perna, podem ser utilizados como biomonitores da contaminação marinha.

9. Com relação ao número de amostras analisadas, que no presente trabalho foi de 12 amostras de tecidos de mexilhões (amostras coletadas em 3 pontos diferentes durante as 4 estações do ano), é de grande interesse estender 
essas análises para um número maior de amostras para uma melhor compreensão a nível de monitoramento ambiental nas águas litorâneas.

10. Os resultados obtidos para $\mathrm{Br}, \mathrm{Cl}, \mathrm{K}, \mathrm{Mg}, \mathrm{Mn}$ e $\mathrm{V}$ nos mexilhões Perna perna poderão contribuir como uma base de dados para futuros trabalhos de biomonitoramento ambiental afim de se realizar um estudo comparativo. 


\section{REFERÊNCIAS BIBLIOGRÁFICAS}

ABNT, ASSOCIAÇÃO BRASILEIRA DE NORMAS TÉCNICAS. Conteúdo de certificados de materiais de referência. Rio de Janeiro: ABNT, 2000 (ABNT ISSO Guia 30).

AGUIAR, A. R. Aplicação do método de análise por ativação com nêutrons à determinação de elementos traço em unhas humanas. 2001. Dissertação (Mestrado) - Instituto de Pesquisas Energéticas e Nucleares.

ALFASSI, Z. B. Activation Analysis, Florida: CRC Press, v. 01, 1990.

ASCHNER, J. L. e ASCHNER, M. Nutritional aspects of manganese homeostasis. Mol. Aspects Med., v. 26, p.353 - 362, 2005.

BARNES, R. S. K.; CALOW, P. e OLIVE, P. J. W. Os invertebrados uma nova síntese. São Paulo: Atheneu, 526p., 1995.

BASSET, J.; DENMEY, R. C.; JEFFERY, G. H.; MENDHAL, J. Análise inorgânica quantitativa. Rio de Janeiro: Editora Guanabara Dois S. A., $4^{a}$ ed., p. $57,1981$.

BELLOTTO, V. R. e FRANCIONI, R. Níveis de metais em Perna perna e sua aplicação na análise e monitoramento ambiental. In: RESGALLA Jr, C.; WEBER, L. I. e CONCEIÇÃO, M. B. O mexilhão Perna perna (L.). Rio de Janeiro: Interciência, $1^{\text {a }}$ ed., cap. 13, p. 207-235, 2008.

BEIRAS, R.; FERNÁNDEZ, N.; BELLAS, J.; BESADA, V.; GONZÁLEZ-QUIJANO, A. e NUNES, T. Integrative assessment of marine pollution in Galician estuaries 
using sediment chemistry, mussel bioaccumulation, and embryo-larval toxicity bioassays. Chemosphere, p. 1209-1224, 2003.

BODE, P. e GOEIJ, J. M. Activation Analysis. In: MEYERS, R. A. Encyclopedia of Environmental Analysis and Remediation. John Wiley \& Sons Inc., p. 68-84, 1998.

BODE, P. e VAN DIJK, C. P. Operational management of results in INAA utilizing a versatile system of control charts. Journal of Radioanalytical and Nuclear Chemistry, v. 215, n. 1, p. 87-94, 1997.

BODE, P.; FERNANDES, E. A. N. e GREENBERG, R. R. Metrology for chemical measurements and the position of INAA. Journal of Radioanalytical and Nuclear Chemistry, v. 245, n. 1, p. 109-114, 2000.

BOLDRINI, C. V. Mercúrio na Baixada Santista. In: HACON, S.; LACERDA, L. D.; PfEIfFER, W. C.; CARVALHO, D. Seminário Nacional sobre Riscos e Consequência do Uso de Mercúrio, FINEP/ CNPq/ UFRJ, Rio de Janeiro, p. 161195, 1990.

BONETTI, C. Foraminíferos como bioindicadores do gradiente de estresse ecológico em ambientes costeiros poluídos. Estudo aplicado ao sistema estuarino de Santos - São Vicente (SP, Brasil). Tese de Doutorado. Universidade de São Paulo, Instituto Oceanográfico. São Paulo. 229p + anexos, 2000.

BONETTI FILHO, J. Sensoriamento remoto aplicado à análise de ambientes costeiros impactados - Avaliação metodológica: Baixada Santista. Tese de Doutorado. Universidade de São Paulo, FFLCH, Departamento de Geografia. São Paulo, SP. 260p. + anexos, 1996.

BROWN, T. L.; LEMAY Jr., H. E.; BURSTEN, B. E. e BURDGE, J. R. Química: a ciência central. São Paulo: Pearson Prentice Hall, $9^{a}$ ed., p. 856-883, 2005. 
BU-OLAYAN, A. H. e AL-YAKOOB, S. Lead, nickel and vanadium in seafood: an exposure assessment for Kuwaiti consumers. The Science of the Total Environment, v. 223, p.81-86, 1998.

BYRNE, A. R. e KOSTA, L. Vanadium in foods and in human body fluids and tissues. Sci. Total Environ., v. 10, p. 17 - 30, 1978.

CALLIL, C.T. Utilização de moluscos como indicadores de mercúrio: proposta de biomonitoração. In: $5^{\circ}$ ECOTOX-Encontro Brasileiro de Ecotoxicologia. ItajaíSC-Brasil, 05 a 08 de Outubro de 1998.

CARVAlHo, C. E. V.; CAVAlCANTE, M. P. O.; GOMES, M. P.; FARIA, V. V. e REZENDE, C. E. Distribuição de metais pesados em mexilhões (Perna perna, L.) da Ilha de Santana, Macaé, SE, Brasil. Ecotoxicology and Environmental Restoration, v. 4, $\mathrm{n}^{\circ} 1,2001$.

CASTRO, M.; SANTOS, M. M.; MONTEIRO, N. M.; VIEIRA, N. Measuring lysosomal stability as na effective tool for marine coastal environmental monitoring. Marine Environmental Research, v. 58, p. 741 - 745, 2004.

CATHARINO, M. G. M.; VASCONCELlOS, M. B. A.; SOUSA, E. C. P. M.; MOREIRA, E. G. e PEREIRA, C. D. S. Journal of Radioanalytical and Nuclear Chemistry, v. 278, p. 547-551, 2008.

CETESB - COMPANHIA DE TECNOLOGIA DE SANEAMENTO AMBIENTAL. Relatório de qualidade das praias litorâneas do estado de São Paulo. Relatório técnico CETESB, 165p., 2010.

CETESB - COMPANHIA DE TECNOLOGIA DE SANEAMENTO AMBIENTAL. Relatório de qualidade das águas litorâneas do estado de São PauloBalneabilidade das praias 2011. Relatório técnico CETESB, 194p., 2011.

CHUNG, H. Y.; MA, W. C. J. e KIM, J-S. Seasonal distribution of bromophenols in selected Hong Kong seafood. J. Agric. Food Chem., v. 51, p. 6752 - 6760, 2003. 
COLINA, M.; GARDINER, P. H. E.; RIVAS, Z. e TRONCONE, F. Determination of vanadium species in sediment, mussel and fish muscle tissue samples by liquid chromatography-inductively coupled plasma-mass spectrometry. Analytica Chimica Acta, v. 538, p. 107-115, 2005.

CORSI, I.; MARIOTTINI, M.; SENSINI, C.; LANCINI, L.; FOCARDI, S. Fish as biomarkers of brackish ecosystem health: integrating biomarker responses and target pollutant concentrations. Oceanologica Acta, v. 26, p. 129-138, 2003.

DE SOETE, D.; GIJELS, R. e HOSTE, J. Neutron activation analysis. WileyInterscience, London, 1972.

EKINCI, C. e KÖKLÜ, Ü. Determination of vanadium, manganese, silver and lead by graphite furnace atomic absorption spectrometry after preconcentration on silica-gel modified with 3-aminopropyltriethoxysilane. Spectrochimica Acta Part B: Atomic Spectroscopy, v. 55, nº 9, p. 1491-1495, 2000.

EPAGRI-EMPRESA DE PESQUISA AGROPECUÁRIA E EXTENSÃO RURAL DE SANTA CATARINA. Apostila de maricultura. São Francisco do Sul, 1996.

EVANGELOU, A. M. Vanadium in cancer treatment. Oncol. Hematol., v. 42, p. $249-265,2002$.

FERREIRA, J. F.; MAGALHÃES, A. R. M. Cultivo de Mexilhões. In Aqüicultura experiências brasileiras. POLI, C. R.; POLI, A. T. ANDREATTA, E.; BELTRAME, E. organizadores. Florianópolis, SC: Multitarefa, 2004.

FOWLER, S. W.; READMAN, J. W.; OREGIONI, B.; VILLENEUVE, J. P.; MCKAY, K. Petroleum hydrocarbons and trace metals in nearshore Gulf sediments and biota before and after the 1991 war: An assessment of temporal and spatial; trends. Mar. Poll. Bull., v. 27, p. $171-182,1993$.

FRANCIONI, E.; WAGENER, A. L. R.; CALIXTO, R. C. e BASTOS, G. C. Evaluation of Perna perna (Linné, 1758) as a tool to monitoring trace metals 
contamination in estuarine and coastal Waters of Rio de Janeiro, Brazil. Journal of the Brazilian Chemical Society, v. 15, $n^{\circ}$ 1, p. 1-10, 2004.

FUKUSHIMA, M.; SUZUKI, H.; SAITO, K. e CHATT, A. Vanadium levels in marine organisms of Onagawa Bay in Japan. J. Radioanal. Nucl. Chem., v. 282, p. 8589, 2009.

FUNDAÇÃO SISTEMA ESTADUAL DE ANÁLISE DE DADOS - SEADE. Dados 2000. Disponível em <http://www.seade.gov.br/>, acessado em 3 de janeiro de 2010.

FURLEY, T. H.; OLIVEIRA FILHO, A. C. Monitoramento do efluente da Aracruz Celulose S/A através do uso de mexilhões como indicadores de metais pesados e organoclorados. In: $5^{\circ}$ ECOTOX-Encontro Brasileiro de Ecotoxicologia, ItajaísSC-Brasil, 05 a 08 de Outubro de 1998.

GONZALEZ-REYES, R. E.; GUTIERREZ-ALVAREZ, A. M. e MORENO, C. B. Manganese and epilepsy: a systematic review of the literature. Brain Res. Rev., v. 53, p. $332-336,2007$.

GRAY, T. Os elementos: uma exploração visual dos átomos conhecidos no universo. São Paulo: Blucher, p. 49, 2011.

HAMEL, F. G.; SOLOMON, S. S.; JESPERSEN, A. S.; BLOTCKY, A.; RACK, E. e DUCKWORTH, W. C. Alteration of tissue vanadium content in diabetes. Metab. Clin. Exp., v. 42, n. 12, p. 1503 - 1505, 1993.

KELLER, C. Radiochemistry. Chichester: Ellis Horwood, 1988.

KELLNER, R.; MERMET, J. M.; OTTO, M.; WIDMER, H. M. Analytical Chemistry. New York, N.Y.: Wiley, 1998. Cap. 8, Activation Analysis, p. 491-513.

KENNISH, M. J. Ecology of estuaries: anthropogenic effects. Boca Raton, Florida: CRC Press, 494p., 1991. 
KIMURA, C. B.; REIS, C. R. dos e FERNANDES, L. C. Efeito do consumo de água rica em sais de vanádio sobre a glicemia de ratos diabéticos. Estudo de Biologia, v. 28, n. 65, p. 87 - 96, 2006.

KUCERA, J.; BODE, P. e STEPANECK, V. Uncertainty evaluation in instrumental and radio-chemical neutron activation analysis. IAEA-TECDOC1404 (2004). Disponível em : $\quad$ enttp://wwwpub.iaea.org/MTDC/publications/PDF/te_1404_web.pdf>, acessado em 05 de março de 2012.

LAMPARELLI, C. C. (coord.) Mapeamento dos ecossistemas costeiros do Estado de São Paulo. São Paulo: Secretaria do Meio Ambiente, Cetesb, 108p., 1999.

LAVILLA, I.; VILAS, P. e MILLOS, J.; Bencdicho, C. Development of na ultrasound-assisted extraction method for biomonitoring of vanadium and nickel in the coastal environment under the influence of the Prestige fuel spill (North east Atlantic Ocean). Analytica Chimica Acta, v. 577, p. 119-125, 2006.

LIONETTO, M. G., CARICATO, R., GIORDANO, M. E., PASCARIELLO, M. F., MARINOSCI, L., SCHETTINO, T. Integrated use of biomarkers (acetyl cholinesterase and antioxidant enzymes activities) in Mytillus galloprovincialis and Mullus barbatus in an Italian coastal marine area. Marine Pollution Bulletin, v. 46, p. 324-330, 2003.

LITORAL VIRTUAL. Fazenda de Mexilhão atrai turistas. Disponível em <http://www.litoralvirtual.com.br/noticias/2007/01/18.html\#Caraguatatuba>, acessado em 02 de outubro de 2011.

LIU, J. H. e KUEH, C. S. W. Biomonitoring of heavy metals and trace organics using the intertidal mussel Perna viridis in Hong Kong coastal Waters. Mar. Poll. Bull., v. 51, p. 857-875, 2005. 
LOPES, S. G. B. C. e FONSECA, M. L. O mexilhão Perna perna (Linnaeus, 1758)-taxonomia, morfologia e anatomia funcional. In: RESGALLA Jr., C.; WEBER, L. I. e CONCEIÇÃO, M. B. O mexilhão Perna perna. Rio de Janeiro: Interciência, p. 3-23, 2008.

LUZ, R. C. S.; SILVA, L. M. S.; LOPES, G. S.; MARQUES, A. B. e MARQUES, E. P. Determinação de vanádio em óleo diesel por espectrometria de absorção atômica em forno de grafite (GFAAS). Rev. Anal., n. 7, p. 48 - 56, 2003.

MAANAN, M. Biomonitoring of heavy metals using Mytilus galloprovincialis in Safi coastal waters, Morocco. Environmental Toxicology, v. 1, p. 525-531, 2007.

MARKERT, B. ;WAPPELHORST, O.; WECKERT, V.; HERPIN,U; SIEWERS, U.; FRIESE, K. e BREULMANN, G. The use of bioindicators for monitoring the heavymetal status of the environment. J. Radioanal. Nucl. Chem., v. 240, n. 2, p. 425 429, 1999.

MOLICA, J. Entrando de gaiato no navio: Espécies exóticas invadem a costa brasileira, prejudicam a biodiversidade e até a saúde da população. Disponível em <http://cienciahoje.uol.com.br/noticias/ecologia-e-meioambiente/entrando-de-gaiato-no-navio/>, acesso em 15 de fevereiro de 2012.

MONTEIRO, C. A. F. A dinâmica climática e as chuvas no Estado de São Paulo: estudo geográfico sob a forma de atlas. Laboratório de Climatologia, Instituto de Geografia. Universidade de São Paulo, São Paulo, 130p., 1973.

MOTA DA SILVA, V.; ARAÚJO LOPES, W.; DE ANDRADE, J.; DA CUNHA VELOSO; M.C.; DOS SANTOS, G.V. e OLIVEIRA, A. S. Bromofenóis simples relacionados ao "flavor" de organismos marinhos, Quím. Nova, v.30, p.629 - 635, 2007.

NAGAOSA, Y. e KIMURA, Y. High-performance liquid chromatography with electrochemical detection for the determination of vanadium $(\mathrm{V})$ in river water and mussel samples. Analytica Chimica Acta, v. 327, p. 203-209, 1996. 
NAP, THE NATIONAL ACADEMIES PRESS-FOOD AND NUTRITION BOARD. Dietary reference intakes for calcium, phosphorus, magnesium, vitamin $D$, and fluoride, p.190-249, 1997.

NAP, THE NATIONAL ACADEMIES PRESS-FOOD AND NUTRITION BOARD. Dietary reference intakes for vitamin A, vitamin $\mathrm{K}$, arsenic, boron, chromium, copper, iodine, iron, manganese, molybdenium, nickel, silicon, vanadium and zinc, p.394 - 553, 2001.

NAP, THE NATIONAL ACADEMIES PRESS-FOOD AND NUTRITION BOARD. Dietary reference intakes for water, potassium, sodium, chloride and sulfate, p.186-268, 2005.

NIST, National Institute of Standards and Technology. Standard Reference Material 2976 SRM Mussel Tissue. Certificate from National Institute of Standards and Technology. USA, p. 1 - 8, 1998.

NIST, National Institute of Standards and Technology. Standard Reference Material 1566b SRM Oyster Tissue. Certificate from National Institute of Standards and Technology. USA, p. 1- 8, 2001.

OLIVEIRA JUNIOR, O. P. O uso de materiais de referência certificados para garantir a comparabilidade dos resultados das medições químicas. In: Congresso da qualidade em metrologia, 2008, São Paulo. Anais eletrônicos. São Paulo, 2008.

Disponível

em:

<http://www.vertent.net/remesp/enqualab2008/cdrom/pdf/TT068.pdf>, acessado em 15 de maio de 2012.

ORIEUX, M. Invertebrados. Rio de Janeiro: Liceu, 95 p., 1967.

RECHI, E. Estuário - definição e caracterização. INFOAQUA.NET. Disponível em <http://www.infoaqua.net/estuario-definicao-caracterizacao/>, acessado em 21 de novembro de 2012. 
RODRIGUES, S. A. Zoologia. São Paulo: Cultrix, v. 3, p. 163-179, 1975.

MITICULTURA em $\quad$ Floripar $\quad$ Disponível em <http://brasilnews1.blogspot.com/2008/08/milicultura-em-floripa.html>, acessado em 15 de agosto de 2011.

RUPPERT, E. E.; FOX, R. S. e BARNES, R. D. Zoologia dos invertebrados: uma abordagem functional-evolutiva. São Paulo: Roca, $7^{a}$ ed., p. 323-477, 2005.

SAAVEDRA, Y.; FERNÁNDEZ, P. e GONZÁLEZ, A. Determination of vanadium in mussels by electrothermal atomic absorption spectrometry without chemical modifiers. Analytical and Bioanalytical Chemistry, v. 379, p. 72-76, 2004.

SABESP - Companhia de Saneamento Básico do Estado de São Paulo. Programa de investimento em saneamento básico na Baixada Santista. SABESP, 70p., 1997.

SANDER, S. Simultaneous adsorptive stripping voltammetric determination of molybdenum (VI), uranium (VI), vanadium (V), and antimony (III). Analytica Chimica Acta, v. 394, p.81-89, 1999.

SANTOS, L. G. C. Supressão Compton na análise por ativação neutrônica instrumental de produtos agrícolas destinados à alimentação humana. 2004. Dissertação (Mestrado) - Centro de Energia Nuclear na Agricultura, Piracicaba, São Paulo.

SEMMLER, M.G.M.C. Biomonitoração de $\mathrm{Hg}, \mathrm{Cd}, \mathrm{Pb}$ e outros elementos em áreas costeiras do Estado de São Paulo por meio do mexilhão transplantado Perna perna (Linnaeus, 1758). Tese de doutorado do Instituto de Pesquisas Energéticas e Nucleares (IPEN). 2007.

SEO, D.; SAIKI, M.; CATHARINO, M. G. M.; MOREIRA, E. G. e VASCONCELLOS, M. B. A. Aplicação da irradiação curta na análise por ativação com nêutrons de amostras de mexilhão. In: 2007 INAC - International Nuclear 
Atlantic Conference, Santos - SP - Brasil, 30 de setembro a 05 de outubro de 2007.

SEO D.; VASCONCELlOS, M. B. A.; SAIKI, M.; CATHARINO, M. G. M.; MOREIRA, E. G.; SOUSA, E. C. P. M. de e PEREIRA, C. D. S. Active biomonitoring og magnesium and manganese using the Perna perna mussel collected in the north shore of São Paulo, Brasil. In: 2009 INAC - International Nuclear Atlantic Conference, Rio de Janeiro - SP - Brasil, 27 de setembro a 02 de outubro de 2009.

SEO, D.; VASCONCELlOS, M. B. A.; SAIKI, M.; CATHARINO, M. G. M.; MOREIRA, E. G.; SOUSA, E. C. P. M. de e PEREIRA, C. D. S. Avaliação de magnésio e manganês em mexilhões Perna perna transplantados no litoral norte paulista. In: XI ECOTOX-Encontro Brasileiro de Ecotoxicologia, BombinhasSC-Brasil, 19 a 23 de Setembro de 2010.

SEO, D.; VASCONCELLOS, M. B. A.; SAIKI, M.; CATHARINO, M. G. M.; MOREIRA, E. G.; SOUSA, E. C. P. M. e PEREIRA, C. D. S. Vanadium biomonitoring by using Perna perna (Linnaeus, 1758) mussels transplanted in the coast of the State of São Paulo, Brazil. J. Radioanal. Nucl. Chem., v. 291, p. 101 - 105, 2011.

SILVA, C. A. R., RAINBOW, P. S., SMITH, B. D., SANTOS, Z. L. Biomonitoring of trace metal contamination in the Potengi estuary, Natal (Brazil), using the oyster Crassostrea rhizophorae, a local food source. Water Research, v. 35, $n^{\circ} 17, p$. 4072-4078. 2001.

SPERLING, K. R.; BAHR, B. e OTT, J. Vanadium in marine mussels and algae. Fres. J. Anal. Chem., v. 366, p. 132 - 136, 2000.

STOHS, S. J. e BAGCHI, D. Oxidative mechanisms in the toxicity of metal íns. Free Radical Biology \& Medicine. V. 18, n² 2, p.321-336, 1995. 
STORER, T. I. e USINGER, R. L. Zoologia Geral. São Paulo: Companhia Editora Nacional, $2^{a}$ ed., p. 411-517, 1976.

SUNILA, I. Histopathology of mussels (Mytilus edulis L.) from the Tvärminne area, the Gulf of Finland (Baltic Sea). Annales Zoological Fennici. v. 24, p. 55-69, 1987.

THOMPSON, M. Recent trends in inter-laboratory precision at ppb and sub-ppb concentrations in relation to fitness for purpose criteria in proficiency testing. Analyst, v. 125, p. $385-386,2000$.

TOMMASI, L. R. Considerações ecológicas sobre o sistema estuarino de Santos (SP). São Paulo, 1979. Tese (Livre-Docência). Instituto Oceanográfico, USP, São Paulo.

TOMINAGA, M. e BANSHO, K. The electrothermal atomic absorption spectrometric determination of lead, manganese, vanadium and molybdecum in sea water with ascorbic acid to reduce matrix effects. Analytica Chimica Acta, v. 169, p. 171-177, 1985.

TROPPMAIR, H. Sistemas, geossitemas, geossistemas paulistas, ecologia da paisagem. Rio Claro, 2004.

ÜNSAL, M. The accumulation and transfer of vanadium within the food chain. Marine Pollution Bulletin, v. 13, p. 139-141, 1982.

VALBONESI, P., SARTOR, G., FABBRI, R. Characterization of cholinesterase activity in three bivalves inhabiting the North Adriatic Sea and their possible use as sentinel organisms for biosurveillance programmes. Science of the Total Environment, v. 312, p. 79-88, 2003.

VIARENGO, A. Heavy metals in marine invertebrates: mechanisms of regulation and toxicity at the cellular level. Reviews in Aquatic Sciences, v.1, p.295, 1989. 
VIARENGO, A. e CANESI, L. Mussels as biological indicators of pollution. Aquaculture, v. 94, p. 225-243, 1991.

VIEIRA, S. Estatística experimental. São Paulo: Atlas S. A., $2^{\text {a }}$ ed., 185p., 1999.

VORMANN, J. e ANKE, M. Dietary magnesium: supply, requirements and recommendations - results from duplicate and balance studies in man. J. Clin. Basic Cardiol., v. 5, p.49 - $53,2002$.

ZARONI, L. P.; ABESSA, D. M. S.; RACHID, B. R. F. E SOUSA, E. C. P. M. Diferenças no estado fisiológico de adultos e na viabilidade de embriões do mexilhão Perna perna provenientes de duas populações coletadas em Ubatuba - SP. In: Moraes, R.; Crapez, M.; Pfeiffer, W.; Farina, M.; Bainy, A. e Teixeira, V. Efeitos de Poluentes sobre Organismos Marinhos. São Paul : Arte \& Ciência Villipres, p. 15-25, 2001.

ZEISLER, R. e STONE, S. F. Sequential determination of biological and pollutant elements in marine bivalves. Analytical Chemistry. v. 60, p. 2760-2765, 1988.

WEISS, H. V.; GUTTMAN, M. A.; KORKISCH, J. e STEFFAN, I. Comparison of methods for the determination of vanadium in sea-water. Talanta, v. 24, p. 509$511,1977$.

WIKIPÉDIA, A Enciclopédia Livre. Bivalvia. Disponível em <http://pt.wikipedia.org/wiki/lmagem:Valva-Vistalnterna.png>, acesso em 29 de Junho de 2012.

YUSOF, A.M.; YANTA, N.F.; WOOD, A.K.H. The use of bivalves as bio-indicators in the assessment of marine pollution along a coastal area. Journal Radioanalytical and Nuclear Chemistry, v. 259, $n^{\circ}$ 1, p. 119-127, 2004. 


\section{APÊNDICE - ARTIGOS PUBLICADOS}

Neste apêndice são apresentados os artigos científicos relacionados ao projeto de Iniciação Científica e Mestrado da aluna que foram publicados até o momento do término desta dissertação:

- $\quad$ Apresentação e publicação como autora nos Anais do evento e no Journal of Radioanalytical and Nuclear Chemistry on-line (JRNC) do trabalho intitulado "Vanadium biomonitoring by using Perna perna (Linnaeus, 1758: Mollusca, Bivalvia) mussels transplanted in the coast of the State of São Paulo, Brazil". Autores: Daniele Seo, Marina B. A. Vasconcellos, Mitiko Saiki, Marília G. M. Catharino, Edson G. Moreira, Eduinetty C. P. M. de Sousa e Camilo Dias Seabra Pereira no MTAA 13 - 13th International Conference on Modern Trends in Activation Analysis, realizado em College Station, Texas no período de 13 a 18 de março de 2011.

- Publicação como co-autora nos Anais do evento e no Journal of Radioanalytical and Nuclear Chemistry on-line (JRNC) do trabalho intitulado "Biomonitoring of coastal regions of São Paulo State, Brazil, using mussels Perna perna". Autores: M. G. M. Catharino, M. B. A. Vasconcellos, A. A. Kirschbaum, M. R. Gasparro, C. C. Minei, E. C. P. M. de Sousa, D. Seo e E. G. Moreira no MTAA 13 - 13th International Conference on Modern Trends in Activation Analysis, realizado em College Station, Texas no período de 13 a 18 de março de 2011.

- $\quad$ Apresentação e publicação como autora nos Anais do evento e no Journal of Radioanalytical and Nuclear Chemistry on-line (JRNC) do trabalho intitulado "Vanadium determination in Perna perna mussels (Linnaeus, 1758: Mollusca, Bivalvia) by Instrumental Neutron Activation Analysis using the passive biomonitoring in the Santos coast, Brazil". Autores: Daniele Seo, Marina B. A. Vasconcellos, Marília G.M.Catharino, Edson G. Moreira, Eduinetty C. P. M. de 
Sousa e Mitiko Saiki no MARC IX - Methods \& Application of Radioanalytical Chemistry, realizado em Kona, Hawaii no período de 25 a 30 de março de 2012Publicação como co-autora nos Anais do evento e no Journal of Radioanalytical and Nuclear Chemistry on-line (JRNC) do trabalho intitulado "Trace element determination in a mussel reference material using short irradiation instrumental neutron activation analysis". Autores: Edson G. Moreira, Daniele Seo, Marina B. A. Vasconcellos e Mitiko Saiki no MARC IX - Methods \& Application of Radioanalytical Chemistry, realizado em Kona, Hawaii no período de 25 a 30 de março de 2012. 


\title{
Vanadium biomonitoring by using Perna perna (Linnaeus, 1758) mussels transplanted in the coast of the State of São Paulo, Brazil
}

\author{
D. Seo - M. B. A. Vasconcellos - M. Saiki • \\ M. G. M. Catharino - E. G. Moreira • \\ E. C. P. M. de Sousa • C. D. S. Pereira
}

Received: 30 May 2011

(C) Akadémiai Kiadó, Budapest, Hungary 2011

\begin{abstract}
The increased pollution in the aquatic ecosystem has led to the investigation of toxic elements in sea water by using marine organisms to assess marine pollution from human activities. Among these organisms, the mollusks bivalves have been used as biomonitors since they can accumulate trace elements and other substances, without the occurrence of their death. In this study, Perna perna mussels were transplanted from a mussel farm (reference region) to four sites located in coastal regions of São Paulo State, Brazil, close to anthropic discharge areas. Vanadium was determined in mussel tissues by instrumental neutron activation analysis (INAA). Quality control of $\mathrm{V}$ analysis was checked by analyzing biological reference materials and the results obtained were precise and in good agreement with the certified values. Comparisons between the $\mathrm{V}$ concentrations obtained in transplanted mussels indicated that those from São Sebastião region, close to an oil terminal presented the highest concentration of this element, during spring.
\end{abstract}

D. Seo $(\bowtie) \cdot$ M. B. A. Vasconcellos - M. Saiki -

M. G. M. Catharino - E. G. Moreira

Instituto de Pesquisas Energéticas e Nucleares, IPEN — CNEN/

SP, Av. Prof. Lineu Prestes, 2242, Cidade Universitária,

São Paulo, SP 05508-000, Brazil

e-mail: danyseo@uol.com.br

\section{E. C. P. M. de Sousa}

Laboratório de Ecotoxicologia Marinha e Microfitobentos, Instituto Oceanográfico da Universidade de São Paulo, IO-USP, Praça do Oceanográfico, 191, Cidade Universitária, São Paulo, SP 05508-120, Brazil

\section{D. S. Pereira}

Universidade Santa Cecília UNISANTA, Rua Oswaldo Cruz, 266, Boqueirão, Santos, SP 11045-907, Brazil
Keywords Vanadium - Neutron activation analysis . Perma perna mussel $\cdot$ Biomonitoring

\section{Introduction}

In recent years, the increase of marine contamination has led to the investigation of toxic elements in coastal waters $[1,2]$. To assess marine environmental contamination, the marine bivalves including mussels have been used as biomonitors, since they can accumulate several elements $[3,4]$. The use of Pema perna mussel species has proven to be very efficient for the assessment of inorganic marine contamination [5, 6]. In this study, P. perna mussel was used to assess $\mathrm{V}$ concentrations in a marine environment of north coastal waters of the State of São Paulo, Brazil.

Vanadium present in seawater is of great importance to evaluate marine contamination from industrial sources as well as to identify health hazards since mussels are used as food. This element is known as toxic at high levels [7] and its toxicity increases with the oxidation states.

The evaluation of V contamination in coastal waters of the State of São Paulo is important since these areas are subjected to industrial discharges and discharges from ships and boats. Among several analytical techniques available for $\mathrm{V}$ determination $[4,8,9]$, Instrumental Neutron Activation Analysis (INAA) was chosen to be applied in the analysis of mussel's tissues because this method presents advantages for this determination due to its simplicity and quickness in the analysis, as well as to nondestructive characteristic.

The aim of this study was to evaluate the contamination levels by the $\mathrm{V}$ concentration in samples of mussels transplanted from Cocanha beach to polluted shores in the coast of the State of São Paulo by using INAA. 
Fig. 1 Sampling sites in shores of the State of São Paulo

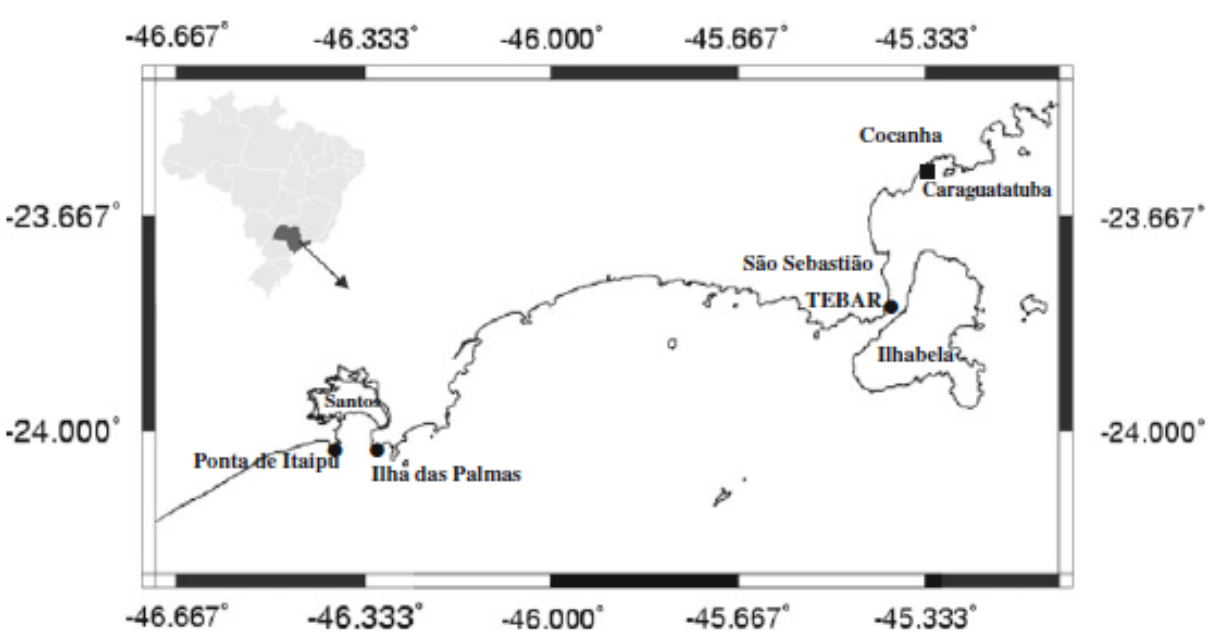

Transplant, collection and preparation of P. perna mussel samples

The samples of the P. perma mussel acquired in a mussel farm situated at Cocanha beach, in Caraguatatuba considered as the reference area, were transplanted to four sites along the shore of the State of São Paulo: South Pier of PETROBRÁS (Brazilian Oil Company), TEBAR in São Sebastião, Praia do Engenho d'Água, in Ilhabela, Ilha das Palmas and Ponta de Itaipu in Santos that are close to the areas of industrial emission, ships and boat circulation and domestic discharges.

The transplantation of mussels started in the autumn 2005 and ended in the summer 2006. One rope of mussels (Fig. 3) acquired in the farm of the Cocanha beach, was placed in each sampling site.

After a period of exposure of 3 months in each site, the ropes were removed and 90 mussels of different sizes were selected ( 30 small, 30 medium-sized and 30 big ones). The algae and other organisms that were attached to the shells of the mussels were removed using a titanium knife. Once the sessil organisms were removed, each mussel was washed with seawater and the biometric measurements of the shells were made. The tissues of the mussels were detached from the shells and afterwards ground and homogenized in a blender with titanium blades. After the homogenization, the samples were placed in plastic containers, weighed and then frozen, for further freeze-drying during a period of $48 \mathrm{~h}$, at temperature of $-52{ }^{\circ} \mathrm{C}$ and pressure of $74 \mathrm{mbar}$. The dried samples were ground in an agate mortar and sieved through a 100 mesh polyethylene sieve. Finally, the samples in powder form were stored in plastic containers, identified and kept in a freezer until the analyses. The residual moisture of these lyophilized mussel samples was also analyzed, by drying an aliquot of each sample in an oven, for $24 \mathrm{~h}$ at $85^{\circ} \mathrm{C}$. The mean percentages of water loss, after 


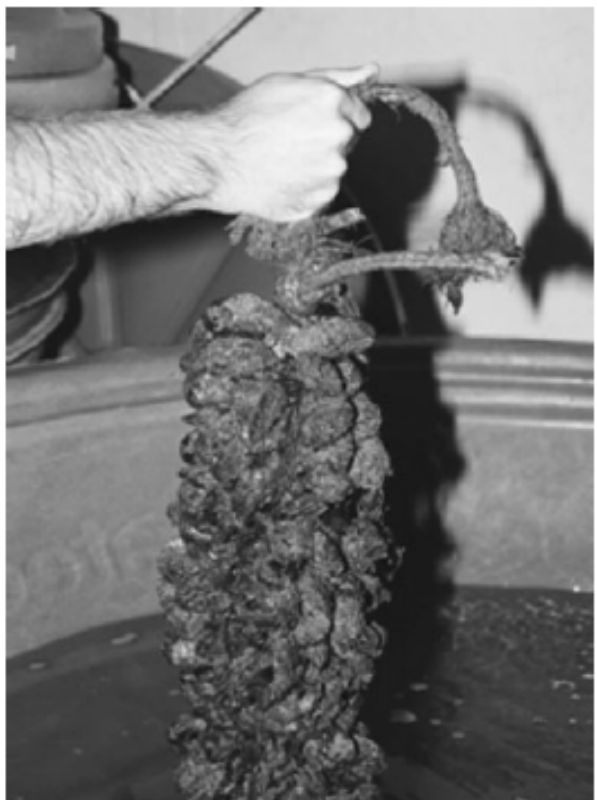

Fig. 3 Picture of the rope of mussels acquired in Cocanha beach, reference area

lyophilization and drying in the oven were 83.4 and $7.3 \%$, respectively. The sites of Ilha das Palmas and Ponta de Itaipu were not sampled in some seasons (summer and autumn) due to sample loss.

\section{Procedure for INAA}

The procedure for INAA consisted of irradiating about $180 \mathrm{mg}$ of each mussel sample and the biological reference materials NIST SRM 1566b Oyster tissue, INCT-TL-1 tea leaves and INCT-OBTL-5 Oriental Basma tobacco leaves [11-13] together with the synthetic standard of $\mathrm{V}$ in the IEAR1 nuclear research reactor through the pneumatic transfer system. Short irradiations of $8 \mathrm{~s}$, under a thermal neutron flux of $6.6 \times 10^{12} \mathrm{~cm}^{-2} \mathrm{~s}^{-1}$, were used in these analyses. After a decay time of about $5 \mathrm{~min}$, the gamma radioactivity measurement was carried out, using a model GC2018 semiconductor hyperpure Ge detector coupled to DSA1,000 Digital Spectral Analyzer, both from Canberra. For spectral data acquisition and processing, the Genie 2,000 version 3.1 software from Canberra was used. The V concentration in the sample was calculated by the comparative method [14]. The radioisotope measured and its gamma-ray energy and half-life were: ${ }^{52} \mathrm{~V}, \mathrm{E}_{\gamma}=1434.08 \mathrm{keV}$ and $\mathrm{T}_{1 / 2}=3.75 \mathrm{~min}$.

\section{Statistical analysis}

The seasonal and spatial variations of the $\mathrm{V}$ concentrations obtained were evaluated by one-way analysis of variance
Table 1 Concentration of $\mathrm{V}$, in $\mu \mathrm{g} \mathrm{g}^{-1}$, in the certified reference materials

\begin{tabular}{|c|c|c|c|c|}
\hline Mean $\pm \operatorname{SD}^{a}\left(n^{b}\right)$ & $\mathrm{RSD}^{c} \%$ & $\mathrm{Er}^{\mathrm{d}} \%$ & z-Score & $\overline{\text { Certified value }}$ \\
\hline \multicolumn{5}{|c|}{ NIST SRM 1566b Oyster tissue } \\
\hline $0.55 \pm 0.04(7)$ & 7.27 & 4.68 & -0.6 & $0.577 \pm 0.023$ \\
\hline \multicolumn{5}{|c|}{ INCT-TL-1 tea leaves } \\
\hline $1.79 \pm 0.12(8)$ & 6.61 & 9.14 & -0.46 & $1.97 \pm 0.37$ \\
\hline \multicolumn{5}{|c|}{ INCT-OBTL-5 Oriental Basma tobacco leaves } \\
\hline $3.99 \pm 0.25(6)$ & 6.31 & 3.16 & -0.22 & $4.12 \pm 0.55$ \\
\hline
\end{tabular}

${ }^{a}$ Arithmetic mean and standard deviation, ${ }^{\mathrm{b}}$ number of determinations, ${ }^{\mathrm{c}}$ relative standard deviation, ${ }^{\mathrm{d}}$ relative error

(ANOVA) and Tukey test [15] at the confidence level of $95 \%$, using Origin software version 7.5 .

\section{Results and discussion}

\section{Analysis of certified reference materials}

In Table 1 are presented the results of the $\mathrm{V}$ concentration $\left(\mu \mathrm{g} \mathrm{g}^{-1}\right)$ obtained in the analyses of biological reference materials and the certified values. The results of the standardized difference or z-score [16] calculated in order to evaluate the accuracy of the results are also presented in Table 1.

Comparisons made between the mean value obtained and the certified value (Table 1) indicated a good agreement of the results, showing that the applied procedure of INAA was adequate for this determination. The relative errors obtained were lower than $9.1 \%$ and the relative standard deviations were below $7.3 \%$, demonstrating good accuracy and precision of the results. The lz-scorel values obtained were lower than 1 indicating that the obtained results are within the range of certified values, at the confidence level of $68 \%$, this means $1 \sigma$ of uncertainty.

Analysis of mussel samples

The selection of an adequate short irradiation time $(8 \mathrm{~s})$ for mussel sample analysis was crucial in the $\mathrm{V}$ determination due to high activities of ${ }^{24} \mathrm{Na}$ and ${ }^{38} \mathrm{Cl}$ formed during irradiations as the high count rates of these radionuclides did not allow the determination of $\mathrm{V}$. The interferential nuclear reactions that could lead to ${ }^{52} \mathrm{~V}$ production in a fast neutron flux irradiation are ${ }^{52} \mathrm{Cr}(\mathrm{n}, \mathrm{p}){ }^{52} \mathrm{~V}$ and ${ }^{55} \mathrm{Mn}(\mathrm{n}, \alpha)$ ${ }^{52} \mathrm{~V}$. The interferences from these two reactions were verified experimentally by irradiating synthetic standards of $\mathrm{Cr}, \mathrm{Mn}$ and $\mathrm{V}$ and they could be considered negligible. These interferences by fast neutron have to be considered when the concentrations of $\mathrm{Cr}$ and $\mathrm{Mn}$ in the $180 \mathrm{mg}$ 
D. Seo et al.

Table 2 Concentrations of $\mathrm{V}$ in the mussel samples exposed in different periods and sampling sites of coastal area of São Paulo State, in $\mu \mathrm{g} \mathrm{g}^{-1}$ (dry weight)

\begin{tabular}{|c|c|c|c|c|}
\hline \multirow[t]{2}{*}{ Sampling sites } & \multicolumn{4}{|l|}{ Periods of exposure } \\
\hline & $\begin{array}{l}\text { Spring } \\
\text { Mean } \pm \operatorname{SD}^{\mathrm{a}}\left(n^{\mathrm{b}}\right)\end{array}$ & $\begin{array}{l}\text { Summer } \\
\text { Mean } \pm \mathrm{SD}(n)\end{array}$ & $\begin{array}{l}\text { Autumn } \\
\text { Mean } \pm \mathrm{SD}(n)\end{array}$ & $\begin{array}{l}\text { Winter } \\
\text { Mean } \pm \text { SD }(n)\end{array}$ \\
\hline Cocanha beach & $6.59 \pm 0.67(4)$ & $3.01 \pm 0.49$ (4) & $<3.96^{c}$ & $<3.08^{\mathrm{c}}$ \\
\hline Ilhabela & $6.0 \pm 0.72(5)$ & $2.59 \pm 0.44$ & $1.82 \pm 0.34(3)$ & $2.88 \pm 0.24(4)$ \\
\hline São Sebastião & $6.76 \pm 0.25(5)$ & $2.49 \pm 0.45$ & $1.21 \pm 0.23$ & $5.40 \pm 0.94$ \\
\hline Ponta de Itaipu & $3.82 \pm 0.19$ & d & d & $3.12 \pm 0.68$ \\
\hline Illa das Palmas & $2.60 \pm 0.50(5)$ & $1.84 \pm 0.40$ & d & $1.96 \pm 0.36(3)$ \\
\hline
\end{tabular}

${ }^{\mathrm{a}}$ Standard deviation, ${ }^{\mathrm{b}}$ number of determinations, ${ }^{\mathrm{c}}$ detection limit, ${ }^{\mathrm{d}}$ sample was lost (data is not available)

sample are theoretically more than 3.0 and $0.4 \mu \mathrm{g} \mathrm{g}^{-1}$, respectively.

The reproducibility of the $\mathrm{V}$ results in mussel samples was verified by analyzing each sample in triplicate. These results presented relative standard deviations varying from 4.4 to $8.5 \%$, indicating the homogeneity of the sample prepared in relation to $\mathrm{V}$ contents [17].

Results of mean concentrations of $\mathrm{V}$ in mussels exposed in different study areas and also those in the reference region (Cocanha beach) during different periods of exposure are presented in Table 2. In two samples from the reference site (Cocanha beach), in autumn and winter, V was not detected, and in this case the detection limit was calculated according to the Currie criterion [18]. Among different sampling sites, the results of Table 2 show that mussels from the places Cocanha beach, Ilhabela and São Sebastião presented higher concentrations of $\mathrm{V}$ than those found for samples from Ponta de Itaipu and Ilha das Palmas $(P<0.05)$. This increase of $\mathrm{V}$ concentrations in the sites of Ilhabela and São Sebastião could be attributed probably to the proximity of TEBAR, a ship terminal that is used by ships that transport oil and its derivatives, operating in two piers, with an extension of $905 \mathrm{~m}$. In this location, a first separation of oil is made before transport to the oil refinery and in this process effluents are discharged to the sea. Besides, higher levels of $\mathrm{V}$ (from $2.60 \pm 0.50$ to $6.76 \pm$ $0.25 \mu \mathrm{g} \mathrm{g}^{-1}$ ) were found in mussels exposed in spring season when compared with other seasons for same sampling sites. For mussels exposed during the autumn, the $\mathrm{V}$ levels decreased and varied from $1.21 \pm 0.23$ to $1.82 \pm$ $0.34 \mu \mathrm{g} \mathrm{g}^{-1}$, probably due to the increase in hydrodynamism caused by cold fronts.

The V concentration in the Cocanha Beach (reference site) was also higher in the spring and comparable to the values found for Ilhabela and São Sebastião and although this seems to be unusual, an eventual transport of oil by ships or boats to this site cannot be excluded. The accumulation of this element showed a significant difference when V results obtained for control (Cocanha) were compared with those from areas of Ponta de Itaipu and Ilha das Palmas. For samples exposed in the Ilha das Palmas site during summer season a significant decrease of $\mathrm{V}$ concentration after transplantation was verified $(P<0.05)$.

The mussel samples analyzed in this study presented higher levels of $\mathrm{V}$ than those found in mussels from Onagawa Bay in Japan [4] and the coast in Portugal [3] and, lower values than those obtained from the Gulf region [19] and Lake Maracaibo in Venezuela [11]. In addition, our V results are of the same order of magnitude when compared with those obtained in the Galician coast in Spain [10], the Hong Kong shoreline [1] and the German Bight coast [20].

\section{Conclusions}

The $\mathrm{V}$ results obtained in the analysis of the certified reference materials allowed concluding that the INAA applied was satisfactory, showing good precision and accuracy of the results. This work presents preliminary results and it is required to continue this study so as to draw definitive conclusions. From the mussel results obtained we can conclude that there was seasonal variability of $\mathrm{V}$ concentrations in mussel since there was influence of cold fronts and the increase of the hydrodynamism during autumn and winter, and also the number of boats and ships are increased during the summer due to the holidays season. Besides, differences for $\mathrm{V}$ concentrations in mussels exposed were found in distinct sites of coast of the State of São Paulo. High concentrations of $\mathrm{V}$ for mussels exposed in the São Sebastião region may be attributed to the proximity to the TEBAR terminal of ships that transport oil and its derivatives.

Acknowledgments The authors would like to acknowledge to the São Paulo Research Foundation and Brazilian National Council for Scientific and Technological Development from Brazil and the International Atomic Energy Agency for the financial support. To Oceanographic Institute of the University of São Paulo for the support in the sample collection. 


\section{References}

1. Liu JH, Kueh CSW (2005) Mar Poll Bull 51:857-875

2. Lobel PB, Belkhode SP, Bajdik C, Jackson SE, Longerich HP (1992) Mar Environ Res 33:111-126

3. Castro M, Santos MM, Monteiro NM, Vieira N (2004) Mar Environ Res 58:741-745

4. Fukushima M, Suzuki H, Saito K, Chatt A (2009) J Radioanal Nucl Chem 282:85-89

5. Catharino MGM, Vasconcellos MBA, Sousa ECPM, Moreira EG, Pereira CDS (2008) J Radioanal Nucl Chem 278:547-551

6. Seo D, Catharino MGM, Moreira EG, Saiki M, Vasconcellos MBA, Pereira CDS, Sousa ECPM (2008) J Braz Soc Ecotoxicol 3:85-90

7. Byme AR, Kosta L (1978) Sci Total Environ 10:17-30

8. Saavedra Y, Femández P, González A (2004) Anal Bioanal Chem 379:72-76

9. Colina M, Gardiner PHE, Rivas Z, Troncone F (2005) Anal Chim Acta 538:107-115

10. Lopes SGBC, Fonseca ML (2008) In: Resgalla C Jr (ed) O mexilhão Perna perna, 1st edn. Interciência, Rio de Janeiro

11. NIST, National Institute of Standards and Technology (2001) Standard Reference Material 1566b SRM Oyster Tissue. Certificate from National Institute of Standards and Technology. USA, $1-8$
12. INCT, Instytut Chemii i Techniki Jadrowej (2002) Polish certified reference material for multielement trace analysis INCT-TL1 tea leaves. Certificate from Institute of Nuclear Chemistry and Technology. Poland, pp 1-4

13. INCT, Instytut Chemii i Techniki Jadrowej (2010) Polish certified reference material for multielement trace analysis INCTOBTL-5 Oriental Basma Tobacco Leaves. Certificate from Institute of Nuclear Chemistry and Technology. Poland, pp 1-4

14. De Soete D, Gijels R, Hoste J (1972) Neutron activation analysis. Wiley, London

15. Vieira $\mathrm{S}$ (1997) Introdução à bioestatística. Campus, Brazil

16. Bode P (1996) Instrumental and organizational aspects of a neutron activation analysis laboratory. Ph.D Thesis, Delft University of Technology, The Netherlands

17. Seo D, Vasconcellos MBA, Saiki M, Catharino MGM, Moreira EG, Sousa ECPM, Pereira CDS (2009) Estabelecimento de procedimento para determinação de vanádio em mexilhões pelo método de análise por ativação com nêutrons. In: Proceedings of International Atlantic Nuclear Conference 2009, CD-ROM

18. Currie LA (1968) Anal Chem 40:586-593

19. Fowler SW, Readman JW, Oregioni B, Villeneuve JP, McKay K (1993) Mar Poll Bull 27:171-182

20. Sperling KR, Bahr B, Ott J (2000) Fres J Anal Chem 366: $132-136$ 


\section{Biomonitoring of coastal regions of São Paulo State, Brazil, using mussels Perna perna}

M. G. M. Catharino * M. B. A. Vasconcellos *

A. A. Kirschbaum - M. R. Gasparro - C. C. Minei *

E. C. P. M. de Sorsa - D. Seo - E. G. Moreira

Received: 9 June 2011

Q Akadémiai Kiad6, Budapest, Hungary 2011

\begin{abstract}
The marine environment is constantly affected by anthropic actions, with causes consequent degradation of the waters and marine biota by various discharges of xenobiotics. In the present study, the focus was the study of a region of the marine coast of the State of São Paulo (city of Santos), which is one of the most industrialized parts of Braziland suffers also from a strong impact of domestic effluents. The mussel Pema perna, very abundant in the coast of the State of São Paulo, Brazil, was selected as the biomonitoring organism for the determination of inorganic elements and a passive biomonitoring was performed. The organisms were collected at two sites in São Paulo State coast: Cocanha beach in Caraguatatuba (mussel farm) and Santos Bay (Itaipu and Palmas). Seasonally, the Perna pema were collected between September/08 and July/09 in each study sites. After removal and sample preparation, the elements $\mathrm{As}, \mathrm{Co}, \mathrm{Cr}, \mathrm{Fe}, \mathrm{Se}$ and $\mathrm{Zn}$ were determined by instrumental neutron activation analysis (INAA) and $\mathrm{Cd}, \mathrm{Pb}$ and $\mathrm{Hg}$ were determined by atomic absorption spectroscopy (AAS) in this organism.
\end{abstract}

Keywords Neutron activation analysis - Atomic absorption spectroscopy - Pema perna mussel . Biomonitoring

M. G. M. Catharino (四) - M. B. A. Vasconcellos -

D. Seo - E. G. Moreira

Instituto de Pesquisas Energéticas e Nucleares, IPEN-CNEN/SP Av. Prof. Lineu Prestes, 2242, Cidade Universitária, Săo Paub, SP 05508-000, Brazil

e-mail: mgcatharino@uol.con.tx

A. A. Kirschbaum - M. R. Gasparro - C. C. Minei .

E. C. P. M. de Sousa

Laboratbrio de Ecotoxicologia Marinha e Microfitobentos, Instituto Oceanográfico da Universidade de Sżo Paulo, IO-USP Praça do Oceanográfico, 191, Cidade Universitária, Săo Paulo, SP 05508-120, Brazil

\section{Introduction}

The advance of the industrial and urban development has caused a continuous flow of xenobiotics to the oceans, disturbing the life in the marine environment, particularly in estuaries and coastal areas.

Nowadays, the Santos Estuarine System is considered one of the most critical areas in São Paulo State, conceming the degradation level of the different compartments [1] due to a high density of human population, the industrial development and the intense dock activities [2].

Many contaminants have toxic potential that can induce physiological damages and bioaccumulate, directly or indirectly, in the organisms tissues [3, 4].

Since the middle of 1970 s, filter feeding bivalves (mussels and other shellfish) have been used as sentinel organisms suitable for studies of monitoring the environmental quality of coastal waters due to their sedentary habits and their ability to bioconcentrate pollutants $[5,6]$.

The aim of the present study was the study of a region of the marine coast of the State of São Paulo, through the determination of inorganic elements in Perna perna tissue, using passive monitoring.

\section{Experimental}

Study area

The study area is located at region of the marine coast of the State of São Paulo and extends from Santos to Caraguatatuba $\left(23^{\circ} 58^{\prime}-23^{\circ} 39^{\prime} \mathrm{S}, 46^{\circ} 30^{\prime}-45^{\circ} 25^{\prime} \mathrm{W}\right)$. Figure 1 shows the localization of the mussel farm situated at Cocanha beach in Caraguatatuba (mussel farm) and two 
M. G. M. Catharino et al.

Fig. 1 Study area located at coast of São Paulo State

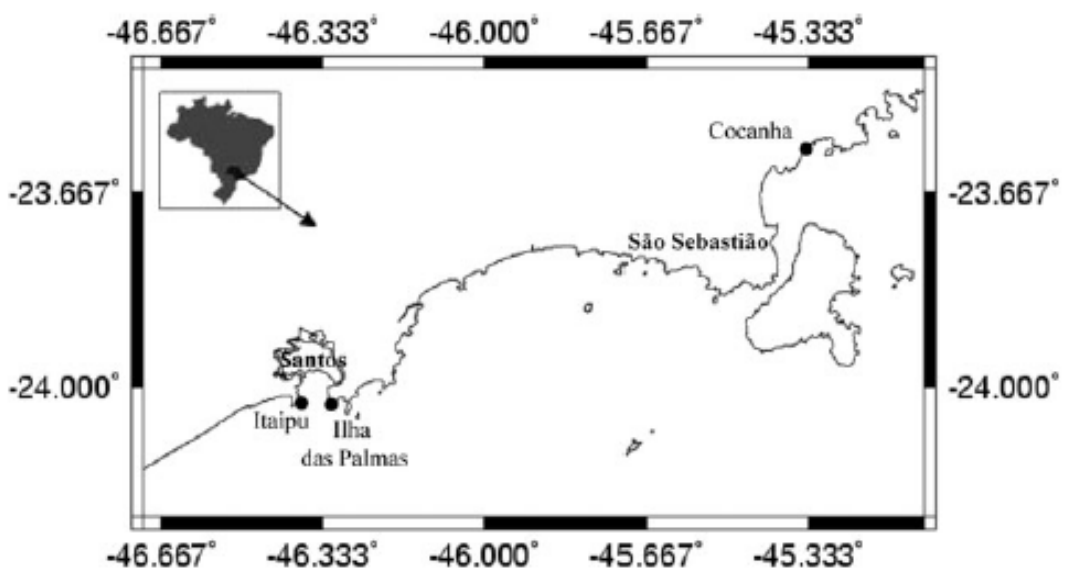

points at Santos Bay (Itaipu and Palmas), which has a strong impact of domestic effluents.

\section{Collection of mussel samples}

The mussels Perna perna (Linnaeus, 1758: Mollusca, Bivalvia), very abundant in the coast of the State of São Paulo, Brazil, were collected at two sites in São Paulo State coast: Cocanha beach in Caraguatatuba (mussel farm) and Santos Bay (Itaipu and Palmas) in the four seasons of the year between September/2008 and July/2009. The collection was performed in close collaboration with the Oceanographic Institute of São Paulo University, IO-USP. The organisms were left for about three hours in tanks containing seawater and with aeration, for their recovery.

\section{Sample preparation}

Ninety organisms were selected from each point and season of the year. Sessile organisms were removed from the shells with a titanium knife. Biometric measurements of the shells were then made, after which the organisms were removed from their shells and crushed in a domestic blender equipped with titanium knives. After this first crushing and homogenization, the organisms were lyophilized and crushed again in the blender, then manually in an agate mortar and passed through a 100 mesh nylon sieve. Loss of humidity after lyophilization was of the order of $80 \%$.

Finally, the samples were stored in plastic bottles and kept in a freezer at $-20{ }^{\circ} \mathrm{C}$ for further chemical analysis.

Analysis of certified reference material (SRM)

In order to evaluate the quality of the analytical results, the reference material NIST SRM 2976 Mussel Tissue was analyzed along with samples [7].
Instrumental neutron activation analysis (INAA)

Comparative method instrumental neutron activation analysis was employed to measure $\mathrm{As}, \mathrm{Co}, \mathrm{Cr}, \mathrm{Fe}, \mathrm{Se}$ and $\mathrm{Zn}$. Appropriate volumes of certified standard solutions (Spex Certiprep) were pippeted onto Whatmann filter papers which were folded to the same geometry of samples after drying on air. About $150 \mathrm{mg}$ of the mussel sample were weighed in polyethylene envelopes and irradiated with the standards for a period of $8 \mathrm{~h}$, in a thermal neutron flux of about $3 \times 10^{12} \mathrm{n} \mathrm{cm}^{-2} \mathrm{~s}^{-1}$, in the IEA-R1 nuclear research reactor. After appropriate decay periods, samples, standards and SRMs were measured in a gamma-ray spectrometer model GC2018 semiconductor hyperpure Ge detector coupled to DSA-1000 Digital Spectral Analyzer, both from CANBERRA.

Atomic absorption spectroscopy (AAS)

Cold vapour atomic absorption spectroscopy (CV AAS) was employed to measure $\mathrm{Hg}$, in the Perkin Elmer ${ }^{\circledR}$ FIMS equipment and using stannous chloride as reducing agent.

Eletrothermal atomic absorption spectroscopy (ET AAS) was employed to measure $\mathrm{Cd}$ and $\mathrm{Pb}$, in the Perkin Elmer $^{\circledR}$ AAnalyst 800 spectrometer.

About $350 \mathrm{mg}$ of sample and SRMs were dissolved by adding Merck ${ }^{\circledR}$ concentrated $\mathrm{HNO}_{3}$ and left standing for a period of $8 \mathrm{~h}$, after which $30 \% \mathrm{H}_{2} \mathrm{O}_{2}$ was added. The flasks were stirred and left again for about $15 \mathrm{~h}$. To finalize digestion, the closed flasks were put in an aluminum block at $90^{\circ} \mathrm{C}$, for $3 \mathrm{~h}$.

Statistical analysis

The seasonal and spatial variations of the elements concentrations obtained were evaluated by one-way analysis of variance (ANOVA) and Tukey test $(P<0.05)$ using Bioestat software version 5.0. 


\section{Results and discussion}

Analysis of reference materials

Calculated IEn| scores, presented on Table 1 were below 1 for all the elements, an evidence of satisfactory performance of the INAA and AAs methods [8].

Analysis of mussel samples

Biometric measurements of the shells were length: $4.0-9.7 \mathrm{~cm}$ and width: $1.8-4.9 \mathrm{~cm}$.

Table 2 and Fig. 2, discussed below, present a summary of means and uncertainties of the results obtained for the mussel samples for spring, summer, autumn and winter for the sites of study: Cocanha (mussel farm), Ilha das Palmas and Itaipu. The uncertainties were calculated according to Moreira et al. $[9,10]$.

\section{Comparison between the sites}

The elements $\mathrm{As}, \mathrm{Fe}, \mathrm{Hg}, \mathrm{Cd}$, and $\mathrm{Se}$ were present at higher concentrations at the Cocanha site for all seasons. Significant differences were observed $(P<0.05)$ in the following cases: Fe for Palmas and Itaipu in all the seasons; $\mathrm{Cd}$ except for winter; $\mathrm{As}, \mathrm{Hg}$ and $\mathrm{Se}$ in winter and $\mathrm{As}$ and $\mathrm{Se}$ in springtime as compared to Itaipu; $\mathrm{As}, \mathrm{Hg}$ and $\mathrm{Se}$ in spring, $\mathrm{Hg}$ in summer, As in autumn and $\mathrm{Se}$ in winter as compared to Palmas.

Lead concentrations were higher in Cocanha in spring, autumn and winter and were significantly different than in other areas only in spring. In summer, on the other hand, Palmas concentrations were significantly higher than in Itaipu and Cocanha.

For arsenic concentrations, a significant difference was observed in Itaipu and Palmas in wintertime, the latter being the lowest value.

Table 1 En score obtained for NIST SRM 2976 Mussel tissue certified reference materials

\begin{tabular}{lccl}
\hline Element & Certified value $\left(\mu \mathrm{g} \mathrm{g}^{-1}\right)$ & This study $\left(\mu \mathrm{g} \mathrm{g}^{-1}\right)^{\mathrm{a}}$ & $\mid$ En \\
\hline $\mathrm{As}$ & $13.3 \pm 1.8$ & $13.3 \pm 0.4$ & 0 \\
$\mathrm{Cd}$ & $0.82 \pm 0.16$ & $0.88 \pm 0.07$ & 1 \\
$\mathrm{Co}$ & $0.61 \pm 0.02^{\mathrm{b}}$ & $0.65 \pm 0.07$ & 1 \\
$\mathrm{Cr}$ & $0.50 \pm 0.16^{\mathrm{b}}$ & $0.46 \pm 0.03$ & 0.5 \\
$\mathrm{Fe}$ & $171.0 \pm 4.9$ & $169 \pm 7$ & 0.5 \\
$\mathrm{Hg}$ & $0.061 \pm 0.0036$ & $0.060 \pm 0.004$ & 0.6 \\
$\mathrm{~Pb}$ & $1.19 \pm 0.18$ & $1.15 \pm 0.07$ & 0.7 \\
$\mathrm{Se}$ & $1.80 \pm 0.15$ & $1.8 \pm 0.2$ & 0 \\
$\mathrm{Zn}$ & $137 \pm 13$ & $140 \pm 2$ & 0.9 \\
\hline
\end{tabular}

${ }^{a}$ Uncertainties are: expanded uncertainties $k=2$

${ }^{\mathrm{b}}$ Informative values

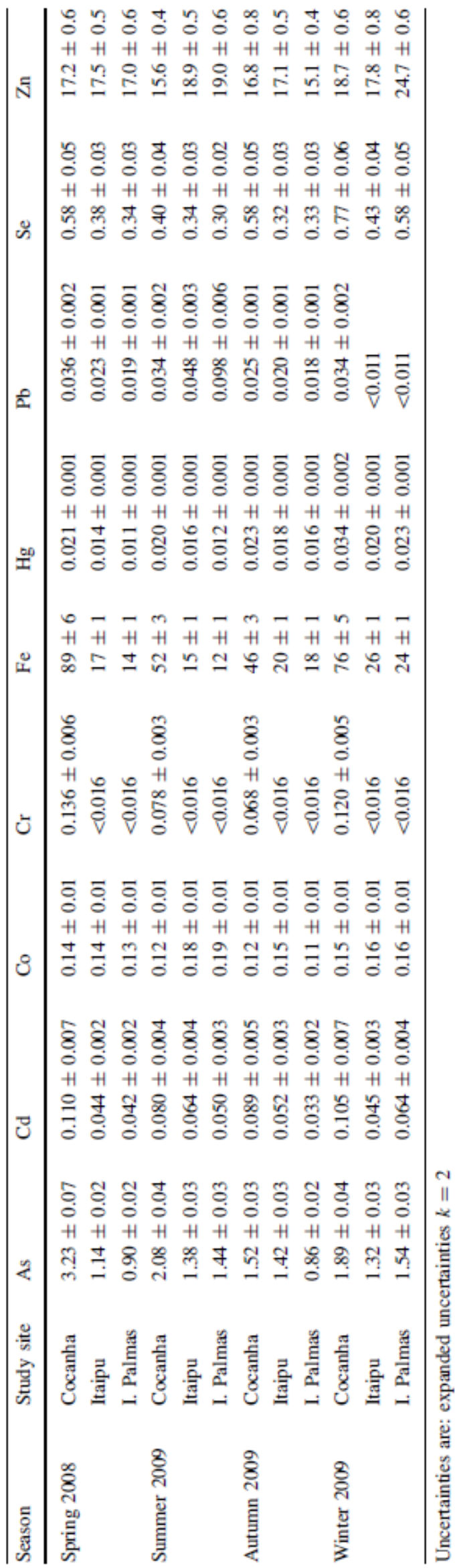



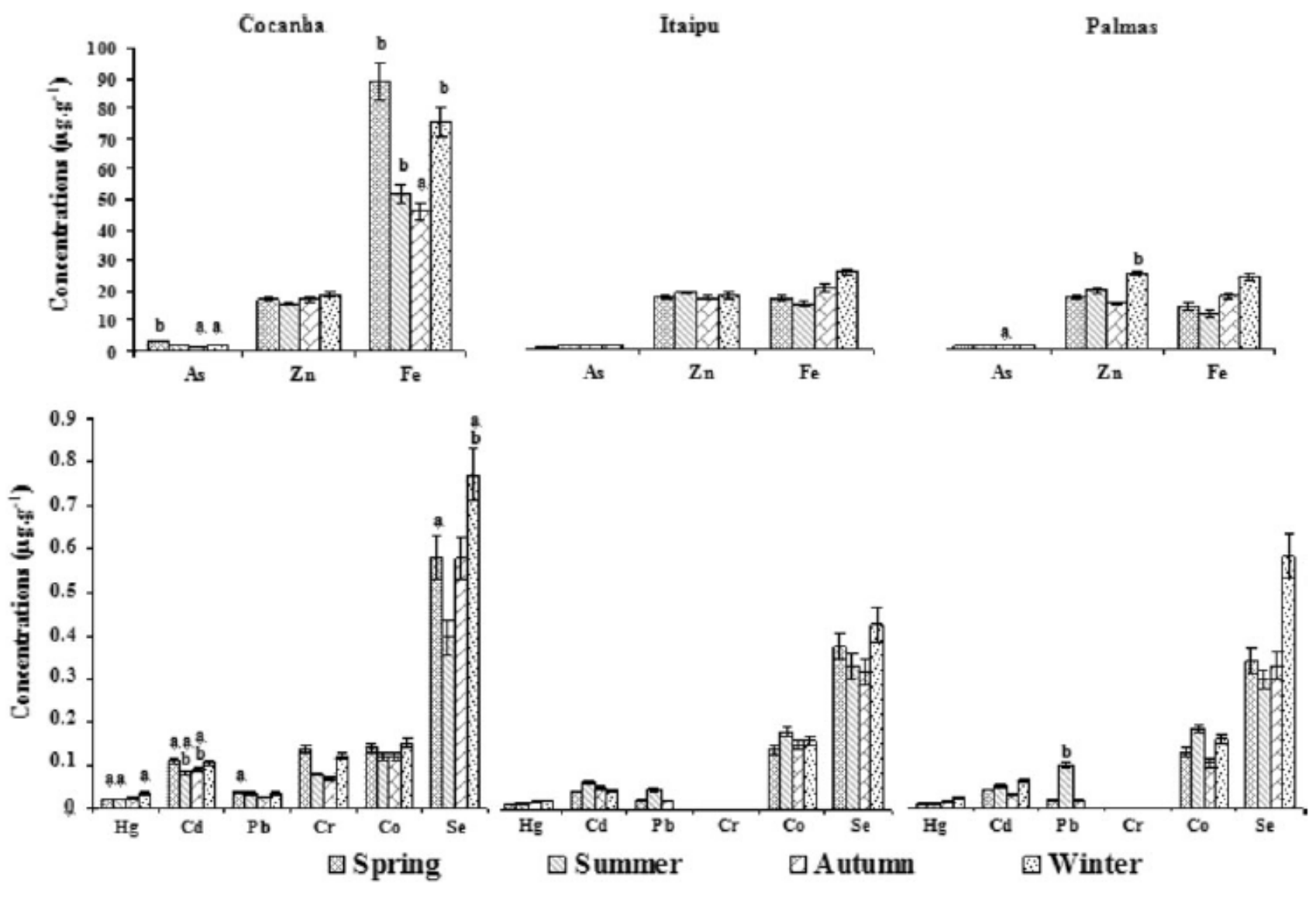

a $-\mathrm{p}<0.05 \quad \mathrm{~b}-<0.01$

Fig. 2 Summary of means and uncertainties of the results obtained for the mussel samples for all seasons and sites of study. Letters in lower case represent significant differences, as obtained in the statistical comparison between the study areas (analysis of variance; $P<0.05$ )

Zinc concentrations were significantly higher in Palmas in winter. In spring, summer and autumn, the highest concentration of the element were found in Itaipu, but no significant seasonal differences were observed.

Finally, for $\mathrm{Cr}$ and $\mathrm{Co}$ no significant differences were found among the study areas.

It was observed that most of the higher values were found for the mussels collected in the Cocanha mussel farm. In a previous study, of active biomonitoring with Pemaperna, carried out by Catharino et al. [11] in the same areas and seasons of the year, the same was observed for Cd (spring), As (spring, summer and winter), Se (summer and winter) and $\mathrm{Fe}$ (summer).

The high values obtained in the Cocanha area could be related to the fact that the region presents an economy based on services related to tourism, and illegal habitational occupation occurs, including in a permanent protection area. On the other hand, inadequate domestic sewage connections exist, which can be a potential cause for the water quality worsening in the last two years, as observed by CETESB [12], which is the state company responsible for environmental control in the State of São
Paulo. In this same study, the authors state that a part of the municipality has already a sewage collection network, but it was not yet connected to the sewage treatment system. As a consequence, this beach that was classified as "good" between 1999 and 2006, has been classified as "regular" in the years 2007 to 2009 . Also, the rivers can be sources of contamination to the beaches of the regions.

\section{Seasonal variations}

A pattern of seasonal variations of the elements was observed in Cocanha, alternating the highest concentrations between spring $(\mathrm{Cd}, \mathrm{Pb}, \mathrm{As}, \mathrm{Cr}$ and $\mathrm{Fe})$ and winter $(\mathrm{Hg}, \mathrm{Co}$, $\mathrm{Se}$ and $\mathrm{Zn}$ ). Significant differences were observed for $\mathrm{Hg}$ (winter $\times$ other seasons), As (spring $\times$ other seasons) and $\mathrm{Fe}$ (spring and winter $\times$ summer and autumn).

In Itaipu, the highest concentrations were observed in summer ( $\mathrm{Cd}, \mathrm{Pb}, \mathrm{Co}$ and $\mathrm{Zn})$, in winter $(\mathrm{Hg}, \mathrm{Se}$ and $\mathrm{Fe})$ and in autumn (As). Significant differences were observed for $\mathrm{Fe}$ (winter $\times$ spring and summer), while for As, in springtime the lowest values were found. 
In Ilha das Palmas, the highest concentrations were observed in winter ( $\mathrm{Hg}, \mathrm{Cd}, \mathrm{As}, \mathrm{Se}, \mathrm{Zn}$ and $\mathrm{Fe}$ ), followed by summer $(\mathrm{Pb}$ and $\mathrm{Co})$. Significant differences were obtained for $\mathrm{Se}$ and $\mathrm{Zn}$ (winter $\times$ other seasons); As and $\mathrm{Cd}$ (winter $\times$ spring and autumn); $\mathrm{Hg}$ (winter $\times$ spring and summer); As, Cd and $\mathrm{Zn}$ (summer $\times$ autumn); As (summer $\times$ spring).

It can be noted that winter was the season of the year that presented the highest values of the elements in most cases. This accumulation of the elements in the organisms is probably due to the presence of domestic effluents, since in wintertime there is an increase of pluviometric indexes, causing a higher carrying of xenobiotics to marine environment.

\section{Tolerance limits}

Based on the tolerance limits established for mussels, for human consumption, by the Brazilian regulations [13, 14] it was observed that the concentrations of $\mathrm{Se}$ in the mussel tissues analyzed were above the limit of $0.30 \mu \mathrm{g} \mathrm{g}^{-1}$, in all sites of study and in all seasons of the year.

As for As, the organisms of the points of Cocanha and Itaipu were above the limit of $1.0 \mu \mathrm{g} \mathrm{g}^{-1}$ in all seasons, while in Palmas the concentration of this element was above the limit only in summer and winter.

For $\mathrm{Cr}$, only the values of Cocanha for spring and winter were above the limit of $0.10 \mu \mathrm{g} \mathrm{g}^{-1}$.

The values for $\mathrm{Hg}, \mathrm{Cd}, \mathrm{Pb}$ and $\mathrm{Zn}$ did not surpass the tolerance limits of $0.5,1.0,2.0$ and $50 \mu \mathrm{g} \mathrm{g}^{-1}$, respectively.

The element Fe has no limit values in the Brazilian legislation.

\section{Conclusions}

The INAA and AAS methods allowed the determination of the concentrations of $\mathrm{As}, \mathrm{Cd}, \mathrm{Co}, \mathrm{Cr}, \mathrm{Fe}, \mathrm{Hg}, \mathrm{Pb}, \mathrm{Se}$ and $\mathrm{Zn}$ with good precision and accuracy, as confirmed by analysis of the NIST SRM 2976 "Mussel Tissue".

Among the sites of collection of the mussels, it was verified that Cocanha was the site where the concentrations of the determined elements presented higher concentrations in most cases.

Concerning the seasonal variations, higher values of studied elements were found in wintertime.

Since the mussels were collected in the coast of the Santos Bay and Cocanha beach, the concentrations found in the organisms provided information about the quality of these environments, reinforcing the beaches conditions balneability as published by CETESB [12], responsible for environmental control in São Paulo state thus showing that the organisms are adequate for environmental biomonitoring.

Acknowledgments The authors would like to acknowledge the financial support from FAPESP (Research Project 2008/01385-5), from Brazil. The Oceanographic Institute (IO) of the São Paulo University (USP) for the support in the collection of the samples.

\section{References}

1. Neves R, Baretta J, Mateus M (2008) Perspectives on integrated coastal management in South America. IST Press, Portugal

2. Sousa ECPM (1983) Primary production of the benthic microflora living on intertidal flats in the Santos Estuarine System $\left(24^{\circ} \mathrm{S}, 46^{\circ} \mathrm{W}\right)$, São Paulo, Brazil. Bolm Inst Oceanogr 32(2):177-186

3. Lamparelli MC, Costa MP, Prósperi VA, Bevilacqua JE, Araújo RPA, Eysink GGJ, Pompéia S (2001) Sistema Estuarino de Santos e São Vicente. http://www.cetesb.sp.gov.br. Accessed 10 Jan 2011

4. Abessa DMS (2002) Avaliação da qualidade do sedimento do Sistema Estuarino de Santos, SP, Brasil. PhD. Thesis, Instituto Oceanográfico da Universidade de São Paulo

5. Pereira CDS (2008) Biomarcadores de exposição, efeito e bioacumulação de xenobióticos em mexilhões Perna perna (Linnaeus, 1758) transplantados ao longo do litoral de São Paulo. $\mathrm{PhD}$. Thesis, Instituto Oceanográfico da Universidade de São Paulo

6. IMW-International Mussel Watch Committee (1995) International mussel watch project: initial implementation phase, final report. Woods Hole Oceanographic Institution. Coastal Research Center, Woods Hole

7. National Institute of Standards and Technology, NIST (1998). Certificate of analysis, Standard Reference Material 2976, Mussel Tissue, Gaithersburg

8. ISO (Intemational Standard Organization) (2005) Statistical methods for use in proficiency testing by interlaboratory comparison-ISO Guide 13528. ISO, Geneva

9. Moreira EG, Vasconcellos MBA, Saiki M (2006) Uncertainty assessment in instrumental neutron activation analysis of biological materials. J Radioanal Nucl Chem 269:377-382

10. Moreira EG, Maihara VA, Catharino MGM, Vasconcellos MBA (2005) Report on NIST-CCHEN SIM 8.16P pilot study, elements in seafood

11. Catharino MGM, Vasconcellos MBA, Sousa ECPM, Moreira EG, Pereira CDS (2008) Biomonitoring of $\mathrm{Hg}, \mathrm{Cd}, \mathrm{Pb}$ and other elements in coastal regions of São Paulo State, Brazil, using the transplanted mussel Perna perna (Linnaeus, 1758). J Radioanal Nucl Chem 278:547-551

12. CETESB (2009) Relatório da qualidade das águas litorâneas do Estado de São Paulo: Monitoramento das águas - projeto ambiental estratégico Onda Limpa: saneamento básico e qualidade das praias. 2008

13. Brasil Ministério da Saúde. Secretaria de Vigilância Sanitária, Portaria $n^{\circ} 685$, de 27 de agosto de 1998 fixa limites máximos de tolerância de contaminantes químicos em alimentos. Diário Oficial da República Federativa do Brasil, Brasília, 24 de setembro de 1998. Seção 1, parte 1, 1998, p 1415

14. Brasil Leis, Decretos, etc., Decreto $n^{\circ} 55871$ de 26 de Março de 1965. Diário Oficial da República Federativa do Brasil, Brasília 09 de abril de 1965, Seção1, parte 1, 1965, p 3611 


\title{
Vanadium determination in Perna perna mussels (Linnaeus, 1758: Mollusca, Bivalvia) by instrumental neutron activation analysis using the passive biomonitoring in the Santos coast, Brazil
}

\author{
D. Seo - M. B. A. Vasconcellos - M. G. M. Catharino * \\ E. G. Moreira * E. C. P. M. de Sousa * \\ M. Saiki
}

Received: 18 July 2012

(6) Akadémiai Kiado, Budapest, Hungary 2012

\begin{abstract}
Vanadium determination present in seawater is of great importance to evaluate marine contamination from industrial sources as well as to identify health hazards since mussels and other marine organisms are used as food. Besides, this evaluation in the Santos coast, SP, Brazil, is important, since this area is impacted by industrial and urban activities and discharges from ships and boats. In a previous study, V results obtained for transplanted mussel (active biomonitoring) were presented. This study aimed the V determination by passive biomonitoring by analyzing Pema perna mussels collected in natural environment, from three sites in São Paulo State coast: Cocanha Beach (reference site), Ponta de Itaipu and Palmas Island. Ninety individuals of mussels were collected in each site between September/08 and July/09 during the four seasons of the year. After shell removal and sample preparation, V was determined by instrumental neutron activation analysis. For analytical quality control, the NIST Standard Reference Material SRM 1566b Oyster Tissue was analyzed and the results presented good accuracy. The $\mathrm{V}$ concentrations in mussels on dry mass basis varied from $0.77 \pm 0.02$ to $3.56 \pm 0.88 \mathrm{mg} \mathrm{kg}^{-1}$. Statistical tests were applied to the
\end{abstract}

D. Seo (ब) - M. B. A. Vasconcellos .

M. G. M. Catharino - E. G. Moreira - M. Saiki

Instituto de Pesquisas Ener géticas e Nucleares, IPEN-CNENISP,

Av. Prof. Lineu Prestes, 2242, Cidade Universitária, Săo Paulo, SP 05508-000, Brazil

e-mail: danyseo@uol.com.tr

E. C. P. M. de Sousa

Laboratbrio de Ecotoxicologia Marinha e Microfitobentos, Instituto Oceanográfico da Universidade de S3o Paulo, IO-USP, Praça do Oceanográfico, 191, Cidade Universitária, Sšo Paulo, SP 05508-120, Brazil results showing differences on V concentrations among the sampling sites and season of sample collection.

Keywords Vanadium - Neutron activation analysis . Perna perna mussel · Passive biomonitoring

\section{Introduction}

The coastal regions are considered as the repositories of urban and industrial discharges which cause contamination of water and marine life by many different kinds of pollutants such as of sewage release from urban areas and runoff from many organic and inorganic products from industrial and agricultural activities. An increase of pollutants levels is being verified worldwide and this is leading to strategies to diminish impacts caused to these ecosystems, which sustain marine biodiversity, fisheries and energy resources [1].

Within this context, one of the approaches to assess the concentrations of toxic substances in seawater is the biomonitoring by using different species of bivalves, such as mussels, recognized as being good biomonitors by several researchers [2-4].

Mussels are common marine mollusks found in most coastal areas and estuaries in a wide range of latitudes. They have been used as sentinel organisms for measuring contaminants and comparing concentrations of radionuclides, heavy metals and organic contaminants in marine environments [5].

Vanadium present in seawater is of great importance to evaluate marine contamination from industrial sources as well as to identify health hazards since mussels are used as food. This element is known as toxic at highlevels [6] and its toxicity increases with the oxidation states. The evaluation 
of $\mathrm{V}$ contamination in coastal waters of the State of São Paulo is important since these areas are subjected to industrial discharges and discharges from ships and boats.

In a previous study, $\mathrm{V}$ results obtained for transplanted mussels (active biomonitoring) were presented [7]. In the present study, passive biomonitoring was used for $\mathrm{V}$ concentration evaluation in Perna pema mussels from the coast of the São Paulo State. The method of active biomonitoring consisted of collecting the mussels from a clean area, away from sources of pollution, and transplant them to areas exposed to environmental contamination and finally analyze them. On the other hand the method of passive biomonitoring adopted in this study, consisted of collecting the mussels from their natural habitat of Santos Estuarine System in order to evaluate the element accumulation in their tissues. Nowadays, the Santos Estuarine System is considered one of the most critical areas in the São Paulo State, in relation to the degradation level of the different compartments [8] as a result of high density of human population, industrial development and the intense dock activities [9]. Moreover the Perna pema species has proven to be very effective for assessment of pollution [2] and it is one of the most consumed by the Brazilian population [10] due to its abundance and wide distribution throughout Brazilian coast.

The present study aimed to evaluate V concentrations in Pema perna mussels collected in the four seasons of the year in the region of the marine coast of the State of São Paulo by applying instrumental neutron activation analysis (INAA).

\section{Experimental}

Study area

The study area is located in the coastal regions of São Paulo State, within the geographical coordinates, $23^{\circ} 58^{\prime}-$ $23^{\circ} 39^{\prime} \mathrm{S}$ and $46^{\circ} 30^{\prime}-45^{\circ} 25^{\prime}$ W. Figure 1 presents the map of the studied region with the three sampling sites: Cocanha Beach located in Caraguatatuba city, Ponta de Itaipu and Palmas Island located in Santos Bay.

\section{Collection and preparation of Perna perna mussel samples}

The samples of the Perna pema mussel (Linnaeus, 1758: Mollusca, Bivalvia) were collected at three sites located in São Paulo State coast: Cocanha Beach (reference area) and Ponta de Itaipu and Palmas Island located in Santos Bay in the four seasons of the year. Mussel collection started in September $/ 2008$ and ended in July/2009. After a period of collection, 90 mussels were selected from each point and season of the year. The algae and other organisms that were attached to the shells of the mussels were removed using a titanium knife. Once the sessile organisms were removed, each mussel was washed with seawater and the biometric measurements of the shells were made. The tissues of the mussels were detached from the shells and afterwards ground and homogenize din a blender with titanium blades. After the homogenization, the samples were placed in plastic containers, weighed and then frozen, for further freeze-drying during a period of $48 \mathrm{~h}$, at temperature of $-52{ }^{\circ} \mathrm{C}$ and pressure of $74 \mu \mathrm{bar}$. The dried samples were ground in an agate mortar and sieved through a 100 mesh polyethylene sieve. Finally, the samples in powder form were stored in plastic containers, identified and kept in a freezer until the analyses. The residual moisture of these lyophilized mussel samples was also analyzed, by drying an aliquot of each sample in an oven, for $24 \mathrm{~h}$ at $85^{\circ} \mathrm{C}$. The mean percentages of waterloss, after lyophi lization and drying in the oven were $84.4 \%$ and $7.2 \%$, respectively.

\section{Analysis of certified reference material}

In order to evaluate the quality of the analytical results, the reference material NIST SRM 1566 b Oyster Tissue was
Fig. 1 Study area located in the coastal region of S3̌o Paulo State, Brazil

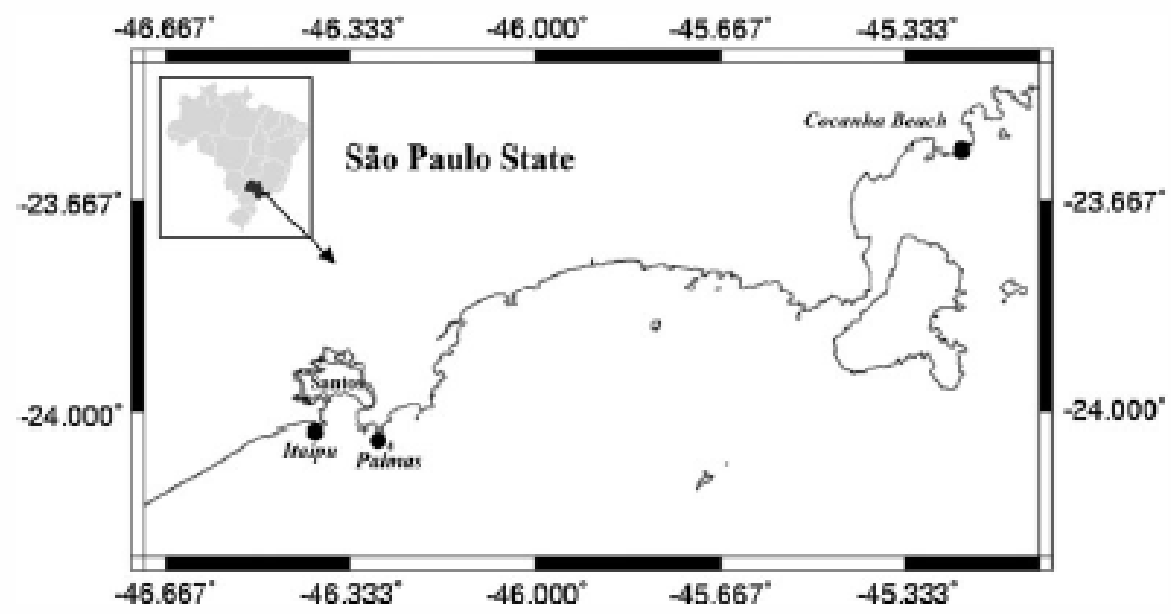


analyzed [11]. To express the results in a dry weight basis, the humidity loss was determined, by drying an aliquot of the material at $85^{\circ} \mathrm{C}$ for $24 \mathrm{~h}$. In this detemination, the humidity loss was of $3.9 \%$ for NIST SRM 1566b Oyster Tissue.

\section{Procedure for INAA}

INAA was employed to measure $\mathrm{V}$ in mussel tissues. The procedure for INAA consisted of irradiating about $180 \mathrm{mg}$ of each mussel sample and the biological reference material NIST SRM 1566b Oyster Tissue together with the synthetic standard of $\mathrm{V}$ in the IEA-R1 nuclear research reactor at IPEN-CNEN/SP through the pneumatic transfer system. Short irradiations of $8 \mathrm{~s}$, under a thermal neutron flux of $6.6 \times 10^{12} \mathrm{~cm}^{-2} \mathrm{~s}^{-1}$, were used in these analyses. After a decay time of about $5 \mathrm{~min}$, the gamma radioactivity measurement was carried out, using a model GC2018 semiconductor hyperpure Ge detector coupled to DSA-1000 Digital Spectral Analyzer, both from Canberra. For spectral data acquisition and processing, the Genie 2000 version 3.1 software from Canberra was used. The $\mathrm{V}$ concentration in the sample was calculated by the comparative method [12]. The radioisotope measured and its gamma-ray energy and halflife were: ${ }^{52} \mathrm{~V}, E \gamma=1,434.08 \mathrm{keV}$ and $t_{1 / 2}=3.75 \mathrm{~min}$.

\section{Statistical analysis}

The seasonal and spatial variations of the $\mathrm{V}$ concentrations obtained were evaluated by one-way analysis of variance (ANOVA) and Tukey test $(p<0.05)$ [13], using Origin software, version 7.5.

\section{Results and discussion}

Analysis of the certified reference material

Table 1 presents the results of $\mathrm{V}$ concentrations ( $\mathrm{mg} \mathrm{kg}^{-1}$ ), obtained in the analysis of certified reference material NIST SRM 1566b Oyster Tissue together with the certified value for comparison.

Results of Table 1 indicate good agreement of our results with the certified value demonstrating that the INAA procedure applied is adequate for $\mathrm{V}$ determinations. The

Table 1 Concentration of $\mathrm{V}$, in $\mathrm{mg} \mathrm{kg}^{-1}$, in the NIST SRM $1566 \mathrm{~b}$ Oyster Tissue certified reference material

\begin{tabular}{lllll}
\hline$x \pm s(n)$ & RSD $(\%)$ & Er $(\%)$ & $z$-score & Certified value \\
\hline $0.567 \pm 0.032(20)$ & 5.69 & 1.73 & -0.29 & $0.577 \pm 0.023$ \\
\hline$x \pm s .57$
\end{tabular}

$x \pm s$ arithmetic mean and standard deviation, $n$ number of determinations, $R S D$ relative standard deviation, $E r$ relative error percentage of relative error was below $1.73 \%$. The results also showed good reproducibility with relative standard deviations lower than $5.7 \%$. The results of certified reference materials were also submitted to the statistical treatment calculating the $z$-score value or standardized difference [14]. This value obtained was $l z$-scorel $<1$ indicating that the $V$ results obtained are within the ranges of certified values at the confidence level of $68 \%$.

\section{Analysis of mussel samples}

The $\mathrm{V}$ results obtained in the analysis of mussels collected in different seasons are shown in Fig. 2.

This figure shows that the $\mathrm{V}$ concentrations in mussels ranged from $0.77 \pm 0.02$ to $3.56 \pm 0.88 \mathrm{mg} \mathrm{kg}^{-1}$ and the mussels collected in Ponta de Itaipu during spring season presented higher $V$ concentrations than those from the other sites of collection and seasons of year.

\section{Comparison between the sites}

Table 2 shows the V results obtained for mussels collected in different seasons and in different sites of collection: Cocanha Beach, Ponta de Itaipu and Palmas Island.

The statistical test (Tukey test) applied to the results showed that the V concentrations found in mussels collected in Cocanha Beach in spring season did not show significant differences $(p<0.01)$ when compared with those other two sites Ponta de Itaipu and Palmas Island located in Santos Bay. The mussels from Cocanha Beach collected in summer season presented higher V concentrations than in the other collection points. However, the samples collected in the Santos Bay (Ponta de Itaipu and Palmas Island) in autumn season presented higher V concentrations than Cocanha Beach. It is also observed that the mussels collected in Ponta de Itaipu during winter season presented significant higher concentrations $(p<0.01)$ than those from Cocanha Beach.

It is possible observed that the mussels analyzed in the present study presented higher levels than those obtained for mussels collected in Onagawa Bay, Japan [15]. However, it is possible to observe that the mussels analyzed in this study obtained lower levels of V compared to mussels collected in the Gulf region and Hong Kong, China [16, 17].

\section{Seasonal variations}

In the seasonal analysis, Table 2 shows that the mussels collected during spring season presented the highest values for the element $\mathrm{V}$ in the three points of study (Cocanha, Ponta de Itaipu and Palmas Island). In the case of the mussels collected during winter season showed the lowest 
Fig. 2 Concentrations of V, in $\mathrm{mg} \mathrm{kg}^{-1}$ (dry weight besis), in mussel samples collected in the cosst of the Stao Paulo State in the four seasons of year. Mean values with same lower letter indicate that the results of samples from Cocanha Beach did not differ with those obtained for the other sampling sites $(p<0.05)$. Mean values with same capital letter indicate that the results of mussels from Cocanha beach did not differ in seasonal analysis $(p<0.05)$

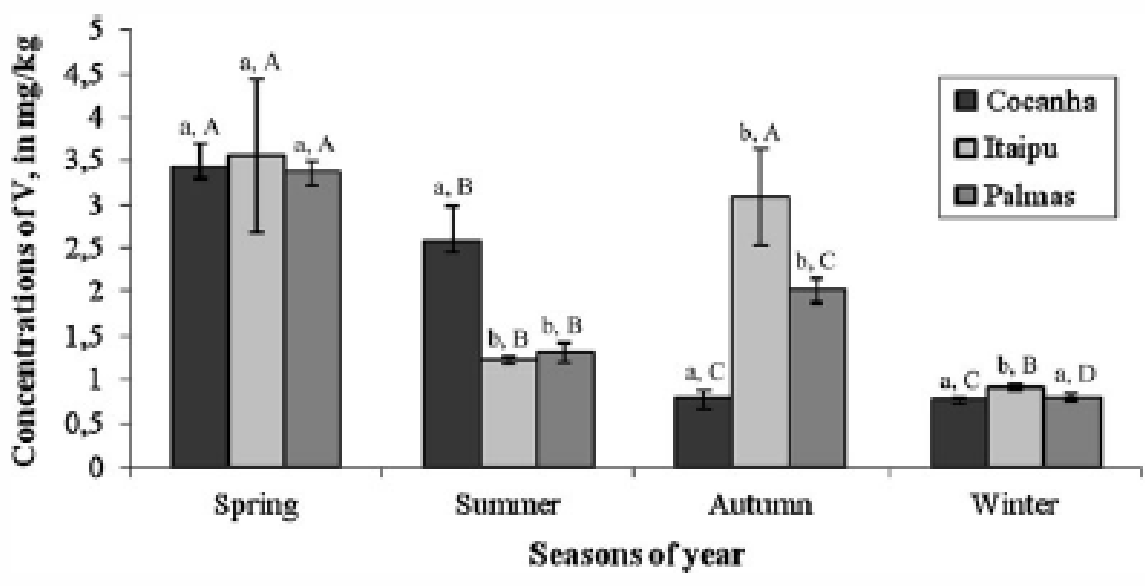

\begin{tabular}{lllll}
\hline Sampling sites & \multicolumn{3}{l}{ Periods of collect } & \\
\cline { 2 - 5 } & $x \pm s(n)$ & Summer & Autumn & Winter \\
\cline { 2 - 5 } & Spring & $2.57 \pm 0.41(4)$ & $0.80 \pm 0.07(4)$ & $0.77 \pm 0.02(4)$ \\
\hline Cocanha beach & $3.43 \pm 0.28(4)$ & $1.23 \pm 0.05(4)$ & $3.08 \pm 0.56(4)$ & $0.91 \pm 0.03(4)$ \\
Ponta de Itaipu & $3.56 \pm 0.88(4)$ & $1.32 \pm 0.11(4)$ & $2.01 \pm 0.14(4)$ & $0.80 \pm 0.04(4)$ \\
Palmas Island & $3.36 \pm 0.14(3)$ & & &
\end{tabular}

Table 2 Concentrations of V, in $\mathrm{mg} \mathrm{kg}^{-1}$ (dry weight basis), in the mussel samples from the coast of the State of S3o Paulo in the four seasons of year

concentrations of this element in the three studied points. It is also possible to observe that the mussels collected in autumn season presented significant high $\mathrm{V}$ concentrations $(p<0.01)$ for the two points located in Santos Bay (Ponta de Itaipu and Palmas Island) when compared with those obtained in summer and winter seasons for the same sites.

\section{Conclusions}

From the results obtained in the analysis of NIST SRM 1566b Oyster Tissue certified reference material we can conclude that the INAA procedure applied for V determinations allowed the obtaintion of results with good accuracy. The high concentrations found for $\mathrm{V}$ for the mussels collected in the sites of Santos Bay during spring and autumn seasons and Cocanha Beach during spring could be due to intense oil carrier ships circulation and boat movement in the region. The mussels collected in the Cocanha Beach during summer may have suffered influence of number of the boats and ships that are increased during this season of the year due to the holiday period. This work presents $\mathrm{V}$ results obtained in mussels collected in the Cocanha Beach and Santos Bay (Ponta de Itaipu and Palmas Island) that provide information about the quality of these environments. The analyses of the mussel tissues showed that the accumulation of $\mathrm{V}$ depends on the season of the year and site of collection. These findings indicate the possibility of using the Pema pema mussel as a passive biomonitor for V. Subsequently, the authors intend to conduct a study to analyze the levels of organic compounds in the Perna perna mussel's tissues.

Acknowledgments The authors would like to acknowledge to FAPESP (S30 Paulo Research Foundation) and to CNPq (Brazilian National Council for Sciertific and Technological Development) from Brazil and the LAEA (International Atomic Energy Agency) for the financial support. Also, to the Oceanographic Institute of the University of Sto Paulo for the support in the sample collection. The author D. Seo acknowledgements to the IPEN-CNEN/SP for the scholar ship.

\section{References}

1. Kemish JM (1991) Eoology of estuaries: anthropogenic effects. CRC Press, Boca Raton

2. Catharino MGM, Vasconcellos MBA, Sousa ECPM, Moreira EG, Pereira CDS (2008) J Radioenal Nucl Chem 278:547-551

3. Francioni E, Wagener ALR, Calixto RC, Bastos GC (2004) J Brae Chem Soc 15:103-110

4. Maanan M (2007) Environ Toxicol 22:525-531

5. Coman O, Germain P, Solier L, Gouret G (2007) J Environ Radiosct 97:168-188

6. Byme AR, Kosta L (1978) Sci Total Environ 10:17-30

7. Seo D, Vasconcellos MBA, Saiki M, Catharino MGM, Moreira EG, Sousa ECPM, Pereira CDS (2012) J Radioanal Nucl Chem 291:101-105

8. Neves R, Baretta I, Mateus M (2008) Perspectives on integrated coastal management in South America. IST Press, Lisboa 
9. Sousa ECPM (1983) Bolm Inst Oceanogr 32:177-186

10. Lopes SGBC, Fonseca ML (2008) O mexilhăo Pema perna (Linnaeus, 1758)-taxonomia, morfologia e anatomia funcional. In: Resgalla C Jr (ed) O mexilhăo Pema pema Interciência. Rio de Janeiro, Brasil

11. NIST, National Institute of Standards and Technology (2001) Standard Reference Material 1566b SRM Oyster Tissue. Certificate from National Institute of Standards and Technology, USA, $\mathrm{ppl}-8$

12. De Soete D, Gijels R, Hoste J (1972) Neurron activation analysis. Wiley, London
13. Vieira $\mathrm{S}$ (1997) Introduçăo à bioestatística. Campus, Brasil

14. Konieczka P, Namiesnik J (2009) Quality assurance and quality control in the analytical chemical laboratory. CRC Press, New York

15. Fukushima M, Suzuki H, Saito K, Chatt A (2009) J Radioanal Nucl Chem 282:85-89

16. Fowler SW, Readman JW, Oregioni B, Villeneuve JP, McKay K (1993) Mar Pollut Bull 77:171-182

17. Liu JH, Kueh CSW (2005) Marine Poll Bull 51:857-875 


\section{Trace element determination in a mussel reference material using short irradiation instrumental neutron activation analysis}

E. G. Moreira * D. Seo *

M. B. A. Vasconcellos - M. Saiki

Received: 24 July 2012

(4) Aksckimiai Kisdó, Budapest, Hungary 2012

\begin{abstract}
The production of certified reference materials in Brazil, and the consequent availability to national end users, is an important task for the enhancement of Metrology in Chemistry status in the country, as these materials are used for method validation, equipment calibration and for establishing metrological traceability links. In this study, Instrumental Neutron Activation Analysis (INAA) was applied to the determination of bromine, chlorine, magnesium, manganese, potassium and vanadium in a mussel reference material produced at IPEN-CNEN/SP. For the determination of these elements via the comparative INAA method, the respective analytical radionuclides, ${ }^{80} \mathrm{Br}$, ${ }^{38} \mathrm{Cl},{ }^{27} \mathrm{Mg}$, ${ }^{56} \mathrm{Mn},{ }^{42} \mathrm{~K}$ and ${ }^{52} \mathrm{~V}$, are short lived and then, short irradiations are used. Six subsamples from two bottles of the Perna perna mussel reference material were analyzed. Each subsample was simultaneously irradiated with elemental standards for $10 \mathrm{~s}$ at the IEA-R1 research nuclear reactor through a pneumatic transfer system. After suitable decay periods, gamma radioactivity measurements were carried out, using a hyperpure germanium detector. The accuracy of the method was checked by using the NIST SRM 1566b-"Oyster Tissue" certified reference material. The comparison of the results obtained in this study to the robust mean of the interlaboratorial collaborative trial used for the characterization of the mussel reference material was performed via $z$-score tests. The comparison showed that the short irradiation INAA method is suitable for the characterization of new reference materials.
\end{abstract}

E. G. Moreira (ब) - D. Seo - M. B. A. Vasconcelles - M. Saiki Instituso de Pesquisas Energeticas e Nucleares, IPEN - CNENSP, Av. Prof. Lineu Prester, 2242, S5o Pauk, SP 05508-000, Brazil

e-mail: emorre ira ipen.br
Keywords Reference material - Mussel - Perna perna . Short irradiation - Instrumental neutron activation analysis

\section{Introduction}

Certified reference materials (CRMs) play an important role in the quality assurance of measurement results as they are used for method validation, equipment calibration and for establishing metrological traceability links of measurement results [1]. A CRM is defined as a reference material, characterized by a metrologically valid procedure for one or more specified properties, accompanied by a certificate that provides the value of the specified property, its associated uncertainty, and a statement of metrological traceability [2]. In the context of trace elements in the environment, the specified properties are the mass fractions of trace elements in the reference material.

The production of certified reference materials in Brazil, and the consequent availability to national end users, is an important task for the enhancement of Metrology in Chemistry status in the country and the interest in this issue is growing fast in the national scientific community.

In this study, the application of Instrumental Neutron Activation Analysis (INAA) to the determination of bromine, chlorine, magnesium, manganese, potassium and vanadium in a Perna perna mussel reference material produced at IPEN-CNEN/SP was investigated. The production of this material was planned as mussels tend to bioaccumulate contaminants from the surrounding waters and are used in biomonitoring programs [3-6].

For the determination of these elements via the comparative INAA method, the respective analytical radionuclides, ${ }^{80} \mathrm{Br},{ }^{38} \mathrm{Cl},{ }^{27} \mathrm{Mg},{ }^{56} \mathrm{Mn},{ }^{42} \mathrm{~K}$ and ${ }^{52} \mathrm{~V}$, are short lived and then, short irradiations were used. 
E. G. Moreira et al.

\section{Experimental}

Sample and elemental standards preparation

Six subsamples of approximately $0.180 \mathrm{~g}$ from bottles number 54 and 129 of the mussel candidate reference material and of NIST SRM $1566 \mathrm{~b}$-"Oyster Tissue" certified reference material were weighed in properly cleaned polyethylene vials using a Shimadzu AEM-5200 analytical balance. The mussel reference material bottles were selected at random, one for each half of the batch. Elemental standards were prepared by pipetting Spex standard element solutions onto Whatman paper filters, using variable volume pipettes (Eppendorf). After drying, paper filters were kept in polyethylene vials with the same geometry as for the samples.

Irradiation and element determination

Subsamples of the mussel reference material, certified reference material and elemental standards were simultaneously irradiated at a thermal neutron fluence of $6.6 \times 10^{13} \mathrm{n} \mathrm{cm}^{-2}$ at the IEA-R1 Nuclear Research Reactor from IPEN-CNEN/SP through a pneumatic transfer system. Immediately after irradiation, ${ }^{30} \mathrm{Br},{ }^{38} \mathrm{Cl},{ }^{27} \mathrm{Mg}$ and ${ }^{52} \mathrm{~V}$ radionuclides were measured for $200 \mathrm{~s}$. After a $1.5 \mathrm{~h}$ decay period, ${ }^{42} \mathrm{~K}$ and ${ }^{56} \mathrm{Mn}$ radionuclides were measured for $600 \mathrm{~s}$. Gamma ray measurements were performed using a GC2018 Canberra hyperpure germanium detector coupled to a Canberra DSA-1000 multichannel analyzer. Gamma ray spectra were collected and processed using a Canberra Genie 2000 version 3.1 spectroscopy software. Element content calculations were carried out using a Microsoft Excel spreadsheet.

Table 1 presents the radionuclides that were used in the two measurement steps of the INAA short irradiation procedure along with their corresponding gamma ray photopeak energies and half lives [7].

\section{Results and discussion}

As the gamma ray energies for $\mathrm{Mg}$ and $\mathrm{Mn}$ radionuclides are very close (Table 1), it was necessary to let the sample decay for $1.5 \mathrm{~h}$ in order to avoid the spectral interference of ${ }^{27} \mathrm{Mg}$ in the determination of ${ }^{56} \mathrm{Mn}$.

Table 2 presents the short irradiation INAA results obtained for the mussel candidate reference material as well as for the NIST SRM $1566 \mathrm{~b}$ certified reference material [8]. Coincident results were obtained for the two bottles of the candidate reference material considering the confidence intervals. This reflects the good homogenization procedure employed during the preparation of the
Table 1 Rachomuclides used in the short irradiation INAA [7]

\begin{tabular}{llcc}
\hline Measurememt & Radionuclide & Half hife & Energy (keV) \\
\hline 1st $(200 \mathrm{~s})$ & ${ }^{30} \mathrm{Br}$ & $17.68 \mathrm{~min}$ & 6163 \\
& ${ }^{38} \mathrm{Cl}$ & $37.24 \mathrm{~min}$ & 1642.7 \\
& ${ }^{27} \mathrm{Mg}$ & $9.46 \mathrm{~min}$ & 843.8 \\
& ${ }^{52} \mathrm{~V}$ & $3.75 \mathrm{~min}$ & 1434.1 \\
2nd $(600 \mathrm{~s})$ & ${ }^{42} \mathrm{~K}$ & $12.36 \mathrm{~h}$ & 1524.6 \\
& ${ }^{56} \mathrm{Mn}$ & $2.58 \mathrm{~h}$ & 846.8 \\
\hline
\end{tabular}

material [4]. Also, from the Student's $t$ test performed on obtained results, it was inferred that the mean values do not differ in a statistically significant manner as $t \leq t_{\text {cat }}$ for the significance level $\alpha=0.01$ [9],

For the purpose of quality assurance, INAA results obtained for the NIST SRM $1566 \mathrm{~b}$ certified reference material were compared to the certified values using $z$-scores. The $z$-score was originally designed for the performance assessment in interlaboratory programs and is calculated as described on Eq. 1 [9].

$z=\frac{w_{\text {lat }}-w_{\text {xef }}}{\hat{\sigma}}$

where $w_{\text {ab }}$ is the mass fraction value obtained by the laboratory, $w_{\mathrm{red}}$ is the certified mass fraction value and $\hat{\sigma}$ is the target range.

In this study, the modified Horwitz equation was used to estimate the reproducibility standard deviation of the method $\left(s_{\mathrm{R}}\right)$ which was used as the target range, according to $\mathrm{Eq} .2[10,11]$.

$s_{R}=\left\{\begin{array}{cc}0.22 c & \text { if } c<1.2 \times 10^{-7} \\ 0.22 c^{0.895} & \text { if } 1.2 \times 10^{-7} \leq c \leq 0.138 \\ 0.01 c^{0.5} & \text { if } c>0.138\end{array}\right.$

where $c$ is the certified mass fraction expressed in $\mathrm{g} \mathrm{g}^{-1}$.

From the obtained $z$-scores it was concluded that the short irradiation INAA method used is accurate to the analysis of $\mathrm{Cl}, \mathrm{K}, \mathrm{Mg}, \mathrm{Mn}$ and $\mathrm{V}$ in biological materials and in candidate references materials in particular as $|z| \leq 2$ [10]. As there is no certified value for $\mathrm{Br}$ in NIST SRM 1566b, NIST SRM 2976-"Mussel Tissue" was used for this element [12]. The INAA result was $332 \pm 22 \mathrm{mg} \mathrm{kg}^{-1}$ and the certified value for $\mathrm{Br}$ is $329 \pm 15 \mathrm{mg} \mathrm{kg}^{-1}$. From the $z$ score result $(z=0.013), \mathrm{Br}$ results were also considered satisfactory.

Figure 1 presents the graphical representation of the obtained results in comparison to the robust mean and corresponding expanded uncertainty obtained during the interlaboratory program used in the characterization of the mussel candidate reference material [13].

With the exception of $\mathrm{Cl}$ and $\mathrm{K}$, it was observed that INAA results overlap the uncertainty interval proposed for the interlaboratory program, confirming the suitability of 
Trace element determination in a musel reference material

Table 2 Element mass fraction in mg kg ${ }^{-1}$ at dry mass basis abtained by INAA for the candidav mussel reference material and for the oyster tissue certified reference makrial

\begin{tabular}{|c|c|c|c|c|c|}
\hline \multirow[t]{2}{*}{ Element } & \multicolumn{2}{|c|}{ Mussel reference makerial } & \multicolumn{3}{|c|}{ NIST SRM 1566b-Oyster Tissu } \\
\hline & Botde 54 & Bottle 129 & This study & Certified value" & ascorre \\
\hline Br & $245 \pm 30$ & $230 \pm 24$ & $43.8 \pm 2.6$ & - & - \\
\hline $\mathrm{Cl}\left(\mathrm{g} \mathrm{kg}^{-1}\right)$ & $48.9 \pm 3.4$ & $42.0 \pm 4.4$ & $5.20 \pm 0.15$ & $5.14 \pm 0.10$ & 0.023 \\
\hline $\mathrm{K}\left(\mathrm{g} \mathrm{kg}^{-1}\right)$ & $6.40 \pm 1.09$ & $7.25 \pm 0.65$ & $6.34 \pm 0.41$ & $6.520 \pm 0.090$ & -0.060 \\
\hline $\mathrm{Mg}\left(\mathrm{g} \mathrm{kg}^{-1}\right)$ & $3.61 \pm 0.22$ & $3.41 \pm 0.30$ & $1.104 \pm 0.054$ & $1.085 \pm 0.023$ & 0.028 \\
\hline Mn & $20.5 \pm 1.1$ & $21.9 \pm 12$ & $18.63 \pm 0.37$ & $18.5 \pm 0.2$ & 0.0061 \\
\hline $\mathrm{V}$ & $2.60 \pm 0.20$ & $2.74 \pm 0.31$ & $0.566 \pm 0.033$ & $0.577 \pm 0.023$ & -0.010 \\
\hline
\end{tabular}

Mean values and confidence inverval at $95 \%$ for $n=6$

ancertaimies are expanded uncertainties informed by the producer

Fig. 1 Graphical represemation of the results ohtained by INAA for the mussel reference material (mean value and confidence imerval, $95 \%$ ) compared to the collahorative program resalts (robust mean (soilid line) and expanded uncertainty, $k=2$ (dashed line))

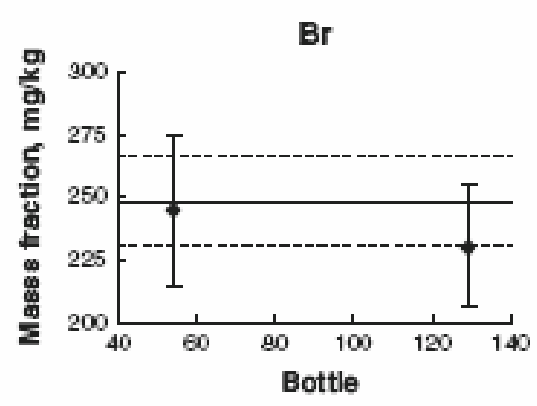

K

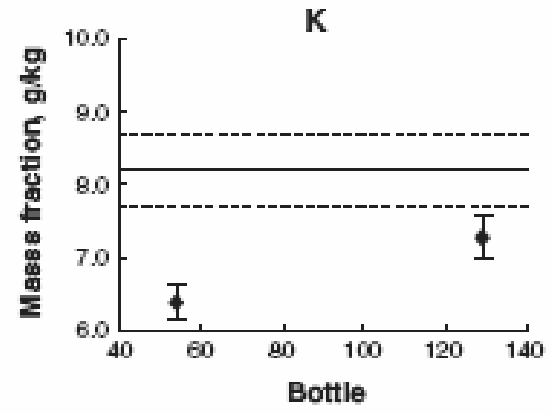

Mn

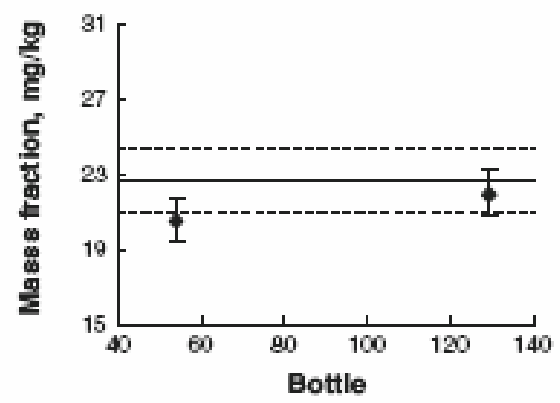

Cl

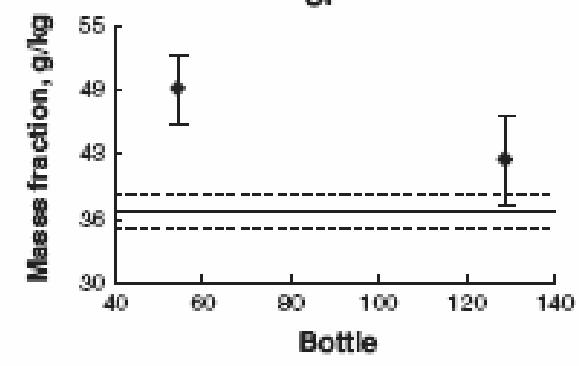

Mg

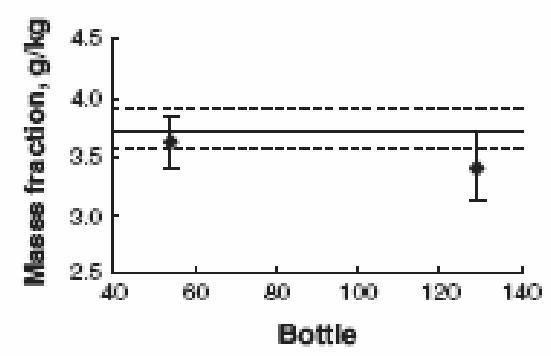

V

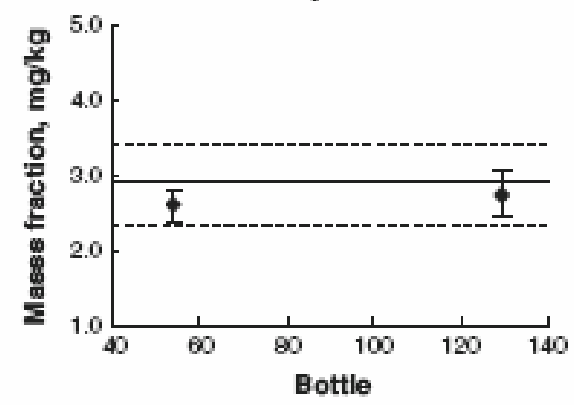

the INAA short irradiation method proposed. The observed differences for $\mathrm{Cl}$ and $\mathrm{K}$ need to be better investigated as CRM results for these elements presented satisfactory $z$-scores. On the other hand, if $z$-scores are used to assess the suitability of the obtained results, using the interlaboratory comparison data on Eq. 1, the observed INAA data 
may be considered satisfactory as for $\mathrm{Cl}, z=0.89$ and $z=0.38$ for bottles 54 and 129 , respectively and for $\mathrm{K}$, $z=-0.48$ and $z=-0.25$ for bottles 54 and 129 , respectively.

\section{Conclusions}

In this study a short irradiation Instrumental Neutron Activation Analysis method was applied for the determination of bromine, chlorine, magnesium, manganese, potassium and vanadium in two bottles of a Perna perna mussel reference material produced at IPEN-CNENSP, in Brazil. The accuracy of the method was checked by using the NIST SRM $1566 \mathrm{~b}-$ "Oyster Tissue" certified reference material and it was considered adequate. The comparison of the obtained results to the robust mean of the interlaboratorial program used for the characterization of the mussel reference material showed that the short irradiation INAA method is suitable for the characterization of the new reference material.

Acknowledgments Authors are indebted to the financial support received from IPEN-CNEN/SP, the State of Sio Paulo Research Foundation (FAPESP) and the Brazilian National Council for Scientific and Technological Development (CNPq).

\section{References}

1. Zschunke A (ed) (2000) Reference materials in analytical chemistry-a guide for selection and use. Springer, Berlin
2. International Organization of Standardization-ISO (2006) Certification of reference materiak-general and statistical principlesISO Guide 35, 3rd edn. Geneva

3. More ira EG, Vasconcellos MBA, Maihara VA, Catharino MCiM, Saiki M (2007) Mussel reference material preparation proposal as a quality assurance ool for Brazilian seashore tiomonitoring. J Braz Soc Ecotoxic ol 2:61-65

4. Morreira EG, Vaxconcellos MBA, Catharino MGM, Maihara VA, Saiki M (2012) Applying INAA to the homageneity study of a Perna perna mussel reference makerial. I Radioanal Nucl Chem 291:107-111

5. Goding E (2003) Bivalve mollusks-hiology, ecology and culture. Blackwell, Oxford

6. Catharino MGM, Vasconcellos MBA, Scusa ECPM, Moreira EG Pereira CDS (2008) Biomonitoring of $\mathrm{Hg}, \mathrm{Cd}, \mathrm{Pb}$ and other elements in coastal regions of S3o Paulo State, Brazil, using the transplamted mussel Perna perna (Limseuk, 1758). I Radicanal Nucl Chem 278547-551

7. Imternational Atomic Energy Agency (IAEA) (1990) Practical appects of operating a neutron activation analysis laboratoryTEC-DOC-564. LAEA, Vienna

8. National Institute of Standards \& Technology (NIST) (2001) Standard reference makerial $1566 \mathrm{~b}$, Oysker Tissue-certificate of analysis. NIST, Gaithensturg

9. Koriecrka P, Namiesnik J (2009) Ouality assurance and quality control in the analytical chemical laboratory-a practical approsch. CRC, Boca Raton

10. Prichard E, Barwick V (2008) Quality assurance in anslytical chemistry. Wiley-LOC, Tedlington

11. Thompson $\mathrm{M}(2000)$ Recent trends in inver-bart asory precision at $\mathrm{ppb}$ and sub-ppb cancentrations in relation to fitness for purpose criteria in proficiency witing Analyst 125:385-386

12. National Institute of Standards \& Technology (NIST) (2008) Standard reference materia1 2976 , musel tissue (trace elements and methylmercury)-certificate of anslysis. NIST, Geithensturg

13. Morre ira EG, Vasconcelks MBA, Maihara VA, Catharino MCMM, Saiki M (2012) Inverbhor atory comparison for the characterization of a Bragitian mussel reference material. Accred Qual Assur (Submitted) 